\title{
The availability and quality of family planning services across eight districts in Pakistan: The potential and the constraints
}

Gul Rashida

Iram Kamran

Population Council

Khan Muhammad

Rehan M. Niazi

Tahira Parveen

Population Council

Follow this and additional works at: https://knowledgecommons.popcouncil.org/departments_sbsr-rh

Part of the Demography, Population, and Ecology Commons, Family, Life Course, and Society Commons, International Public Health Commons, and the Women's Health Commons How does access to this work benefit you? Let us know!

\section{Recommended Citation}

Rashida, Gul, Iram Kamran, Khan Muhammad, Rehan M. Niazi, and Tahira Parveen. 2015. "The availability and quality of family planning services across eight districts in Pakistan: The potential and the constraints." Islamabad: Population Council. 


\section{POPULATION}

Ideas. Evidence. Impact.

The Population Council confronts critical health and development issues-from stopping the spread of HIV to improving reproductive health and ensuring that young people lead full and productive lives. Through biomedical, social science, and public health research in 50 countries, we work with our partners to deliver solutions that lead to more effective policies, programs, and technologies that improve lives around the world. Established in 1952 and headquartered in New York, the Council is a nongovernmental, nonprofit organization governed by an international board of trustees.

Population Council

House \#7, Street 62, F-6/3, Islamabad, Pakistan

Tel: 92518445566

Fax: 92512821401

Email: info.pakistan@popcouncil.org

Web: http://www.popcouncil.org 


\section{POPULATION 9 COUNCIL \\ Ideas. Evidence. Impact.}

The Population Council confronts critical health and development issues - from stopping the spread of HIV to improving reproductive health and ensuring that young people lead full and productive lives. Through biomedical, social science, and public health research in 50 countries, we work with our partners to deliver solutions that lead to more effective policies, programmes, and technologies that improve lives.

(c) 2015 The Population Council, Inc.

Declaration

I have read the report "The Availability and Quality of Family Planning services across Eight Districts in Pakistan; the Potential and Constraints", and acknowledge and agree with the information, data and findings contained.

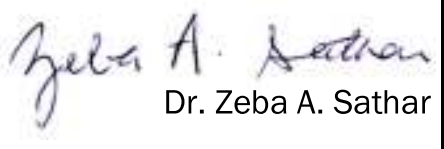

Principal Investigator

Acknowledgment

Investigating the Low Patterns of Modern Contraceptive Use in Pakistan is a project funded by the Maternal and Newborn Health Programme, Research and Advocacy Fund (RAF), and is implemented by Population Council, Pakistan.

Disclaimer

This document is an output from a project funded by the UK Department for International Development (DfID) and the Australian Department of Foreign Affairs and Trade (DFAT) for the benefit of developing countries. The views expressed and information contained are not necessarily those of or endorsed by DfID, DFAT, or the Maternal and Newborn Health Programme, Research and Advocacy Fund (RAF), which can accept no responsibility or liability for such views, for completeness or accuracy of the information, or any reliance placed on them. 


\section{Table of Contents}

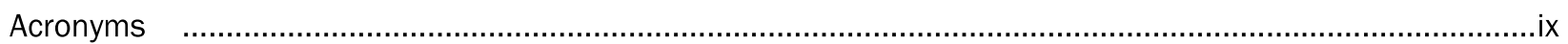

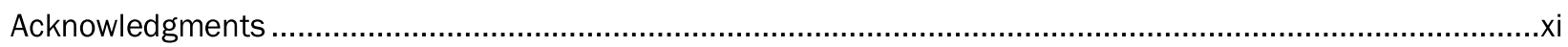

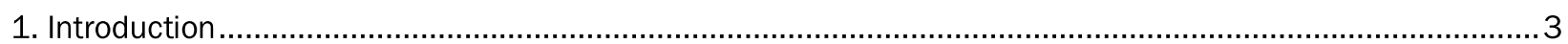

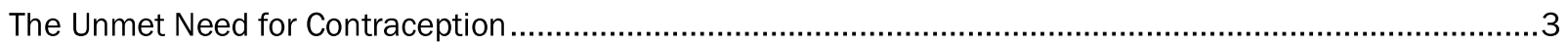

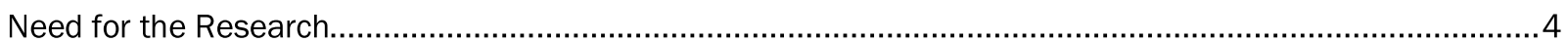

Study Objectives, Design and Methodology..........................................................................................

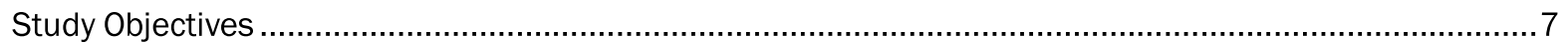

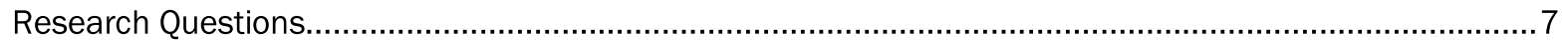

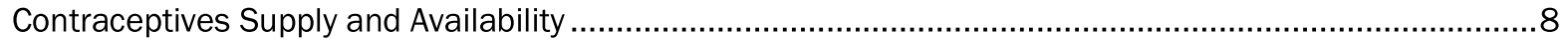

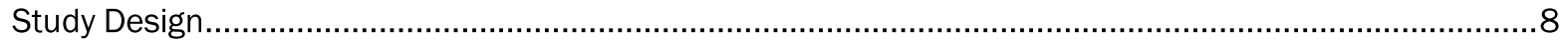

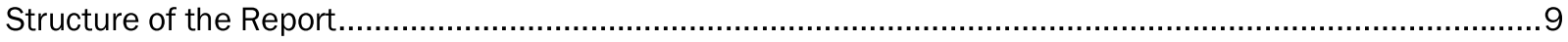

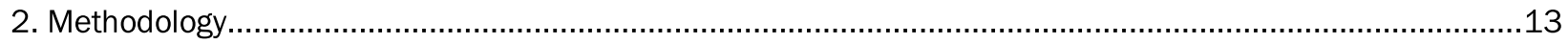

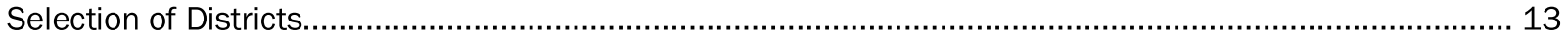

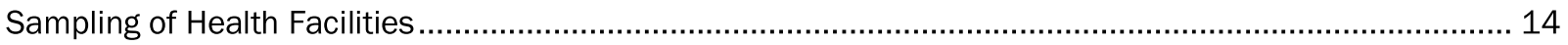

Sampling and Selection of Contraceptive Stock Availability Points ........................................................ 15

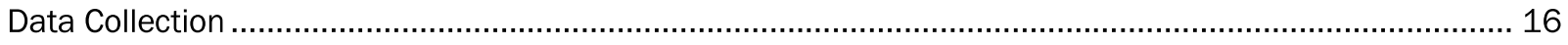

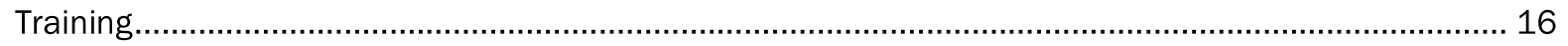

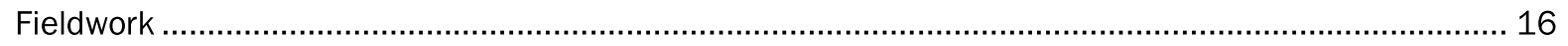

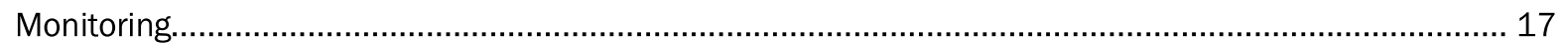

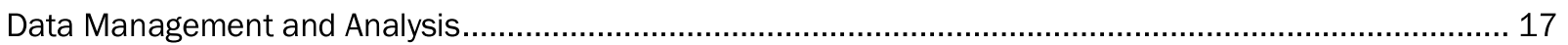

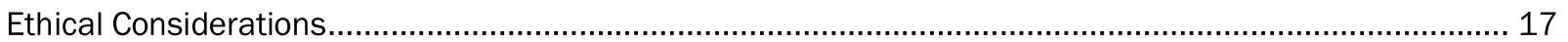

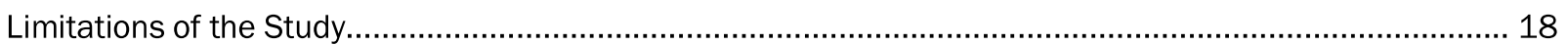

3. Capacities of Service Providers for FP Service Provision.............................................................................21

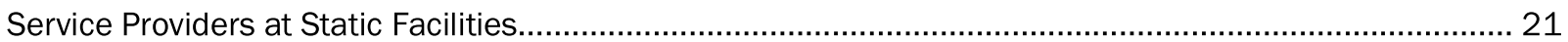

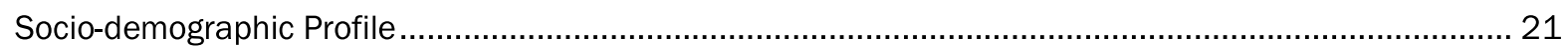

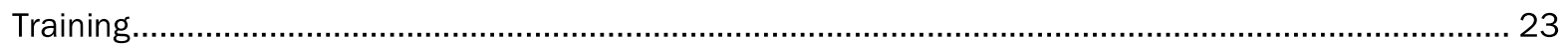

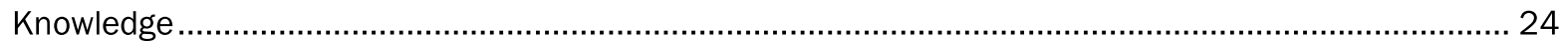

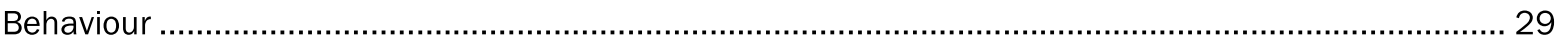

Source: Observation of interactions between service providers and clients............................................ 33

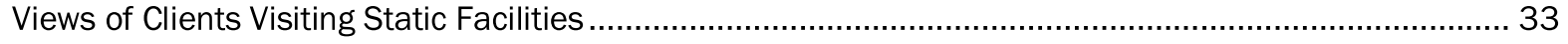

Knowledge among Lady Health Workers ............................................................................................ 35

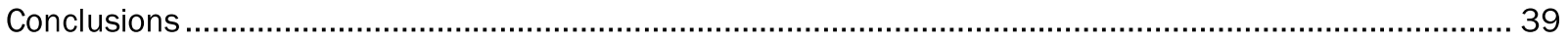




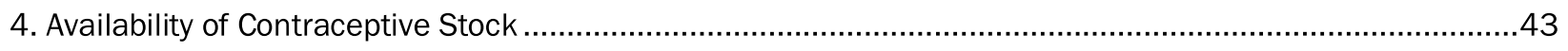

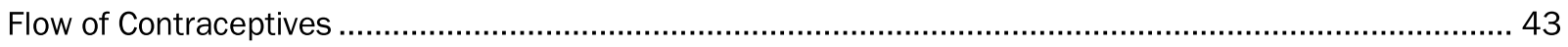

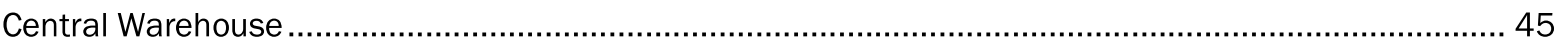

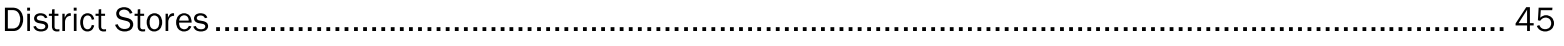

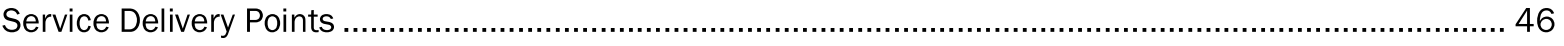

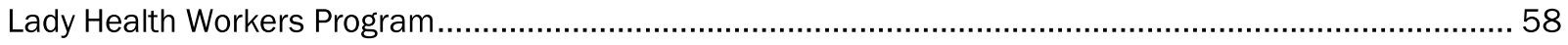

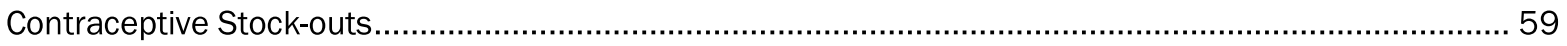

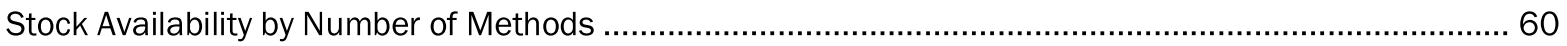

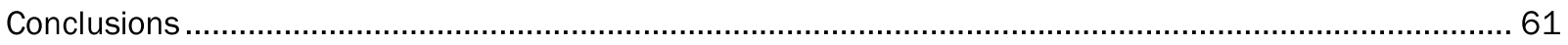

5. Readiness of Health Facilities for Family Planning Service Provision ......................................................65

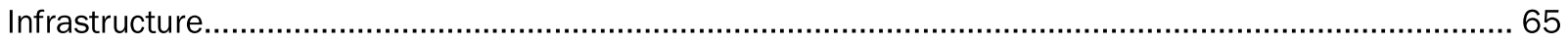

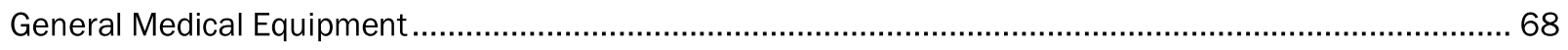

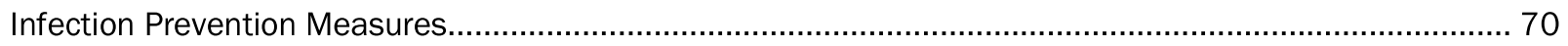

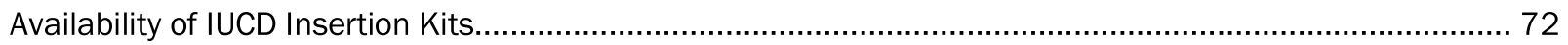

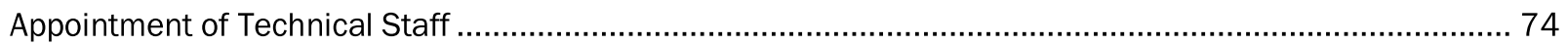

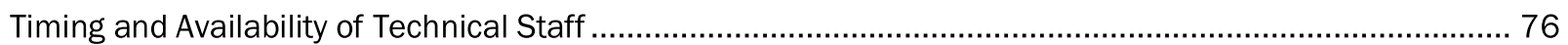

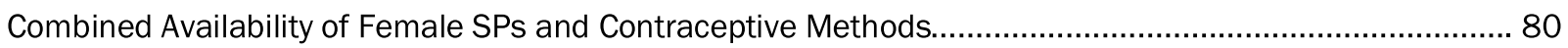

Districts at a Glance: Variation in FP service availability ...................................................................... 86

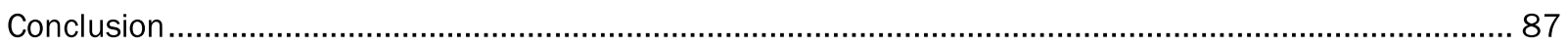

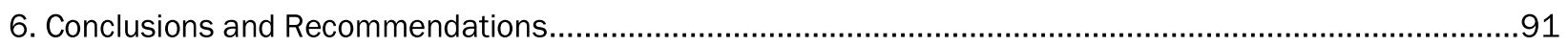

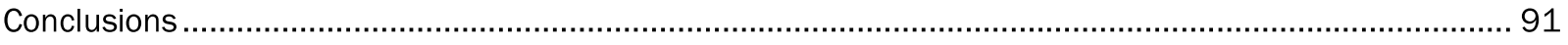

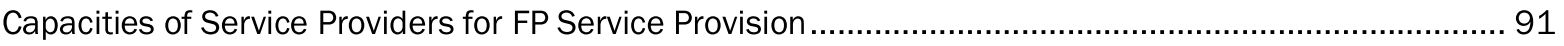

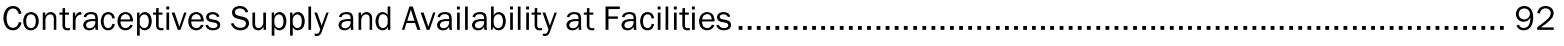

Readiness of Health Facilities for Family Planning Service Provision ...................................................... 93

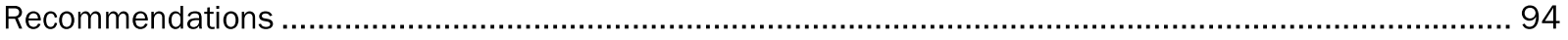

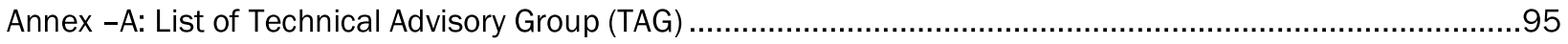

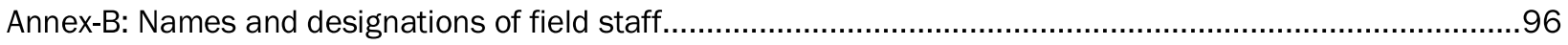




\section{List of Tables}

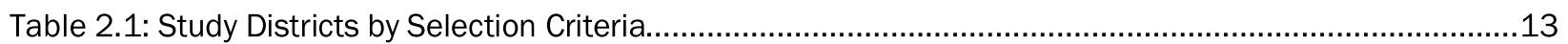

Table 2.2: Health Facilities in Planned Study Sample...............................................................................14

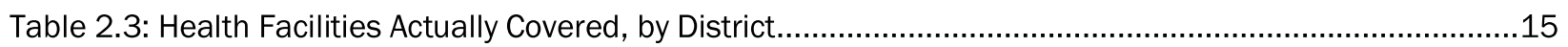

Table 2.4: District Contraceptive Stores Visited, by Sector .......................................................................15

Table 3.1: Socio-demographic Characteristics of Service Providers ...............................................................22

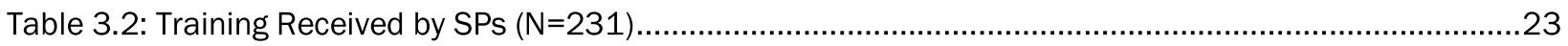

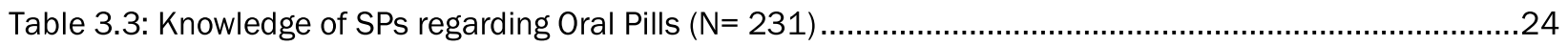

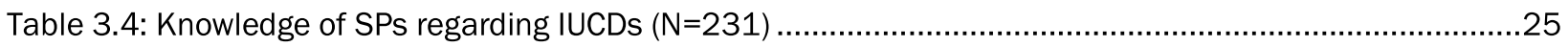

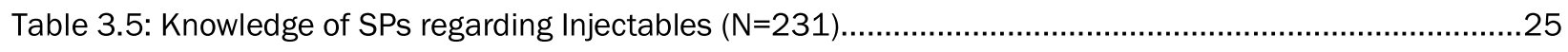

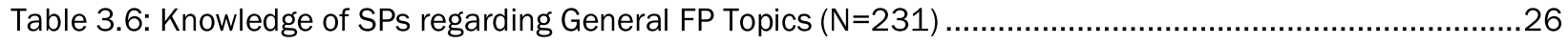

Table 3.7: Mean of Right Answers Given by SPs about Different Contraceptive Methods by District and

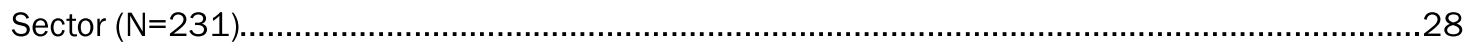

Table 3.8: Proportion SPs following Salutation Protocols by whether they were Trained $(\mathrm{N}=432) \ldots \ldots \ldots \ldots \ldots \ldots . . .29$

Table 3.9: Proportion of SPs following Assessment Protocols by whether they were trained $(\mathrm{N}=432) \ldots \ldots \ldots \ldots . . .30$

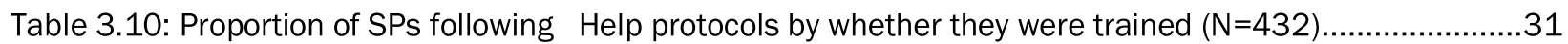

Table 3.11: Information Provided by SPs When a Client Accepts a New FP Method $(\mathrm{N}=231) \ldots \ldots \ldots \ldots \ldots \ldots \ldots . . . . .31$

Table 3.12: Information Provided by SPs When Referring a Client to another Facility $(\mathrm{N}=231)$......................32

Table 3.13: Proportion of SPs following Reassurance Protocols by whether they were trained $(\mathrm{N}=432) \ldots \ldots \ldots . . .33$

Table 3.14: Socio-demographic Characteristics of Clients Interviewed .........................................................33

Table 3.15: Client's Purpose of Visiting Health Facility on Day of Interview by type of provider $(\mathrm{N}=436) \ldots \ldots \ldots . . .34$

Table 3.16: Socio-demographic Profile of Lady Health Workers Interviewed ....................................................35

Table 3.17: Knowledge of LHWs about Healthy Timing and Spacing of Pregnancy by Province $(\mathrm{N}=23) \ldots \ldots \ldots . . . .36$

Table 3.18: Knowledge of LHWs regarding Timing of Depo-Provera Injection, by Province $(N=23)$...................36

Table 3.19: Knowledge of LHWs regarding Side Effects of Injectables, by Province $(\mathrm{N}=23)$...........................37

Table 3.20: Knowledge of LHWs regarding Management of Irregular Bleeding while on Oral

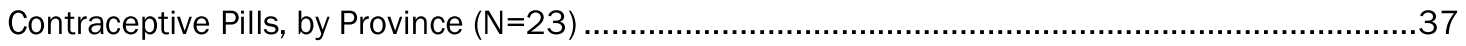

Table 3.21: Proportion of Correct Answers Given by LHWs about Contraceptives by Province $(\mathrm{N}=23)$...............38

Table 4.1: Types of Service Delivery Points Served by Different Sectors' District Stores .................................44

Table 4.2: Contraceptive Stock-outs in the Past Year by Sector across Districts ..............................................47

Table 4.3: Contraceptive Stock-outs in Past Year by Type of Facility and Sector ..............................................48

Table 4.4: Facilities that Arrange Supplies from Additional Sources by Type of facility and Sector ...................50

Table 4.5: Availability and Reporting of Stocks of Contraceptives by District.................................................52

Table 4.6: Availability of Stocks and Reporting of Specific Contraceptive Methods by Type of Facility...............55 
Table 4.7: Range of Contraceptive Methods available at Facilities by District.

Table 5.1: Availability of Necessary Infrastructure and Amenities for Family Planning by Type of Facility and Sector

Table 5.2: Availability of Necessary Infrastructure and Amenities for Family Planning by Sector, and District

Table 5.3: Availability of Functional General Examination Equipment by Level of Facilities ..... .68

Table 5.4: Availability of Functional General Examination Equipment by District and Sector ..... .69

Table 5.5: Availability of Infection Prevention Arrangements by Facility Level ............................................

Table 5.6: Availability of Infection Prevention Arrangements by Sector and District.................................... 71

Table 5.7: Availability of Essential/Complete IUCD Insertion Kit by Level of Facility....................................

Table 5.8: Availability of Essential/Complete IUCD Insertion Kits by Sector and Districts ...............................73

Table 5.9: Filling of Sanctioned Posts for Technical Staff at Public Health Facilities, \% of Facilities $(\mathrm{N}=185)$

Table 5.10: Staffing against Sanctioned Posts for Technical Staff at Public Health Facilities by Sector and Districts, \% of Facilities ( $\mathrm{N}=185)$.

Table 5.11: Availability of Technical Staff in Morning/Evening Shifts at Health Facilities by Sector and

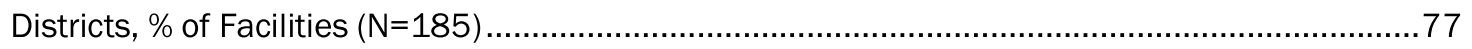

Table 5.12: Availability of At Least one Female SP and Injectables by Level, \% of Facilities.............................81

Table 5.13: Availability of At Least one Female SP and Injectables by Timing and by Sector and Districts, $\%$ of Facilities.

Table 5.14: Availability of At Least one Female SP and IUCDs in the Morning, Evening and Both Shifts by Level, \% of Facilities .84

Table 5.15: Availability of At Least One Female SP and IUCD by timing and by Sector and Districts, \% of Facilities .85

Table 5.16: District Index including Both Public and Private Facilities........ .86

Table 5.17: District Index and Ranking in Readiness of providing FP services , Public Facilities Only...... .87 


\section{List of Figures}

Figure 1.1: Current Use of Modern and Traditional Contraceptive Use (1991-2013).................................... 4

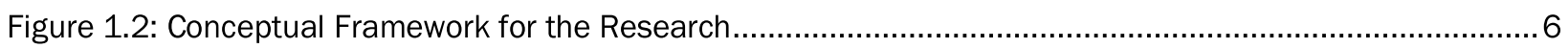

Figure 1.3: Study Framework for Situation Analysis of Health Facilities ...................................................... 8

Figure 3.1: Mean number of Right Answers Given about Different Contraceptive Methods by SP Cadre

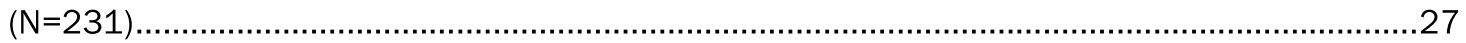

Figure 4.1: Flow of Contraceptives to Public and Private Health Facilities and Clients...................................44

Figure 4.2: Stock-out of Any or More than One Contraceptive in the Past Year at Different Types of Facilities (Public Sector), \% of Facilities.

Figure 4.3: Stock-out of Contraceptives in Past Year by Type of Facility (Public Sector) and Province, $\%$ of Facilities

Figure 4.4: Distribution of Public Sector Facilities by Number of Contraceptive Methods Available on Day of Visit..

Figure 4.5: Distribution of Private Sector Facilities by Number of Contraceptive Methods Available on Day of Visit...

Figure 4.6: Sources of Contraceptives for LHWs, by Province. .58

Figure 4.7: Stock-outs of Contraceptives Experienced by LHWs, by Province .59

Figure 4.8: Number of Methods for which LHWs Experienced Stock-Outs in Different Provinces. .60

Figure 4.9: Availability of Contraceptives with LHWs on the Day of the Visit...... 60

Figure 4.10: Choice of Contraceptive Method Mix Available with LHWs on the Day of Visit, by Province. .61

Figure 5.1: Morning and Evening Availability of Women Medical Officers at Public and Private Facilities, $\%$ of Facilities $(\mathrm{N}=185)$

Figure 5.2: Morning and Evening Availability of Female Mid-level providers at Public and Private Facilities, \% Facilities ( $\mathrm{N}=185)$

Figure 5.3: Availability of At Least One Female Technical Staff Member in Morning, Evening and Both Shifts at Public and Private Facilities, \% of Facilities ( $N=185)$ .79

Figure 5.4: Availability of At Least one Female SP and Injectable by Level, \% of Facilities... .80

Figure 5.5: Availability of At Least one Female SP and IUCD by Level of Facility, \% of Facilities .83

Map1: District Index including Both Public and Private Facilities. .88

Map 2: District Index including Public Facilities Only .89 



\section{Acronyms}

\begin{tabular}{|c|c|}
\hline $\mathrm{BHU}$ & Basic Health Unit \\
\hline CPR & Contraceptive Prevalence Rate \\
\hline $\mathrm{CWH}$ & Central Warehouse \\
\hline DFAT & The Australian Department of Foreign Affairs and Trade \\
\hline DfID & Department for International Development \\
\hline DHQ & District Head Quarter \\
\hline DPIU & District Project Implementation Units \\
\hline DPWO & District Population Welfare Officer \\
\hline DTC & District Technical Committee \\
\hline ECP & Emergency Contraceptive Pills \\
\hline EDO & District Officer-Health \\
\hline FALAH & Family Advancement for Life and Health \\
\hline FHT & Female Health Technician \\
\hline FMT & Female Medical Technician \\
\hline FPAP & Family Planning Association of Pakistan \\
\hline $\mathrm{FP}$ & Family Planning \\
\hline FWC & Family Welfare Centre \\
\hline FWW & Family Welfare Worker \\
\hline GIS & Geographical Information System \\
\hline GYN & Gynaecologist \\
\hline IEC & Information Education Communication \\
\hline IRB & Institutional Review Board \\
\hline IUCD & Intrauterine Contraceptive Device \\
\hline $\mathrm{KP}$ & Khyber Pakhtunkhwa \\
\hline LAM & Locational Amenorrhea Method \\
\hline LHV & Lady Health Visitor \\
\hline LHS & Lady Health Supervisors \\
\hline LHW & Lady Health Worker \\
\hline $\mathrm{MCH}$ & Mother and Child Health \\
\hline MBBS & Bachelor of Medicine and Surgery \\
\hline MHT & Male/ Medical Health Technician \\
\hline MO & Medical Officer \\
\hline MSS & Marie Stopes Society \\
\hline NGO & Non-Governmental Organization \\
\hline PDHS & Pakistan Demographic Health Survey \\
\hline PPHI & Peoples Primary Health Initiative \\
\hline PRSP & Punjab Rural Support Program \\
\hline
\end{tabular}


RAF

$\mathrm{RH}$

$\mathrm{RHC}$

RHS-A

SAHR

SDP

SM

SPS

TAG

THQ

WMO
Research and Advocacy Fund

Reproductive Health

Rural Health Centre

Reproductive Health Services Centre

Salutation, Assess, Help and Reassure

Service delivery Points

Social Mobilizers

Service providers

Technical Advisory Group

Tehsil Head Quarter

Women Medical Officer 


\section{Acknowledgments}

This national study on "The Availability and Quality of Family Planning Services across Eight Districts in Pakistan: the Potential and the Constraints" was conducted by the Population Council under the project "Investigating the Low Patterns of Modern Contraceptive Use in Pakistan". We gratefully acknowledge the financial support of the Maternal and Newborn Health Programme - Research and Advocacy Fund (RAF), which made this research possible.

This study greatly relied on the leadership of Dr. Zeba Sathar, Country Director Population Council; we are extremely grateful for her visionary and technical inputs at every stage of the research and report writing. This study was led by Dr Gul Rashida, whose guidance, support encouragement and trust inspired the study team to tackle obstacles in the field and analysis.

We are deeply grateful to the departments of Health and Population Welfare and the provincial and district officers of the National Program for Family Planning and Primary Health Care, People's Primary Health Initiative (PPHI) and Punjab Rural Support Program (PRSP) for their cooperation and unstinting support in the study districts. We especially thank staff at local basic health units (BHUs).

We gratefully acknowledge the inputs of the members of the Technical Advisory Group and for their guidance and constructive inputs in the development of the study report and policy recommendations. All TAG members are named with their designations and departments in Annex-A.

We acknowledge RAF for the technical review of the report that led to its finalization. We also thank John Townsend, Vice President Reproductive Health and Dr. Ali Muhammad Mir for their invaluable reviews of the report.

We would like to appreciate the contribution of Ms. Zeba Tasneem, Senior Program Officer at Population Council, who supported the study through its many stages, from training of the field staff to field monitoring in Sindh. We also appreciate the contribution of Mr. Usman Asif, Deputy Training Coordinator, for his great support in obtaining permissions through correspondence and follow up with officials of study districts. And we are grateful to the administration and finance and IT departments of the Population Council for their valuable support through every stage in the implementation of this national study.

We also extend our sincere thanks to Mr. Mohammad Ali and Mr. Usman Ghani, who provided outstanding support during training of the field staff, and afterwards, managed, organized and processed data set smoothly. We also thank Ms. Shagufta Naheed who prepared manuals of the questionnaires to be used in the field and also assisted in data editing of the questionnaires.

We are very thankful to each member of the research team especially the provincial coordinators, who provided guidance for each stage in fieldwork from conducting interviews to transcription. They are named in Annex-B

We extend our earnest gratitude to the editor of this report, Ms. Kiren Khan for her tireless efforts. We thank Mr. Ali Ammad for formatting and designing.

Finally, we would like to express our deep appreciation and respect for the respondents who participated in this study and shared their personal insights and information with our study teams. This study would not have been possible without their cooperation. 



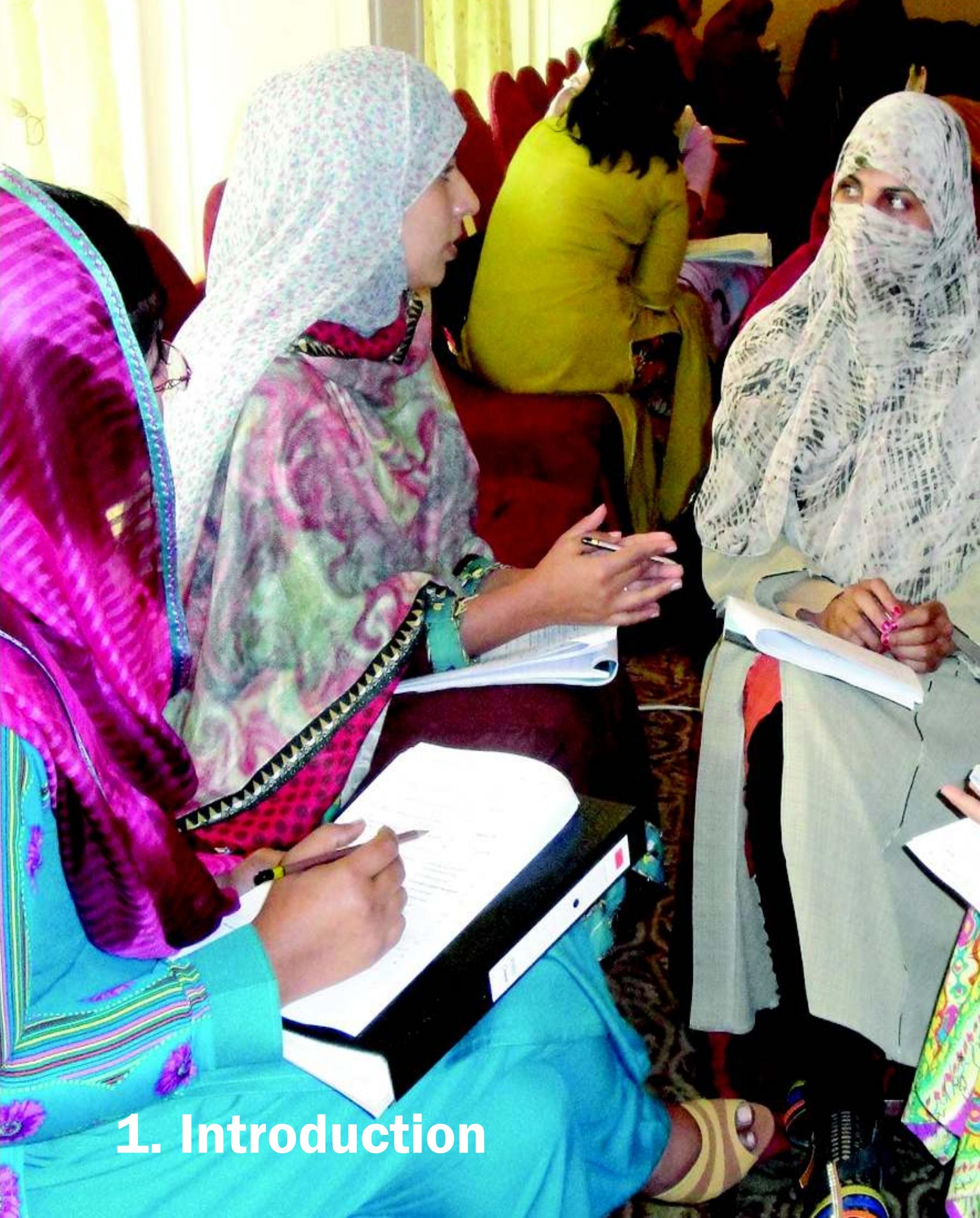





\section{Introduction}

This report forms part of a multipronged investigation to determine why, despite evident unmet need for family planning, contraceptive prevalence especially for modern methods remains so low in Pakistan. The research, conducted by the Population Council with the support of the Research and Advocacy Fund (RAF), consists of four component studies: (1) review of relevant academic, program and policy literature1; (2) a qualitative study of perspectives of men, women and service providers in the country on family planning;; (3) a situation analysis of contraceptive quality, supply and access factors at health facilities; and (4) an examination of supply issues affecting the availability of contraceptives. This report presents the latter two studies.

\section{The Unmet Need for Contraception}

Pakistan has one of the highest fertility rates in Asia, and the lowest rates of contraceptive use, resulting in poor reproductive health indicators for women and high neonatal mortality. ${ }^{3}$ There is a large need for methods to space and limit children: overall demand for contraception is very high, with 19.1 percent of respondents wanting a child later; 42.3 percent wanting no more children; and 8.9 percent being sterilized. ${ }^{4}$ In the past decade, the incidence of post-abortion complications has risen, indicating an increase in recourse to induced abortion.

Despite this evident desire to limit pregnancies, however, rise in the contraceptive prevalence rate (CPR) has been slow (Figure 1.1). The previous Pakistan Demographic and Health Survey (PDHS), conducted in 2006-07, found that the CPR had fallen, contraceptive use had stagnated, and a significant portion of women who had used modern contraceptives were giving them up, as indicated by the large gap between numbers of ever users and current users. This discontinuation has been found to be one of the factors leading to the large estimated number of induced abortions. ${ }^{5}$ While the latest PDHS (2012-13) does report a modest increase in the CPR from 29.6 percent in 2007 to 35.4 percent in 2012,6 nearly half of the increase in contraceptive use is in traditional, and not modern, methods. Moreover, ever use of modern contraceptive methods, at 54 percent, remains much higher than current use, which is 35 percent, suggesting substantial discontinuation of contraceptive methods. This could be due to a number of factors, such as poor counselling, inadequate skills of providers, gaps in management of side effects, and non-availability of contraceptives.

\footnotetext{
${ }^{1}$ Findings from the first component are published in a separate report by the Population Council entitled "Reasons for Low Modern Contraceptive Use - Insights from Pakistan and neighbouring countries".

2 Finding from the qualitative study of perspective of men, women and service providers are published as a separate report by the Population council entitled "Investigating the Low Patterns of Modern Contraceptive Use in Pakistan".
}

${ }^{3}$ Aga Khan University, International Advocacy Seminar on Family Planning and Reproductive Health, February 12-13, 2013 (Karachi: Department of Community Health Sciences, Aga Khan University, 2013).

${ }^{4}$ National Institute of Population Studies (NIPS) and ICF International, Pakistan Demographic and Health Survey 2012-13 (Islamabad and Calverton, Maryland, USA: NIPS and ICF International).

${ }^{5}$ G. Rashida, I. Kamran, K. Eshai and Z. Tasneem, “Post-abortion Care in Pakistan: The Influence of Gender and Poverty” (research brief, Population Council, Islamabad, 2013).

6 National Institute of Population Studies (NIPS) and ICF International, Pakistan Demographic and Health Survey $2012-13$ (Islamabad and Calverton, Maryland, USA: NIPS and ICF International). 


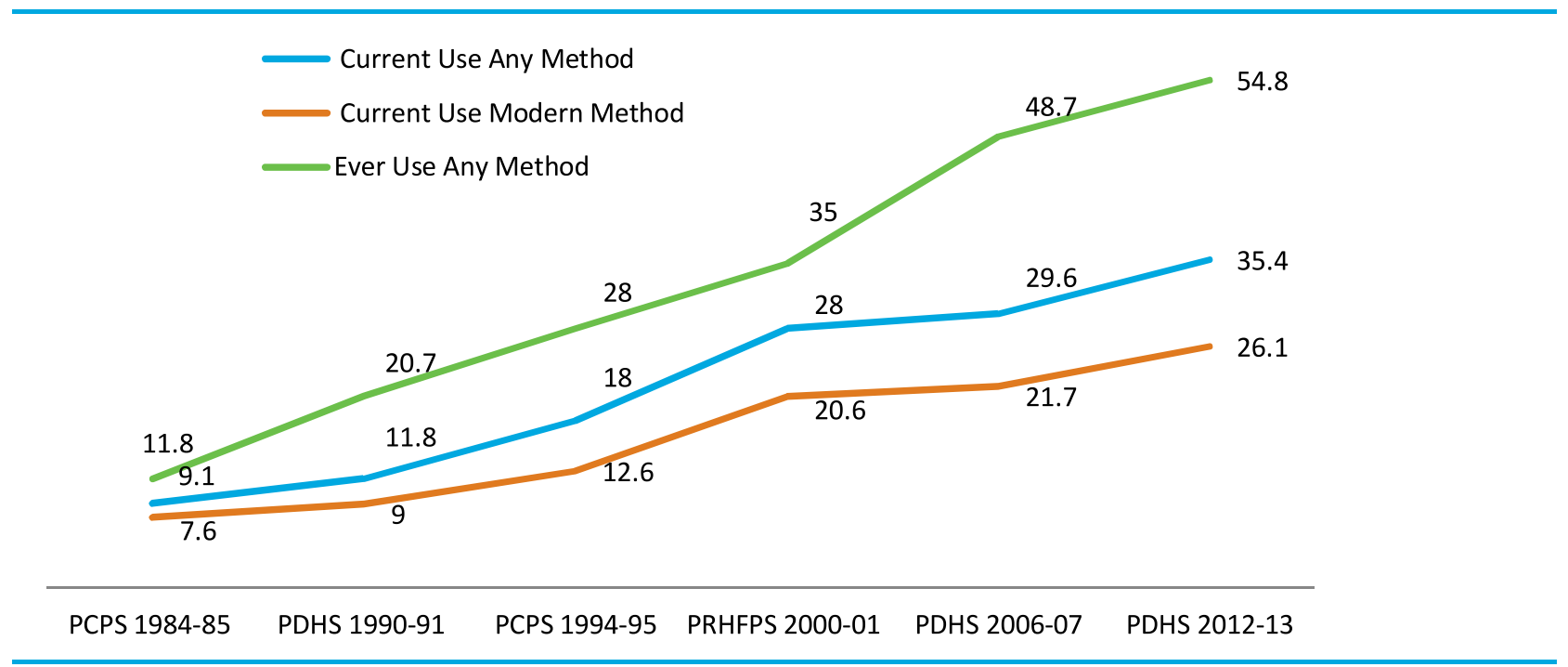

Sources: Pakistan Contraceptive Prevalence Surveys (1984-85 and 1994-95), Demographic and Health Surveys (1990-91, 2006-07 and 2012-13), and Pakistan Reproductive Health and Family Planning Survey (2000-2001)

On the supply side, past efforts particularly those focused in primarily rural districts show that the uptake and continuation of contraceptive use can be quite fast if quality services are available; much of the problem with the delivery of family planning services has been identified in the erratic supply chain for contraceptive methods, and the irregular availability of supplies to providers and facilities. ${ }^{7}$

Low usage of modern contraceptives entails significant health and development costs. One in three pregnancies and childbirth-related deaths would be avoided if women who want to use contraception were able to access it. The use of effective contraception would also reduce the need for induced abortions, which currently lead to 700,000 complications cases being presented at health facilities annually. ${ }^{8}$ Early and closely spaced multiple pregnancies are detrimental to the health of mothers and new-borns. Closing the gap between the demand for contraception and its supply, particularly in rural and poor urban areas, is, therefore, central to reducing maternal mortality, making a dent on neonatal mortality, and improving the wellbeing of millions of families in Pakistan.

\section{Need for the Research}

Traditionally, the main reasons given for unmet contraception need relate to supply-side issues of access and quality of services and, secondly, to demand-side obstacles such as husband's approval, approval of modern contraception, and fear of side effects. However, there is now growing recognition that some of the reasons are more deep-rooted. Gaps exist in our information and understanding of specific methods of modern contraception that are important and cannot be addressed entirely through cross-sectional surveys.

Moreover, the family planning scenario has changed significantly. Women and men are demanding family planning services much more keenly and urgently now than they were ten years ago. They may now be held

\footnotetext{
${ }^{7}$ A. Mahmood, J. Arshad and M. Sadiq, Stock Analysis at Service Delivery Points for USAID-Supported Contraceptives: Final Report (Islamabad: Population Council, 2012).

8 Z. Sathar et al. Post-abortion Care in Pakistan: A National Study (Islamabad: Population Council, 2013).
} 
back from modern contraception by a different set of factors, such as poor quality of services, disillusionment with contraceptive products and providers, high costs of procuring family planning methods, negative provider attitudes, or wider issues of healthcare quality.

The Population Council's research was planned as an attempt to probe beyond the standard explanations of demand and supply constraints for the limited uptake of modern contraception in Pakistan. While the questions asked were similar to previous studies of this nature, the methods adopted provided for a deeper investigation, and the analysis linked findings from both the need/demand side and the supply side for a more holistic and comprehensive view.

The findings of our research are expected to help explain the contraceptive prevalence trends identified by the Pakistan Demographic and Health Survey 2012-13, and to inform the decision-making of a wide range of stakeholders, including the national and provincial political leadership; policymakers and program managers concerned with family planning, both in the public and the private sector; civil society and research organizations with an interest in reproductive rights and services; and international institutions with an interest in Pakistan's population sector.

Our investigation into the factors underlying low use of modern contraceptives in Pakistan took the form of four studies, including an extensive literature review and three sets of primary data analysis. Specifically, the studies included the following:

- Review and analysis of relevant literature, including academic, program and policy sources concerning contraception need, demand and supply in Pakistan;

- Qualitative study of perspectives of men, women and providers on family planning drawing on in-depth interviews and focus group discussions with women and men to understand their views and delve beyond standard responses for deeper reasons for non-use of contraception, combined with in-depth interviews of service providers to assess their knowledge and skills in FP techniques, belief systems, and level of comfort in discussing and counselling on family planning with clients;

- Situation analysis of health facilities aimed at gauging the state, quality and accessibility of family planning services (at a representative set of public and private facilities); and

- Examination of the availability and supply of contraceptive stock from the country's central warehouse to the client to assess the efficiency of supply and identify the administrative and logistic issues that affect the availability of the main modern contraceptives.

The key themes and inter-linkages of the four studies are summarized in Figure 1.2. As mentioned earlier, this report presents the third and fourth of the above-listed studies, which are concerned with the supply side of family planning in Pakistan.

The latter three studies listed were conducted in the same eight selected districts, representing all four major provinces of Pakistan, to derive a complete picture of the supply and demand factors, and provincial and national patterns. Primary data for the qualitative study of perspectives of men, women and providers was collected from selected communities representing urban, semi-urban, served and unserved rural areas. For the situation analysis of health facilities, data was collected from sampled health facilities of different levels from both the public and the private sector. For the examination of the availability of contraceptive stock, data was collected from the Central Warehouse in Karachi, district-level stores of relevant departments and health programmes, and from the health facilities. 
Figure 1.2: Conceptual Framework for the Research

\begin{tabular}{|l|}
\hline Myths and \\
misconceptions \\
regarding FP \\
and individual \\
contraceptive \\
methods \\
\hline
\end{tabular}

\begin{tabular}{|l|}
\hline Status of \\
women: mobility, \\
decision \\
making, \\
power dynamics, \\
spousal \\
communication \\
\hline
\end{tabular}
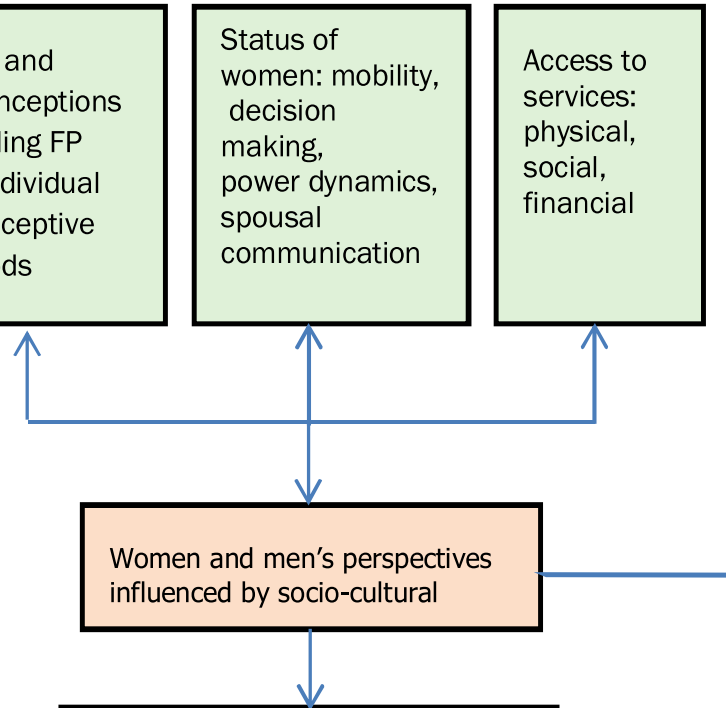

\section{STUDY 2:}

FGDs - Women and Men

IDIs - Women and Men

IDIs - LHWs
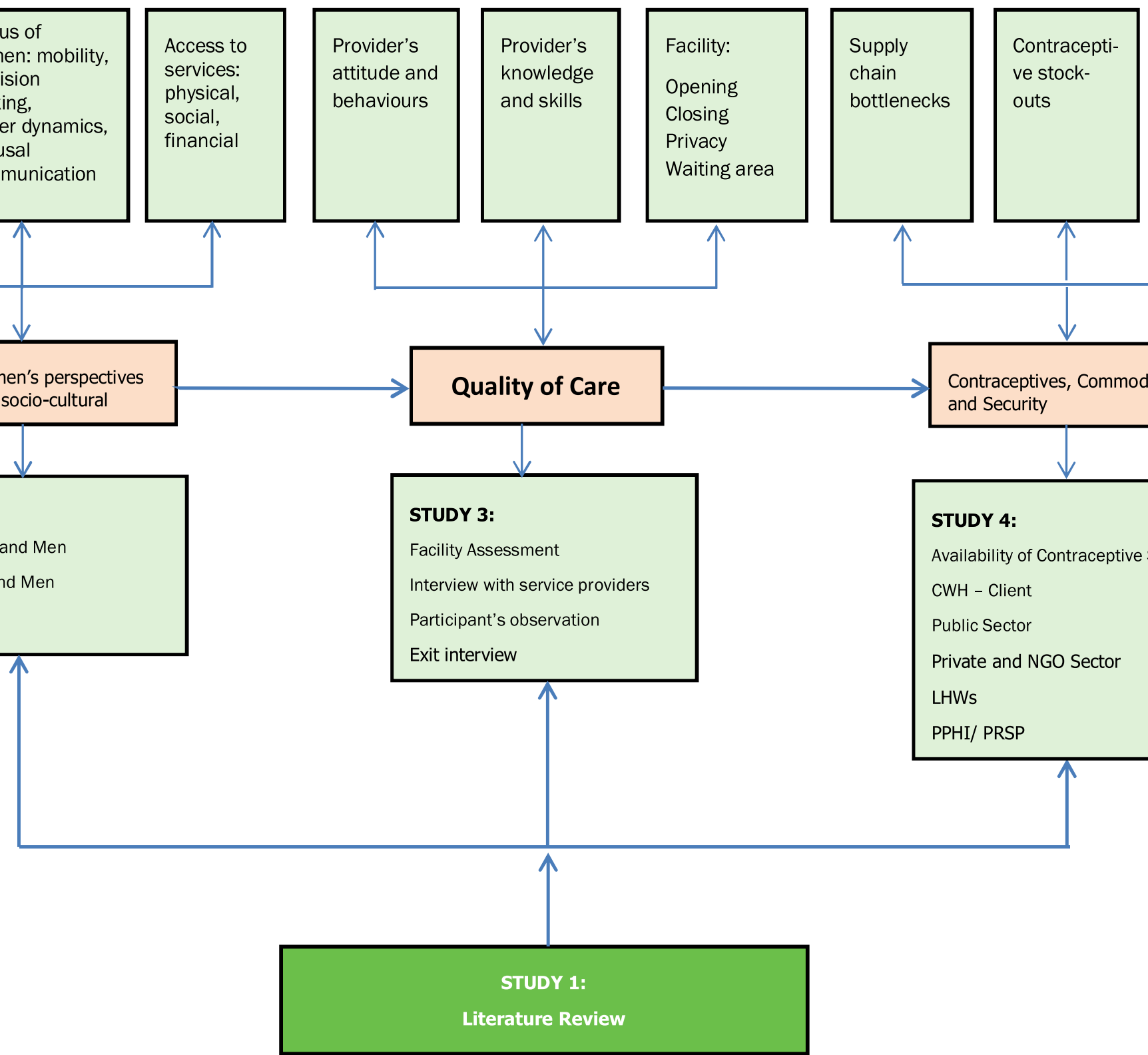

Range of

Contraceptive

Methods

(Method Mix)

\section{STUDY 3:}

Facility Assessment

Interview with service providers

Participant's observation

xit interview

iterature Review 


\section{Study Objectives, Design and Methodology}

quality of family planning services and products in Pakistan. The first study reported is a situation analysis of different types of public- and private-sector health facilities. Based on a representative sample of 185 facilities ranging from small clinics to major hospitals in eight districts, the study evaluates the readiness of health facilities, in terms of availability of staff, medical equipment, amenities, and family planning (FP) methods, and the quality of FP services, as indicated, for example, by service providers' training, technical knowledge, method-specific professional opinion, and interactions with clients.

The second study presented in this report reviews the chain of supply of contraceptives from the Central Warehouse to the district, and from the district to the facilities/providers. Very few such studies have been conducted in Pakistan in the last two decades, and the limited evidence available suggests significant levels of stock-outs at different tiers of service delivery. This study aims to assess the effectiveness of procurement, distribution, and stock replenishment along the supply chain; explore responses, if any, to new ways of ordering and distributing contraceptives; and identify supply and logistics system gaps that interrupt the flow of intrauterine contraceptive devices (IUCDs), pills, injectables and condoms to facilities and clients.

\section{Study Objectives}

The objectives of the two studies were to:

- Assess the levels of knowledge of providers about available contraceptives and identify reasons for use and non-use;

- Assess the existing quality of FP care being offered in private and public facilities and its impact on client satisfaction and FP adoption;

- Assess the logistics supply chain system to identify gaps and issues hindering supply of contraceptives; and

- Provide recommendations for the departments of health and population welfare for strengthening programme strategies, delivery mechanisms, and communications in order to enhance access to services and reduce unmet need.

\section{Research Questions}

Based on their objectives, research for the two studies was based on the following key questions.

Situation Analysis of Health Facilities

How can we further unpack the issue of access and quality of provision of family planning services in Pakistan?

- Are family planning services more readily available in public or private facilities - what level and type of facilities are more ready to provide such services?

- Is there enough choice of contraceptive methods available to women from poor settings?

How important are providers and their own attitudes in the delivery of family planning services?

- What is the role of quality of services, including availability of providers, their training and behaviour, and personal beliefs?

- Are women and men effectively given an informed choice to make?

- Are they given accurate and comprehensive information about how to use methods effectively? 


\section{Contraceptives Supply and Availability}

How important are the factors that affect the supply chain of contraceptive distribution down to the level where they are available to clients?

- Where is the distribution breakdown most likely to occur and why?

- Which facilities and providers are most affected by poor supply chain operations?

- How important are stock-outs of various contraceptive options in influencing the available method mix and subsequent contraceptive adoption?

- What are the main factors that affect the operation of the logistic system from Central Warehouse to the district stores and facilities?

\section{Study Design}

Data for the first study, the situation analysis of health facilities, was collected through five means, including interviews with service providers; observation of provider-client interactions; exit interviews with clients; observation of pre-identified facility parameters, such as staff availability, timings and equipment; and a review of contraceptives availability. This five-pronged inquiry was conducted in 1-2 days at each of the 185 facilities in the eight study districts. The design of the first study is summarized in Figure 1.3.

Data for the study of contraceptive supply and availability was collected through interviews at the Central Warehouse (CWH) in Karachi;9 district- and facility-level contraceptive stores; LHWs; and private sector facilities, including some NGOs and clinics. The questions were designed to assess contraceptive availability, stock-out incidence, and the demand-and-supply mechanism at each tier of the supply chain.

Figure 1.3: Study Framework for Situation Analysis of Health Facilities

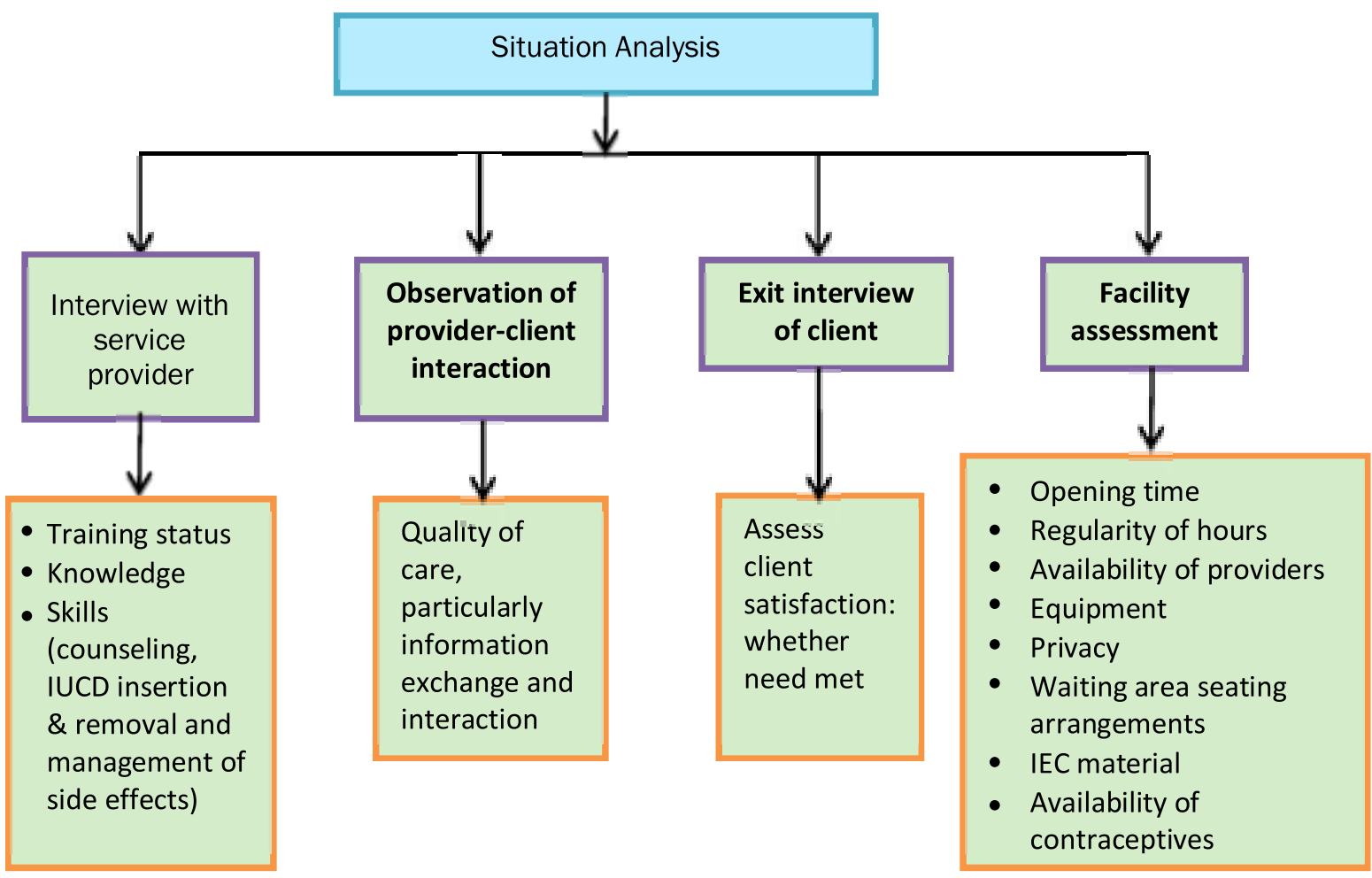

9 , CWH is the only source of contraceptives for public facilities, including those associated with the Department of Health (DoH), Population Welfare Department (PWD), People's Primary Healthcare Initiative (PPHI) and the Punjab Rural Support Programme (PRSP). 


\section{Structure of the Report}

After the introduction, next section outlines the methodology of the two studies presented in this report. Then findings are presented about the capacity of family planning service providers to provide quality care to clients, in terms of their training, knowledge and behaviour. Next the report discusses the situation of supply of contraceptives in the country from the Central Warehouse in Karachi to district stores and onwards to service delivery points in the public and private sector for a better understanding of how supply issues hinder availability of different contraceptive methods. Afterwards, the situation of health facilities is assessed in terms of availability of necessary infrastructure, equipment, staff and contraceptive methods. Conclusions emerging from the analysis are presented along with recommendations in the final section. 



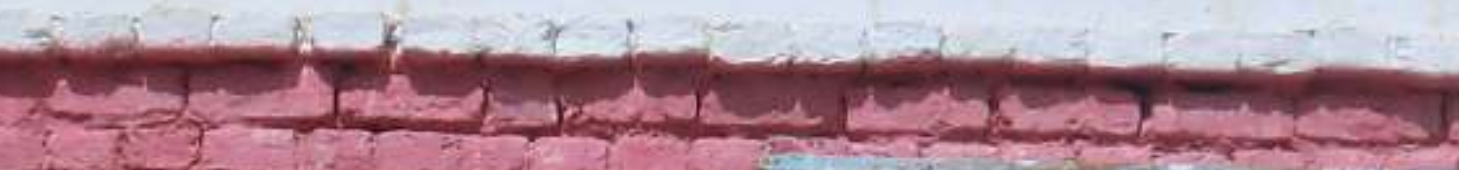

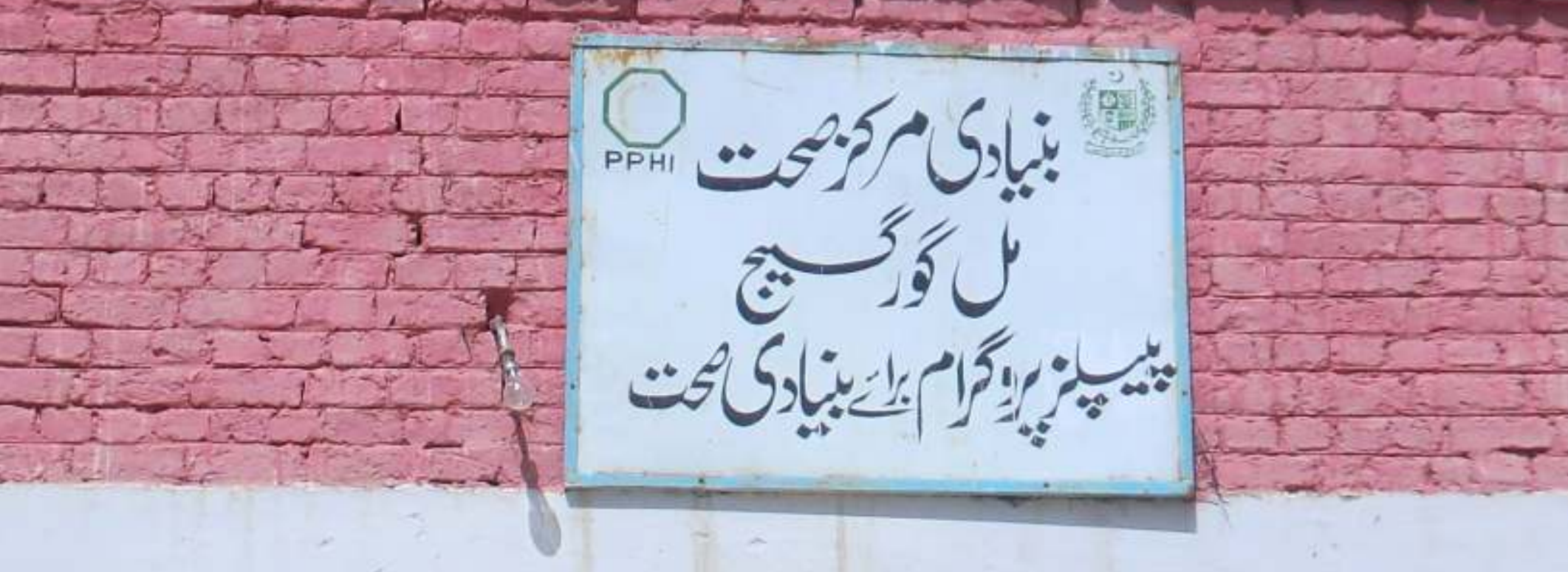




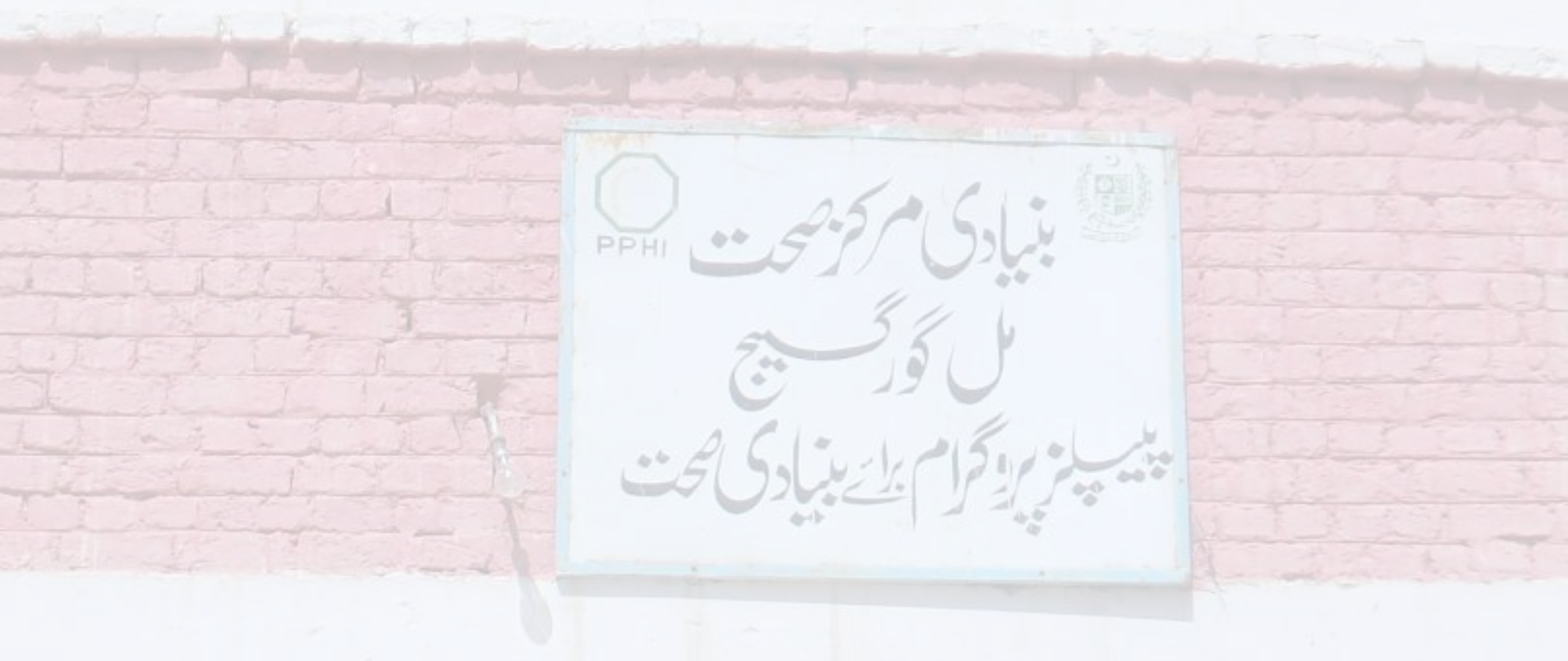




\section{Methodology}

The situation analysis of health facilities and the review of the availability of contraceptives stock were both conducted in the same areas in the districts following a common methodology, which is elaborated below.

\section{Selection of Districts}

The studies were designed as part of a nationwide assessment. Two districts were selected using a deprivation index which provided a development ranking from each of the three provinces, Khyber Pakhtunkhwa (KP), Sindh and Punjab, whereas in Balochistan, districts were purposively selected to avoid the security risks involved in field work in some parts of the province. It was also ensured that there should be representation of Pashtun and Baloch districts.

District selection from KP, Sindh and Punjab was based on the incidence of multidimensional poverty in the district. In 2012, this incidence was quantified at household and district level, using the Pakistan Social and Living Standard Measurement Survey (PSLM), conducted during 2010-1110. Districts were divided into three strata (high, medium and low) at provincial levels in terms of incidence of poverty. Next, one high-poverty district and one medium-poverty district was selected. Low-poverty districts were intentionally excluded to avoid districts that already enjoyed a relatively high level of development.

Within the highest and medium poverty strata, preference was given to districts that had been covered under a "mapping survey" carried out earlier by Population Council11 where data was available on all public and private health facilities and could be used in sampling of health facilities.

The eight districts selected for the study are listed in Table 2.1.

Table 2.1: Study Districts by Selection Criteria

\begin{tabular}{lll}
\hline & Province Name & District Name \\
\hline \multirow{3}{*}{ High Poverty Incidence } & Punjab & Rahim Yar Khan \\
& Sindh & Umerkot \\
& KP & Mardan \\
\hline \multirow{3}{*}{ Medium Poverty Incidence } & Punjab & Khanewal \\
& Sindh & Khairpur \\
\cline { 2 - 3 } & KP & Mansehra \\
\hline
\end{tabular}

Note: Pishin and Sibi districts were purposively selected to avoid security risks though both are on low poverty incidence.

\footnotetext{
10J. Haroon, An Exploratory Analysis of Inter-Temporal Multidimensional Poverty 2012, Research Report No. 83 (n.p.: Social Policy and Development Centre).

${ }^{11}$ Mapping of health and reproductive health services was carried out by Population Council in 35 districts of Pakistan under the FALAH, PAIMAN and Packard projects.
} 


\section{Sampling of Health Facilities}

It was decided that the sample for assessing family planning service availability (both for situation analysis of health facilities and the review of the contraceptives supply chain points) would include 22 health facilities, including 14 public and 8 private facilities, from each of the selected districts. The distribution of facilities per district is shown in Table 2.2. The public-sector facilities included a district headquarters (DHQ) hospital, a tehsil headquarters (THQ) hospital, two rural health centres (RHCs), four basic health units (BHUs), two mother and child health $(\mathrm{MCH})$ centres, and four family welfare centres (FWCs). The 8 private-sector facilities represented a size range equivalent to the range of public-sector facilities (based on number of beds). These facilities were included in the sample to provide a comparative perspective on the choices available in the district; however, their number in the sample was lower than that of public facilities because the public sector caters to a larger proportion of clients.

Table 2.2: Health Facilities in Planned Study Sample

\begin{tabular}{lcccc}
\hline Facility & Public & $\begin{array}{c}\text { Private } \\
\text { (Equivalent)** }\end{array}$ & $\begin{array}{c}\text { Total per } \\
\text { District }\end{array}$ & $\begin{array}{c}\text { Total for 8 } \\
\text { Districts }\end{array}$ \\
\hline $\begin{array}{l}\text { District Headquarter } \\
\text { Hospitals (DHQs) }\end{array}$ & 1 & 1 & 2 & 16 \\
$\begin{array}{l}\text { Tehsil Headquarter } \\
\text { Hospitals (THQs) }\end{array}$ & 1 & 1 & 2 & 16 \\
$\begin{array}{l}\text { Rural Health Centers } \\
\text { (RHCs) }\end{array}$ & 2 & 1 & 3 & 24 \\
$\begin{array}{l}\text { Basic Health Units } \\
\text { (BHUs)* }\end{array}$ & 4 & 2 & 6 & 48 \\
$\begin{array}{l}\text { Mother and Child Health } \\
\text { Centers (MCHs) }\end{array}$ & 2 & $-* * *$ & 2 & 16 \\
$\begin{array}{l}\text { Family Welfare Centers } \\
\text { (FWCs) }\end{array}$ & 4 & - & 4 & 32 \\
$\begin{array}{l}\text { Non-governmental } \\
\text { Organizations' Clinics }\end{array}$ & - & 3 & 3 & 24 \\
(NGOs) & 14 & 8 & 22 & 176 \\
\hline
\end{tabular}

*BHUs are attached with PPHI in KP, Sindh and Balochistan and with PRSP in Punjab.

**Private facilities were categorized by number of beds: 0-4 bed $\equiv$ BHU, 5-19 beds $\equiv$ RHC, 20-80 beds $\equiv T H Q, 81$ and more beds $\equiv D H Q$.

$-* * * \equiv$ Not applicable

Sampling of both public and private health facilities for all districts was carried out using GIS mapping data, except for private-sector facilities in Pishin and Sibi. There was no data for the private sector in both these districts, and therefore, facilities available in the field were covered.

The actual number of facilities visited varied in districts due to non-availability of certain levels of facilities. ${ }^{12}$ Moreover, while most of the identified facilities were covered completely, some facilities agreed to participate only partially or refused to participate altogether. Nevertheless, the number of health facilities covered in the study was greater than the number agreed for sampling, as shown in Table 2.3. The reason for this was that some of the facilities included in the sample housed other facilities, which the study teams included in their visits: DHQs in all provinces other than Balochistan had an attached A-type Reproductive Health Service centre (RHSC-A), and, likewise, some of the RHCs housed separate FWCs.

12Among public health facilities, one THQ hospital in Sibi and three MCHs in Mansehra and Mardan were not available. Among private facilities, six private hospitals equivalent to public DHQs were not available across the districts, except in Rahim Yar Khan and Umerkot. 
Table 2.3: Health Facilities Actually Covered, by District

\begin{tabular}{lcccc}
\hline Province/District & Planned sample & $\begin{array}{c}\text { Covered } \\
\text { completely }\end{array}$ & $\begin{array}{c}\text { Participated } \\
\text { partially }\end{array}$ & $\begin{array}{c}\text { Refused to } \\
\text { participate }\end{array}$ \\
\hline $\begin{array}{l}\text { Punjab } \\
\text { Khanewal }\end{array}$ & 21 & 27 & 0 & 0 \\
$\quad$ Rahim Yar Khan & 22 & 26 & 0 & 0 \\
\hline $\begin{array}{l}\text { Sindh } \\
\text { Khairpur }\end{array}$ & 21 & 25 & 3 & 1 \\
$\quad$ Umerkot & 20 & 26 & 0 & 1 \\
\hline KP Mansehra & 20 & & 0 & 0 \\
$\quad$ Mardan & 19 & 24 & 0 & 0 \\
\hline Balochistan & 14 & 19 & 0 & 0 \\
Pishin & 13 & 14 & 0 & 0 \\
Sibi & 150 & 185 & 3 & 2 \\
Total (N) & & & \\
\hline
\end{tabular}

\section{Sampling and Selection of Contraceptive Stock Availability Points}

In order to assess the contraceptive availability and supply chain, visits and interviews with key functionaries were conducted at the three main tiers of the contraceptive supply chain, i.e., at the Central Warehouse (CWH) in Karachi; at district-level contraceptive stores; and at service delivery points (SDPs).

Notably, no private facility maintains district-level contraceptive stores. Therefore, the district-level contraceptive stores visited were all from the public sector and were associated with the five key entities engaged in contraceptive supply, i.e., of the Department of Health (DoH), the Population Welfare Department, the People' Primary Healthcare Initiative (PPHI)/the Punjab Rural Support Programme (PRSP), and the LHWs Programme. A total of 30 district stores were visited. The sectoral and district distribution of the stores is presented in Table 2.4 .

Table 2.4: District Contraceptive Stores Visited, by Sector

\begin{tabular}{lccccc}
\hline Province & $\begin{array}{c}\text { Department } \\
\text { of Health }\end{array}$ & $\begin{array}{c}\text { Population Welfare } \\
\text { Department }\end{array}$ & $\begin{array}{c}\text { LHW } \\
\text { Program }\end{array}$ & PPHI/PRSP & Total \\
\hline Punjab & 2 & 2 & $1 *$ & $1 * *$ & 6 \\
Sindh & 2 & 2 & 2 & 2 & 8 \\
KP & 2 & 2 & 2 & 2 & 8 \\
Balochistan & 2 & 2 & 2 & 2 & 8 \\
Total (N) & 8 & 8 & 7 & 7 & 30 \\
\hline
\end{tabular}

* In Rahim Yar Khan district, contraceptive store of DoH and LHW program was combined

** In Khanewal district there is no PRSP contraceptive district store available and they arrange stock from other PRSP district stores 
The SDPs included the 22 health facilities (service delivery points) listed in Table 2.2, representing different levels within both the public and the private sector in the eight districts. At this tier, 23 lady health workers (LHWs) representing all eight districts were also visited and interviewed. ${ }^{13}$

\section{Data Collection}

A total of four study teams (one for each province) were engaged to collect data from health facilities (both for Situation analysis of health facilities and the review of the contraceptives supply chain points). Each team comprised of eight female members, including two supervisors and six enumerators, and one male logistics supervisor to facilitate the teams in arranging interviews and managing logistics. In addition, one male enumerator was separately hired for data collection from district contraceptive stores. Information from $\mathrm{CWH}$ was collected by senior member of the Population Council's research staff. All candidates had a background in social science and experience of data collection. All selected candidates were university graduates, mostly residing in the sampled districts, and had experience of working on previous studies conducted by the Population Council. A total of 32 female and five male staff were hired for data collection for both components of the study.

\section{Training}

All selected field staff received intensive 9-day training on research methods and study tools. During the training, interviewing skills were strengthened through role plays. As part of the training, pre-testing on actual data collection methodology was also carried out for two days in the district of Rawalpindi. Each of the study tools was discussed thoroughly to address the issues and challenges that came up during the pre-test.

\section{Fieldwork}

Actual field work took place between March and April 2014, both for situation analysis of health facilities and the review of the contraceptives supply chain points. Data collection started simultaneously in all provinces and was completed at the same time. Each team member was responsible for submitting their filled questionnaires to their respective supervisors for quality checks; hands-on training was also part of the data collection phase.

At each health facility, it took a study team one to two days to complete data collection, which included an indepth interview with the key service provider, exit interviews with clients to obtain their opinion about the services they had received, observations of provider-client interactions, general assessment of facility, and review of procurement procedures and practices.

In all, at the 185 health facilities visited, 231 interviews were conducted with service providers of different cadres, ranging from gynaecologists and medical doctors to health technicians; a total of 432 observations were also conducted of these SPs' interactions with clients; and exit interviews were conducted with 436 clients.

In addition, as mentioned earlier, interviews were conducted with 23 lady health workers to assess their FP service provision capacity, as well as the supply and availability of different contraceptive methods with them.

${ }^{13}$ The original plan had been to interview 24 LHWs, including 3 from each district, but one LHW was unavailable at the time of the study team's visit. 


\section{Monitoring}

The field teams were monitored by Population Council's research staff. During the fieldwork, they visited the study sites to ensure that all protocols were being properly followed. Field staff was provided regular feedback on their questionnaires to improve the quality of data collected. The questionnaire also had a built-in mechanism to reduce inaccuracies in data entry.

\section{Data Management and Analysis}

Data was managed through a systematic process of quality control. The filled questionnaires first underwent a round of quality checks by the team supervisor. Then, a member from the Council's research team performed random checking in the field. The questionnaires, each bearing a serial number, were then sent to the Population Council office in Islamabad, where they were reviewed again. Any discrepancies identified were referred back to the field. Data entry was performed using CSpro (the Census and Survey Processing System). After data editing and cleaning, the data set was checked against original questionnaires for inconsistencies, and corrected as needed. The analysis was performed using SPSS (the Statistical Package for the Social Sciences), version 20 . Consistency and range checks were conducted to verify the quality of the data, and original data were recorded as needed to provide data for presentation in tables.

The results presented are means, proportions, descriptive statistics, two- and three-way cross tabulation of relevant variables, and aggregate counts of events.

\section{Ethical Considerations}

Guiding principles for the study included reduction of any potential harms for participants, respect for human rights and dignity, balancing harms and benefits, respect for the research participants, and obtaining informed consent.

Before commencing the study, ethical approval was obtained from the Institutional Review Board (IRB) of the Population Council's headquarters in New York and the National Bioethics Committee in Pakistan.

During implementation of the study, informed consent for the situation analysis was obtained from all potential study participants after providing an in-depth briefing on the study, its objectives, procedures and uses, and giving them options. The participants were informed that they could refuse to participate or answer any question that made them uncomfortable, and terminate the interview at any time without any risk of sanctions. The approximate time required for interviews and the possible risks respondents might face were explained. Respondents were assured about the anonymity and confidentiality of their responses.

Interviews were carried out after obtaining informed consent from the respondents. Service providers were provided a consent form which they read (or asked the interviewer to tell them about) and then signed to show their willingness to be interviewed.

Training had been provided to data collectors to ensure sensitivity in their approach to limit adverse reactions. Interviews were arranged at a time that suited the respondent and ensured cognizance with cultural and gender issues to ensure privacy and minimize social risks and income loss. If a follow-up with interviewees was required, permission was taken in advance and acceptable points of contact agreed upon.

All data collected for the study was kept confidential. It was stored securely, without identifiers of individuals. Access to non-anonymous data was restricted to researchers directly involved in the study. Where possible, any information that could identify or trace research participants was removed from the questionnaires. 


\section{Limitations of the Study}

In-depth interviews (IDIs) with different cadres of service providers had to be conducted at the health facilities while the service providers were busy with their work. At public facilities, especially, service providers are usually surrounded by a large number of patients and clients. Moreover, at some private facilities, service providers showed reluctance to provide information about their facilities. This may have affected the depth or completeness of data collected from these IDIs.

It is possible that provider-client interactions were affected by the study team's presence; the providers' behaviour, generally found to be good, may have been influenced by the fact that the providers were aware of being observed. Therefore data collected from observations of provider-client interactions may not fully represent the actual situation at health facilities.

Exit interviews with clients were generally hurried, as the clients were anxious to leave after spending time at the facilities. Clients normally reported that they were satisfied with the care they had received, and it was difficult to persuade them to discuss their responses in more depth. It is possible that the responses recorded were relatively shallow due to clients' time constraints or stressed state; lack of time for interviewers to build rapport; difficulty in ensuring privacy; and the uncomfortable setting.

Finally, since there is no system in place for district-level contraceptive supply for private sector outlets, the analysis had to be based only on public sector arrangements. Due to this limitation, it was not possible to compare contraceptive supply in the public sector and in the private sector at the district level. 
3. Capacities of Service

Providers for FP Service

Provision

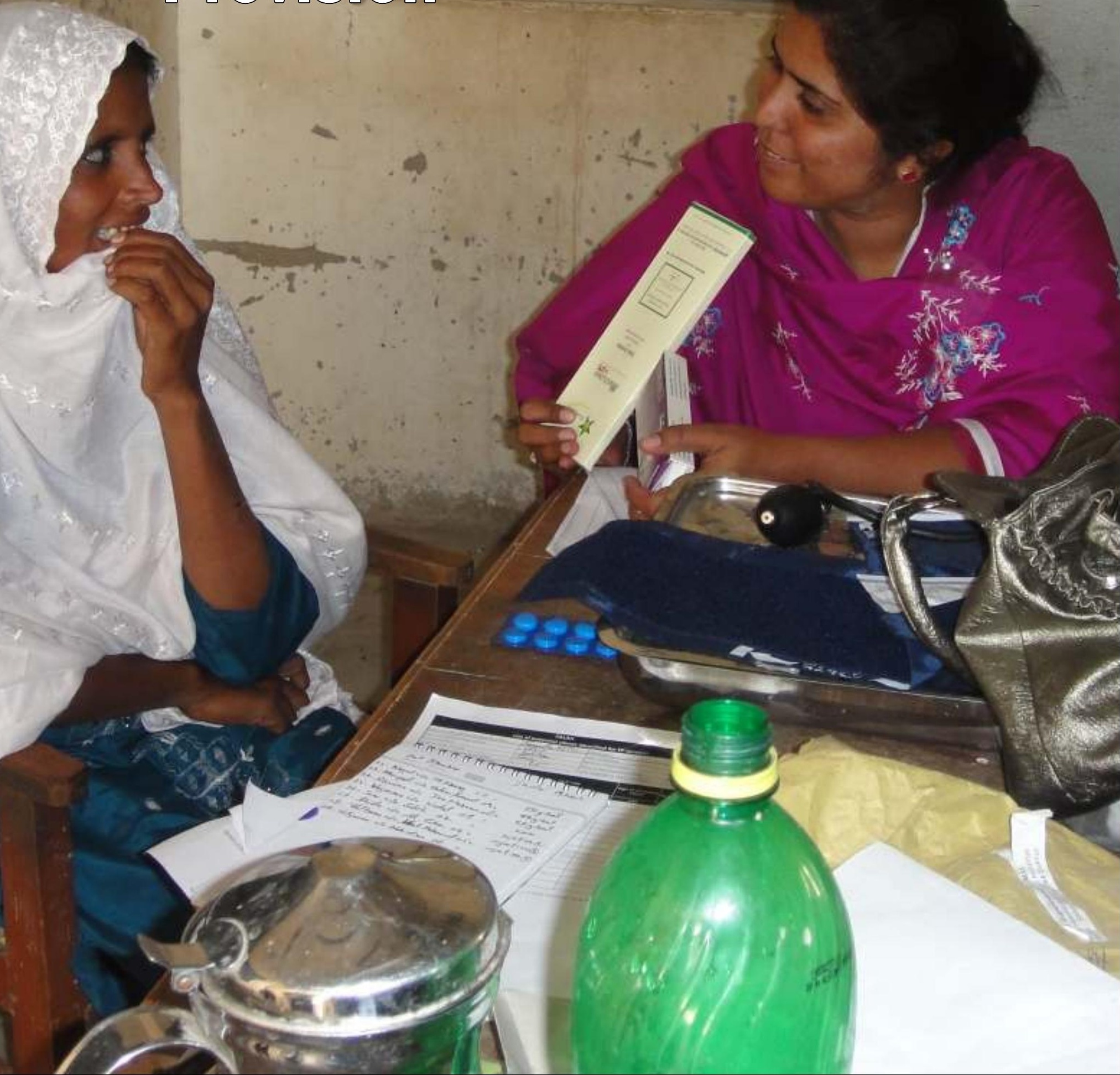




\section{Capacities of Service Providers for FP Service Provision}

- $\quad$ Overall, 75 percent of interviewed service providers have attended any type of FP training. The majority are trained in intrauterine contraceptive device (IUCD) insertion and removal; however, only 13 percent have attended training on client-centered FP services.

- $\quad$ Service providers have better knowledge about IUCDs than about injectables and oral pills. Their knowledge of specific details of vasectomy and emergency contraceptive pills is limited.

- $\quad$ Lady Health Visitors (LHVs) have better knowledge about the use of injectables than any other cadre.

- $\quad$ Service providers do not provide complete information about the selected FP method to new acceptors: only half them mention possible side effects, a quarter talk about management of possible side effects, and a mere 2 percent mention a follow-up visit.

- Although service providers generally behave well in the greeting phase of their interaction with clients, they lack interpersonal skills for assessing clients' need, helping them, and reassuring them to ensure all instructions are understood.

- $\quad$ Although Lady Health Workers (LHWs) are an important source of oral pills for clients, their knowledge about management of irregular bleeding caused by pills is very low. 


\section{Capacities of Service Providers for FP Service Provision}

Service providers (SPs) are the most crucial and necessary element in any family planning service provision mechanism. Their capacity to serve client needs effectively may be gauged from a broad range of personal and professional characteristics, including sex, professional qualification, designation, experience, status of training on FP, and, most importantly, the level of their knowledge regarding family planning and their behaviour during interactions with clients.

This section presents the findings of interviews conducted with service providers from different cadres to assess their capacity to provide FP services and identify gaps, if any. The section consists of two parts. The first, and main, section reviews the situation at static facilities, based on interviews with 231 providers at 185 health facilities representing the four major provinces of Pakistan and all sectors, i.e., the public sector, and the private sector. The second part of the section considers the capacity of lady health workers (LHWs), focusing mainly on their knowledge.

\section{Service Providers at Static Facilities}

The service providers interviewed for this assessment were mainly responsible for dealing with female clients. Generally, one SP was interviewed from each facility but, sometimes, more providers were providing health and family planning services thus they were also interviewed; these additional interviews were usually conducted at public health facilities. The following information about the providers' socio-demographic profile, training status and FP knowledge is based on data collected from these service providers.

In addition, to assess their behaviour, SPs were observed during their interactions with clients based on key protocols of client-centered care developed by the Population Council. ${ }^{14}$ On average, two to three interactions of each provider were observed. The discussion of SPs' behaviour, presented later in this section, is based on observations of 432 interactions of 231 service providers.

Furthermore, the clients with whom service providers interacted were also interviewed to learn about the purpose of their visit and the extent to which they were satisfied with the service providers during that visit. A total of 436 such exit interviews were conducted and the findings are discussed at the end of this section.

\section{Socio-demographic Profile}

Of the 231 service providers interviewed, 133 were employed with the Department of Health (DoH), 1536 with the Population Welfare Department (PWD) and 61 were from the private sector. The majority of the interviewees (214) were female, as women professionals are the main SPs to address female health and family planning needs. Male service providers were interviewed only where there was no female SP available at a health facility. The mean age of service providers was 38 years, for all providers; 38 years, for public sector providers; and 39 years, for private sector providers.

\footnotetext{
14 Population Council, A Client-Centered Approach to Reproductive Health: A Trainer's Manual (Islamabad: Population Council, 2005).

15 Throughout this report, basic health units (BHUs) attached with the Pakistan People's Health Initiative (PPHI) in KP, Sindh and Balochistan, and with the Punjab Rural Support Programme (PRSP) in Punjab are counted among Department of Health facilities.
} 
By designation, 36 percent of the SPs were lady health visitors (LHVs), while the next highest proportion was of family welfare workers/counsellors (FWWs/FWC). LHVs are mainly from the DoH and the private sector, while FWWs and FWCs work exclusively for PWD. Nearly, a quarter of the service providers were female MBBS doctors and less than a tenth were gynaecologists. These SPs were mainly from the DoH and the private sector (including NGO clinics). Table 3.1 summarizes the socio-demographic characteristics of the SPs interviewed.

\section{Table 3.1: Socio-demographic Characteristics of Service Providers}

\begin{tabular}{|c|c|c|}
\hline & Percent & Number of Service Providers \\
\hline \multicolumn{3}{|l|}{ Province } \\
\hline Punjab & 30 & 70 \\
\hline Sindh & 29 & 66 \\
\hline $\mathrm{KP}$ & 26 & 60 \\
\hline Balochistan & 15 & 35 \\
\hline \multicolumn{3}{|l|}{ Gender } \\
\hline Male & 7 & 17 \\
\hline Female & 93 & 214 \\
\hline \multicolumn{3}{|l|}{ Qualification* } \\
\hline MBBS & 30 & 66 \\
\hline DGO (Gynaecologist) & 9 & 20 \\
\hline FRCOG/MRCOG/MCPS/FCPS & 3 & 7 \\
\hline BSc Nursing/Diploma & 2 & 5 \\
\hline LHV/FMT/Diploma & 36 & 81 \\
\hline MHT/Diploma & 3 & 7 \\
\hline FWW/FWC Diploma & 24 & 53 \\
\hline Dispenser Diploma & 1 & 2 \\
\hline FA/BA & 3 & 6 \\
\hline Matric & 1 & 2 \\
\hline \multicolumn{3}{|l|}{ Designation } \\
\hline Qualified Gynaecologist & 8 & 19 \\
\hline Medical Officer & 3 & 7 \\
\hline Women Medical Officer (WMO) & 22 & 50 \\
\hline Lady Health Visitors (LHV)/Female Health Technician (FHT) & 41 & 94 \\
\hline Family Welfare Worker (FWW)/Family Welfare Counsellor (FWC) & 23 & 53 \\
\hline Dispenser/Male Health Technician (MHT)/PHT & 3 & 8 \\
\hline \multicolumn{3}{|l|}{ Type of Facility } \\
\hline $\mathrm{DoH} * *$ & 58 & 133 \\
\hline PWD & 16 & 36 \\
\hline Private & 27 & 61 \\
\hline Total $(\mathrm{N})$ & 100 & 231 \\
\hline
\end{tabular}

Source: Interviews with Service Providers.

*FCPS $=$ Fellow of College of Physicians and Surgeons, MCPS = Member of College of Physicians and Surgeons, MRCOG = Member, Royal, College of Gynaecologists, DGO = Diploma in Gynaecology \& Obstetrics, FMT= Female Health Technician, MHT = Male Health Technician. ** DoH facilities also include BHUs attached with the People's Primary Healthcare Initiative (PPHI) in KP, Sindh and Balochistan and with the Punjab Rural Support Programme (PRSP) in Punjab. 


\section{Training}

Relevant trainings are a key part of developing service provision capacity as they equip SPs with new emerging knowledge, technologies and skills. Family planning trainings and refresher courses are therefore an indicator of the readiness of service providers. Table 3.2 shows the proportion of service providers who had received FP training and the type of FP training they received. Three-fourths of the service providers had received FP related trainings. Almost all providers from PWD had been trained; the next most trained categories were gynaecologists and LHVs. Relatively fewer female MBBS doctors were trained than other female professionals. However, it is encouraging that at least 50 percent of interviewed male service providers were also trained in FP.

Trained service providers were further asked about the nature of training they had undergone. The majority (60 percent) had attended training for IUCD insertion and removal. This indicates reasonable readiness among SPs to support IUCD use.

Training in FP contraceptive technology may rightly be expected to be compulsory for SPs providing FP services, and more necessary than method-specific training. Yet, although nearly all interviewed SPs were providing FP services, only about half of them had received such training.

Similarly, although counselling is a very important skill in providing FP services, only a third of the providers have received training in this area. Moreover, only 13 percent of providers (female doctors, LHVs and FWWs/FWCs) have received training in the client-centered approach, although the general pattern of treating clients is quite discouraging, particularly in the public sector, and indicates a need for intensive behaviour change training. (The manner in which this particular training makes a difference in the knowledge and behaviour of SPs with their clients is discussed later in this section).

Table 3.2: Training Received by SPs $(\mathbf{N}=\mathbf{2 3 1})$

\begin{tabular}{|c|c|c|c|c|c|c|c|}
\hline & \multicolumn{7}{|c|}{$\%$ of SPs who received FP trainings } \\
\hline & \multicolumn{4}{|c|}{ Female Staff } & \multicolumn{2}{|c|}{ Male Staff } & \multirow[b]{2}{*}{$\begin{array}{c}\text { Total } \\
\% \text { of SPS }\end{array}$} \\
\hline & Gynaecologist & WMO & LHV/FHT & FWW/FWC & MO & $\begin{array}{l}\text { Dispenser/ } \\
\text { MHT/PHT }\end{array}$ & \\
\hline \multicolumn{8}{|l|}{ Training status } \\
\hline Trained & 79 & 64 & 73 & 94 & 57 & 50 & 75 \\
\hline \multicolumn{8}{|l|}{ Type of training received } \\
\hline $\begin{array}{l}\text { FP/Birth spacing } \\
\text { (contraceptive technology) }\end{array}$ & 63 & 42 & 44 & 58 & 57 & 38 & 48 \\
\hline IUCD insertion/removal & 58 & 54 & 64 & 77 & 0 & 0 & 60 \\
\hline Counselling technique & 16 & 28 & 36 & 58 & 14 & 13 & 36 \\
\hline Client-centered FP service & 0 & 14 & 15 & 19 & 0 & 0 & 13 \\
\hline Minilap/Vasectomy & 47 & 20 & 6 & 8 & 0 & 0 & 13 \\
\hline Implant & 5 & 8 & 4 & 4 & 0 & 0 & 5 \\
\hline Total $(\mathrm{N})$ & 15 & 32 & 69 & 50 & 4 & 7 & 174 \\
\hline
\end{tabular}

Source: Interviews with Service Providers. Note: Multiple responses are possible. 


\section{Knowledge}

In order to assess the FP knowledge level of SPs, a number of method-specific as well as general FP questions were asked from each level of service providers. Specifically, interviewees were given multiple choice questions for different method-specific situations. The following tables show the proportion of respondents from each cadre who gave the right answers to questions concerning different methods.

Table 3.3 indicates the knowledge of service providers regarding oral pills. SPs were asked about the contraindications of pills, whether a nulliparous woman can take pills, whether a breastfeeding mother can take progestin-only pills, and whether progestin-only pills could be used as emergency contraception. Overall, knowledge of male providers was found to be better for most questions than female providers. By and large, knowledge of most of the providers was better about contraindications of pills and about use of progestin-only pills as emergency contraception. Providers usually did not know about breastfeeding women's use of progestin-only pills; surprisingly, even FWWs/FWCs from the Population Welfare Department lacked this knowledge.

Table 3.3: Knowledge of SPs regarding Oral Pills ( $\mathbf{N}=\mathbf{2 3 1})$

\begin{tabular}{|c|c|c|c|c|c|c|c|}
\hline & \multicolumn{6}{|c|}{$\%$ of SPs who answered correctly } & \multirow{3}{*}{$\begin{array}{l}\text { Total } \\
\% \text { of } \\
\text { SPs }\end{array}$} \\
\hline & \multicolumn{4}{|c|}{ Female Staff } & \multicolumn{2}{|c|}{ Male Staff } & \\
\hline & Gynaecologist & WMO & LHV/FHT & FWW/FWC & MO & $\begin{array}{l}\text { Dispenser/ } \\
\text { MHT/PHT }\end{array}$ & \\
\hline Contraindications of oral pills & 79 & 76 & 87 & 85 & 100 & 100 & 84 \\
\hline $\begin{array}{l}\text { Nulliparous women can take } \\
\text { oral pills }\end{array}$ & 63 & 58 & 51 & 51 & 14 & 50 & 52 \\
\hline $\begin{array}{l}\text { Breastfeeding woman can take } \\
\text { progestin-only pills }\end{array}$ & 21 & 20 & 35 & 13 & 43 & 38 & 26 \\
\hline $\begin{array}{l}\text { Progestin-only pills can be used } \\
\text { as emergency contraception }\end{array}$ & 74 & 66 & 54 & 57 & 71 & 38 & 59 \\
\hline Total (N) & 19 & 50 & 93 & 52 & 7 & 8 & 229 \\
\hline
\end{tabular}

Source: Interviews with Service Providers.

Table 3.4 shows the proportion of SPs who gave correct answers about IUCDs. Overall, no cadre has complete correct knowledge about any condition or situation involving IUCDs, suggesting a general lack of knowledge of the method, even though most of the female providers are trained to provide it. Knowledge related to IUCD use varies by questions: about 70 percent of providers have an accurate understanding of contraindications associated with the method and 66 percent know about the effective strength for decontamination of insertion equipment. About half of the SPs know about the side effects of IUCDs and are aware that a diabetic woman can use this method. Surprisingly, the majority of service providers, particularly qualified gynaecologists and male doctors, did not have right knowledge about when a copper T380a ought to be replaced. 
Table 3.4: Knowledge of SPs regarding IUCDs ( $\mathbf{N = 2 3 1 )}$

\begin{tabular}{|c|c|c|c|c|c|c|c|}
\hline & \multicolumn{6}{|c|}{$\%$ of SPs who answered correctly } & \multirow[b]{3}{*}{$\begin{array}{l}\text { Total } \\
\% \text { of SPs }\end{array}$} \\
\hline & \multicolumn{4}{|c|}{ Female Staff } & \multicolumn{2}{|c|}{ Male Staff } & \\
\hline & Gynaecologist & WMO & LHV/FHT & FWW/FWC & MO & $\begin{array}{l}\text { Dispenser/ } \\
\text { MHT/PHT }\end{array}$ & \\
\hline Contraindications of IUCDs & 84 & 76 & 68 & 60 & 57 & 63 & 69 \\
\hline Side effects of IUCDs & 74 & 64 & 49 & 45 & 86 & 38 & 54 \\
\hline $\begin{array}{l}\text { Effective strength for } \\
\text { decontamination } \\
\text { ( } 0.1 \% \text { Chlorine solution) }\end{array}$ & 53 & 66 & 63 & 77 & 43 & 75 & 66 \\
\hline $\begin{array}{l}\text { Nulliparous woman can } \\
\text { use IUCDs }\end{array}$ & 42 & 38 & 32 & 17 & 71 & 25 & 32 \\
\hline $\begin{array}{l}\text { Diabetic woman can use } \\
\text { an IUCDs }\end{array}$ & 68 & 70 & 40 & 40 & 57 & 75 & 51 \\
\hline $\begin{array}{l}\text { A copper T380a needs to } \\
\text { be replaced after } 12 \text { years }\end{array}$ & 0 & 24 & 16 & 34 & 0 & 13 & 20 \\
\hline Total (N) & 19 & 50 & 84 & 49 & 7 & 8 & 217 \\
\hline
\end{tabular}

Source: Interviews with Service Providers.

Of the major four knowledge questions about injectables, a satisfactory proportion of SPs had the right knowledge regarding three, which concerned use of Norigest for continuous protection; the fact that there is no need for decontamination of the needle and syringe before destruction, and provision of a second injection of Depo-Provera to a client if she visits one week later than scheduled. On the contrary, very few service providers had the right knowledge about the question concerning the bending of the needle of a disposable syringe to prevent reuse.

The table further suggests that LHVs are more knowledgeable in the use of injectables, followed by FWWs/FWCs. However, it is surprising that male providers, including doctors and even dispensers, have better knowledge on these questions than qualified gynaecologists.

Table 3.5: Knowledge of SPs regarding Injectables ( $\mathbf{N}=\mathbf{2 3 1})$

\begin{tabular}{|c|c|c|c|c|c|c|c|}
\hline & \multicolumn{6}{|c|}{$\%$ of SPs who answered correctly } & \multirow{3}{*}{$\begin{array}{l}\text { Tota } \\
\% \text { of } \\
\text { SPs }\end{array}$} \\
\hline & \multicolumn{4}{|c|}{ Female Staff } & \multicolumn{2}{|c|}{ Male Staff } & \\
\hline & Gynaecologist & WMO & LHV/FHT & FWW/FWC & MO & $\begin{array}{c}\text { Dispenser/ } \\
\text { MHT/PHT }\end{array}$ & \\
\hline $\begin{array}{l}\text { Injection Norigest needed for } \\
\text { continuous protection from } \\
\text { pregnancy }\end{array}$ & 33 & 56 & 70 & 68 & 43 & 57 & 62 \\
\hline $\begin{array}{l}\text { Always bend needle of } \\
\text { disposable syringe to prevent } \\
\text { reuse }\end{array}$ & 11 & 18 & 10 & 91 & 14 & 25 & 12 \\
\hline $\begin{array}{l}\text { Needle and syringe need not be } \\
\text { decontaminated before } \\
\text { destroying in destruclip }\end{array}$ & 63 & 72 & 94 & 66 & 57 & 63 & 78 \\
\hline $\begin{array}{l}\text { Second injection of Depo- } \\
\text { Provera can be given to a client } \\
\text { when she comes one week } \\
\text { later than scheduled }\end{array}$ & 58 & 74 & 67 & 74 & 71 & 88 & 70 \\
\hline Total $(\mathrm{N})$ & 16 & 48 & 92 & 51 & 7 & 8 & 222 \\
\hline
\end{tabular}

Source: Interviews with Service Providers. 
Beyond method-specific knowledge, some general FP-related questions were also asked to learn about respondents' professional perceptions and wider knowledge. Table 3.6 illustrates that almost all service providers across the cadres rightly perceived that providers should discuss misconception and rumours related to FP methods with clients. Further, a significant number of providers had the right knowledge that optimum spacing between birth and the next pregnancy is at least two years. Almost all qualified gynaecologists and male doctors gave the right answers, but the knowledge of FWWs/FWCs and dispensers were relatively low in this regard.

Although service providers generally have knowledge about optimum spacing between two births, their knowledge about spacing between an abortion/miscarriage and the next pregnancy is quite low. Less than half of the providers had the right knowledge about how emergency contraceptive pills and vasectomy work to prevent conception. This lack of knowledge among service providers indicates their limited ability to provide FP counselling and services.

Table 3.6: Knowledge of SPs regarding General FP Topics ( $\mathbf{N}=\mathbf{2 3 1})$

\begin{tabular}{|c|c|c|c|c|c|c|c|}
\hline & \multicolumn{6}{|c|}{$\%$ of SPs who answered correctly } & \multirow[b]{3}{*}{$\begin{array}{c}\text { Total } \\
\% \text { of SPs }\end{array}$} \\
\hline & \multicolumn{4}{|c|}{ Female Staff } & \multicolumn{2}{|c|}{ Male Staff } & \\
\hline & Gynaecologist & WMO & $\begin{array}{l}\text { LHV/ } \\
\text { FHT }\end{array}$ & FWW/FWC & MO & $\begin{array}{l}\text { Dispenser/ } \\
\text { MHT/PHT }\end{array}$ & \\
\hline $\begin{array}{l}\text { Provider should not prescribe } \\
\text { about FP according to his/her } \\
\text { best judgment }\end{array}$ & 47 & 36 & 48 & 47 & 0 & 38 & 43 \\
\hline $\begin{array}{l}\text { Providers should discuss } \\
\text { misconceptions and rumours } \\
\text { about FP with client }\end{array}$ & 95 & 98 & 98 & 98 & 100 & 100 & 98 \\
\hline $\begin{array}{l}\text { Couples should wait for at } \\
\text { least } 2 \text { years after last child } \\
\text { birth before attempting next } \\
\text { pregnancy }\end{array}$ & 95 & 88 & 85 & 74 & 100 & 75 & 84 \\
\hline $\begin{array}{l}\text { Married women who have } \\
\text { undergone miscarriage or } \\
\text { abortion should wait for at } \\
\text { least } 12 \text { months before } \\
\text { attempting next pregnancy }\end{array}$ & 58 & 58 & 53 & 60 & 14 & 50 & 55 \\
\hline $\begin{array}{l}\text { Correct knowledge about } \\
\text { Emergency contraception }\end{array}$ & 53 & 42 & 47 & 45 & 57 & 38 & 46 \\
\hline $\begin{array}{l}\text { Correct knowledge about } \\
\text { Vasectomy }\end{array}$ & 37 & 32 & 28 & 23 & 14 & 25 & 28 \\
\hline Total (N) & 19 & 50 & 94 & 53 & 7 & 8 & 231 \\
\hline
\end{tabular}

Source: Interviews with Service Providers.

Based on the above findings on SPs' general and method-specific FP knowledge, Figure 3.1 suggests that while knowledge of IUCDs is generally high in all cadres, it is higher among qualified gynaecologists and male and female doctors, whereas midlevel service providers are relatively less knowledgeable. For pills and injectables, the knowledge level of almost all cadres is virtually the same, with little variation in the case of gynaecologists and male doctors, who lack knowledge about injectables. 


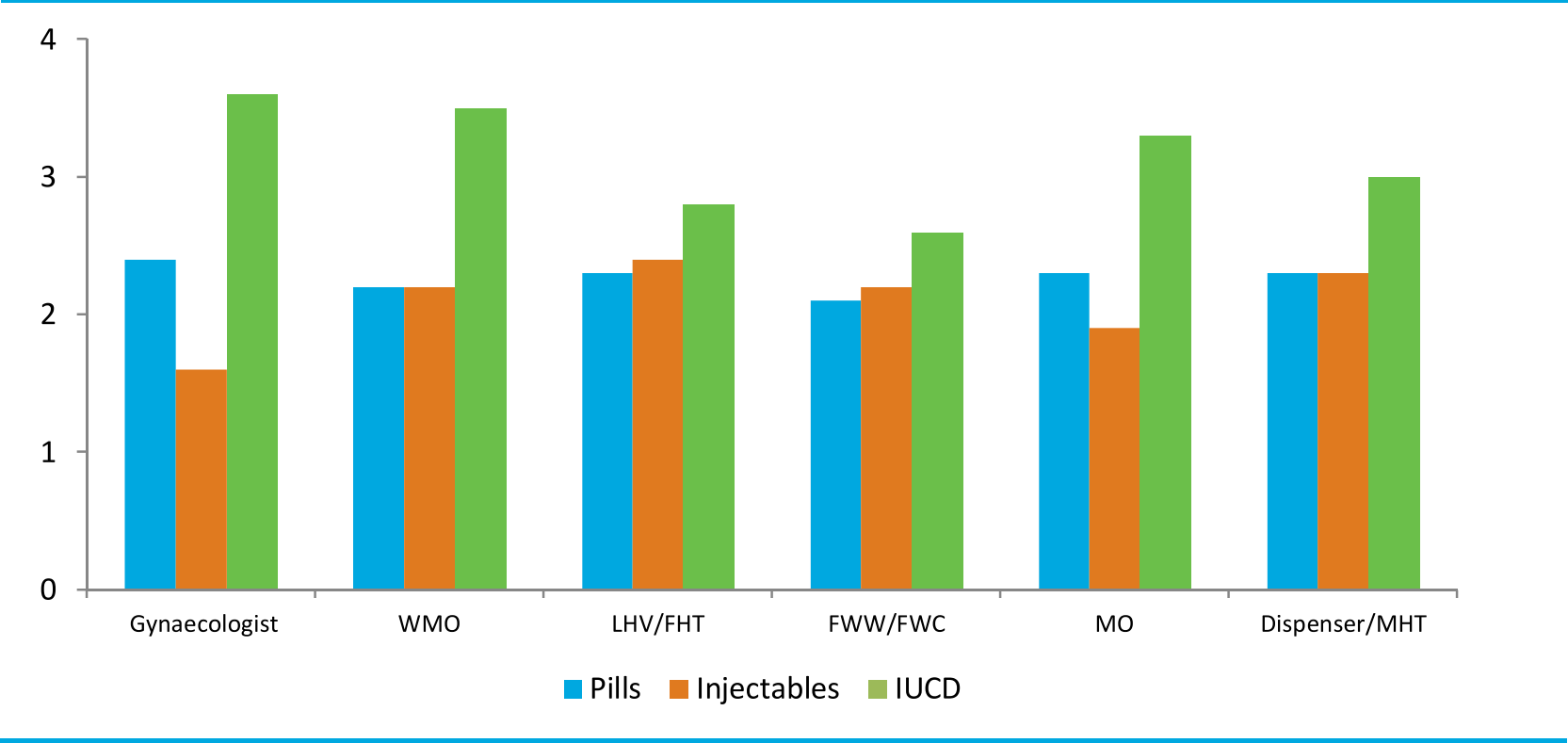

Source: Interviews with Service Providers.

Number of question regarding knowledge of IUCD $=6$, Number of question regarding knowledge of Injectables $=4$

Number of question regarding knowledge of Pills $=9$

Table 3.7 shows the mean correct answers of service providers about pills, injectables and IUCDs by district, sector and by training status. Overall, the comparison of method-specific right answers by SPs with their training status suggests that the knowledge of trained providers is higher than that of providers who have not received any training, particularly in case of IUCDs. Although there is no overall difference between trained and untrained providers' knowledge regarding pills, a difference is visible at sector level. Knowledge about pills among trained providers in DoH facilities of Khanewal, Umerkot and Mansehra districts is better than that of trained providers in other districts. Trained providers of DoH facilities from Mardan and Sibi and private sector providers from Khanewal, Rahim Yar Khan, Mansehra and Mardan have better knowledge than untrained providers.

The most obvious difference between trained and untrained providers concerns knowledge of IUCDs. Trained providers from the public health sector are far better than untrained providers because the majority of trained providers have received training in IUCD insertion/removal. 
Table 3.7: Mean of Right Answers Given by SPs about Different Contraceptive Methods by District and Sector $(\mathrm{N}=\mathbf{2 3 1})$

\begin{tabular}{|c|c|c|c|c|c|c|c|}
\hline & & \multicolumn{2}{|c|}{ Pills } & \multicolumn{2}{|c|}{ Injectables } & \multicolumn{2}{|c|}{ IUCDs } \\
\hline & & Trained & Untrained & Trained & Untrained & Trained & Untrained \\
\hline \multicolumn{8}{|l|}{ Punjab } \\
\hline \multirow{3}{*}{ Khanewal } & DoH & 2.1 & 1.8 & 2.5 & 2.3 & 3.0 & 2.8 \\
\hline & PWD & 1.8 & na & 2.5 & na & 1.8 & na \\
\hline & Private & 2.2 & 2.0 & 2.0 & 1.0 & 2.9 & 3.0 \\
\hline \multirow{3}{*}{$\begin{array}{l}\text { Rahim Yar } \\
\text { Khan }\end{array}$} & DoH & 2.3 & 2.5 & 1.9 & 1.8 & 3.2 & 2.8 \\
\hline & PWD & 1.5 & na & 2.5 & na & 3.0 & na \\
\hline & Private & 2.5 & 2.5 & 2.3 & 1.8 & 3.0 & 3.3 \\
\hline \multicolumn{8}{|l|}{ Sindh } \\
\hline & $\mathrm{DoH}$ & 1.8 & 2.1 & 1.8 & 1.8 & 2.8 & 1.5 \\
\hline \multirow[t]{3}{*}{ Khairpur } & PWD & 2.0 & na & 2.3 & na & 3.3 & na \\
\hline & Private & 2.4 & 1.7 & 1.4 & 2.0 & 2.6 & 2.3 \\
\hline & DoH & 2.5 & 1.4 & 2.2 & 2.6 & 2.5 & 1.2 \\
\hline \multirow[t]{2}{*}{ Umerkot } & PWD & 2.0 & 2.5 & 1.3 & 1.5 & 1.3 & 0.5 \\
\hline & Private & 1.7 & 1.0 & 1.6 & 1.0 & 2.3 & 2.0 \\
\hline \multicolumn{8}{|l|}{ KP } \\
\hline & DoH & 2.7 & 2.0 & 2.3 & 2.0 & 4.0 & 4.5 \\
\hline \multirow[t]{3}{*}{ Mansehra } & PWD & 2.3 & 1.0 & 2.5 & 2.0 & 3.8 & 1.0 \\
\hline & Private & 2.6 & 2.0 & 2.7 & 1.0 & 4.4 & 0.0 \\
\hline & DoH & 2.3 & 2.5 & 3.0 & 2.4 & 4.3 & 3.4 \\
\hline \multirow[t]{2}{*}{ Mardan } & PWD & 2.5 & na & 3.0 & na & 4.5 & na \\
\hline & Private & 2.6 & 3.0 & 3.0 & 2.5 & 4.3 & 5.0 \\
\hline \multicolumn{8}{|l|}{ Balochistan } \\
\hline & $\mathrm{DoH}$ & 2.5 & 2.8 & 2.5 & 2.5 & 4.3 & 3.0 \\
\hline \multirow[t]{3}{*}{ Pishin } & PWD & 2.3 & na & 2.0 & na & 3.3 & na \\
\hline & Private & 2.0 & 2.3 & 3.0 & 3.3 & 5.0 & 4.7 \\
\hline & DoH & 1.8 & 2.0 & 2.3 & 1.0 & 2.3 & 1.0 \\
\hline \multirow[t]{2}{*}{ Sibi } & PWD & 2.4 & na & 1.7 & na & 1.3 & na \\
\hline & Private & 2.5 & na & 2.5 & na & 1.0 & na \\
\hline Overall (Mean) & & 2.2 & 2.2 & 2.2 & 2.1 & 3.1 & 2.6 \\
\hline
\end{tabular}

Source: Interviews with Service Providers.

Note: DoH facilities include BHUs attached with PPHI in KP, Sindh and Balochistan, and with PRSP in Punjab.

na $=$ Not applicable.

Number of question regarding knowledge of Pills $=9$

Number of question regarding knowledge of Injectables $=4$

Number of question regarding knowledge of IUCD $=6$ 


\section{Behaviour}

The data presented above in Table 3.2 has shown that about 75 percent of interviewed service providers have received some type of FP training. Moreover, excluding certain areas, service providers are, in general, reasonably knowledgeable about family planning methods. However, the benefits of SPs' knowledge and training can only translate into sound family planning services when their behaviour and dealing with clients is appropriate and effective. In 2005, the Population Council developed a framework for improving FP service providers' attitudes, behaviour and interactions with clients; Based on a "client-centered approach," 16 the framework introduced stepwise protocols for provider-client interactions, including the key components salutation, assessment, help, and reassurance, designed to enable the provider to determine and meet clients' reproductive health needs.

In order to assess the behaviour of service providers while dealing with their clients, the study teams observed their interactions in their normal course of work. In the analysis of observation data, the above-mentioned framework was adopted as a point of reference to assess the extent to which interviewed providers were receptive and responsive to client needs. The following tables depict the behaviour of service providers with reference to the framework protocols. The results are linked with whether or not SPs are trained to explore the extent to which trainings contribute in shaping behaviour.

\section{Salutation}

Table 3.8 shows the proportion of trained and untrained service providers who fulfilled the ideally first protocol-salutation. A greeting or salutation from the service provider can make a client feel more comfortable and relaxed, which facilitates subsequent discussion. Table 3.8 suggests that, except for offering seats to clients, paying attention to them and asking their names, SPs did not follow any other protocols of salutation. Serious areas of concern are that service providers neither ensure confidentiality nor maintain privacy, even for FP discussions. Although interaction between the client and the provider takes place within a designated room, at public facilities, the room is usually crowded with other waiting clients. In the absence of privacy, a client may not be able to discuss her FP needs even if she wants.

In general, a higher proportion of trained providers followed the protocols of salutation than untrained providers, particularly in terms of greeting the client, offering a seat, ensuring confidentiality, building rapport and maintaining privacy. However, about the same proportion of trained and untrained SPs asked the client's name and paid full attention to the client.

Table 3.8: Proportion SPs following Salutation Protocols by whether they were Trained $(\mathrm{N}=432)$

\begin{tabular}{|c|c|c|c|}
\hline \multirow[b]{2}{*}{ Salutation } & \multicolumn{2}{|c|}{$\%$ of SPs who followed Salutation protocols } & \multirow{2}{*}{$\begin{array}{c}\text { Total } \\
\% \text { of SPs }\end{array}$} \\
\hline & Trained & Untrained & \\
\hline Greet the client & 53 & 44 & 51 \\
\hline Offered the client a seat/bench & 83 & 76 & 81 \\
\hline Asked client's name & 75 & 75 & 75 \\
\hline Ensured confidentiality & 26 & 19 & 24 \\
\hline Built rapport with client by discussing general topics & 59 & 54 & 58 \\
\hline Maintained privacy & 23 & 18 & 22 \\
\hline Paid full attention to the client & 87 & 88 & 87 \\
\hline Total (N) & 320 & 112 & 432 \\
\hline
\end{tabular}

Source: Observation of interactions between service providers and clients.

\footnotetext{
16 Zeba Sathar, Anrudh Jain, Saumya Rama Rao, Minhaj ul Haque, and Jacqueline Kim, “Introducing client-centered reproductive health services in a Pakistani setting," Studies in Family Planning 36, no. 3 (2005): 221-234.
} 


\section{Assessment}

Although clients share their health problems or needs with the service provider when they visit, assessing their current as well as other needs through asking different questions and conducting physical examinations, if required, is solely the responsibility of the service provider. Sound service provision is not possible without assessing the needs of clients. Table 3.9 depicts the proportion of trained and untrained service providers who followed the protocols of assessment. As shown, about 60 percent of providers examined their clients during interactions but only one-third of them asked the client's permission to perform the examination. This was the least observed among all assessment protocols. Further, only half of the providers informed the clients about the outcome of their examination.

These areas require intensive improvement among all providers, trained and untrained. Trained providers are slightly better in assessing clients' other reproductive health needs, performing examinations, and in asking for permission to perform the examination. More focused trainings on behaviour change can help service providers in this regard.

Table 3.9: Proportion of SPs following Assessment Protocols by whether they were trained $(\mathrm{N}=\mathbf{4 3 2})$

\begin{tabular}{|c|c|c|c|}
\hline \multicolumn{3}{|c|}{$\%$ of SPs who followed Assessment protocols } & \multirow{2}{*}{$\begin{array}{c}\text { Total } \\
\% \text { of SPs }\end{array}$} \\
\hline Assessment & Trained & Untrained & \\
\hline Tried to assess other reproductive health needs & 71 & 65 & 70 \\
\hline Performed examination & 58 & 60 & 59 \\
\hline Asked for permission to perform the examination & 21 & 18 & 20 \\
\hline Informed the client about outcome of the examination & 48 & 53 & 49 \\
\hline Total (N) & 311 & 109 & 420 \\
\hline
\end{tabular}

Source: Observation of interactions between service providers and clients.

\section{Help}

Although the main role of the service provider is to address the health or FP needs of clients, there are certain practices that $\mathrm{s} / \mathrm{he}$ should observe in suggesting solutions to help clients understand, such as giving adequate time; discussing all points raised by the client; using informational, educational and communication (IEC) materials to help explain the solution; and discussing all relevant solution possibilities.

Table 3.10 shows the proportion of trained and untrained service providers who followed the protocols of help during their interactions with clients. Overall, there is a slight difference of behaviour between trained and untrained providers. The majority of providers did not convey that they were in a hurry and discussed the points hinted by clients. About half of them also informed the clients about all relevant options for solution or treatment. 
Table 3.10: Proportion of SPs following Help protocols by whether they were trained $(\mathbf{N}=432)$

\begin{tabular}{ccc|c}
\hline Help & \% of SPs who followed Help protocols & Untrained & $\begin{array}{c}\text { Total } \\
\% \text { of SPS }\end{array}$ \\
\hline Acted like she was in hurry & Trained & 15 & 14 \\
Discussed hints mentioned by client on FP & 14 & 86 & 89 \\
Used any written IEC material & 30 & 0 & 3 \\
Gave all relevant options for solution/treatment & 54 & 53 & 54 \\
Total $(\mathbf{N})$ & 320 & 111 & 431 \\
\hline
\end{tabular}

Source: Observation of interactions between service providers and clients..

While the above table is based on observations of client-provider interactions, Table 3.11, based on interviews with service providers, gives more details about how service providers help their clients and what information they provide when a client accepts a new method. The data suggests that the information given by service providers is usually about the pros and cons of the method, how to use it, and duration of use. Service providers usually do not inform clients about management of side effects, which may be a significant reason for the high incidence of contraceptive discontinuation. It is also important to note that service providers do not inform clients when they should come for a follow-up. These facts suggest that service providers lack knowledge about what information needs to be provided to new acceptors.

Table 3.11: Information Provided by SPs When a Client Accepts a New FP Method ( $\mathbf{N}=\mathbf{2 3 1}$ )

\begin{tabular}{|c|c|c|c|c|c|c|c|}
\hline & \multicolumn{4}{|c|}{ Female Staff } & \multicolumn{2}{|c|}{ Male Staff } & \multirow{3}{*}{$\begin{array}{c}\text { Total } \\
\% \text { of SPs }\end{array}$} \\
\hline & Gynaecologist & WMO & LHV/FHT & FWW/FWC & MO & $\begin{array}{c}\text { Dispenser/ } \\
\text { MHT/PHT }\end{array}$ & \\
\hline & $\%$ & $\%$ & $\%$ & $\%$ & $\%$ & $\%$ & \\
\hline Nothing & 5 & 0 & 0 & 0 & 0 & 0 & 5 \\
\hline $\begin{array}{l}\text { Pros and cons of } \\
\text { the method }\end{array}$ & 63 & 47 & 57 & 51 & 67 & 25 & 53 \\
\hline $\begin{array}{l}\text { How to use } \\
\text { method }\end{array}$ & 42 & 61 & 62 & 58 & 50 & 75 & 59 \\
\hline $\begin{array}{l}\text { How often to use } \\
\text { method }\end{array}$ & 42 & 43 & 24 & 25 & 17 & 13 & 29 \\
\hline Duration of use & 42 & 63 & 55 & 51 & 17 & 25 & 53 \\
\hline Effectiveness & 37 & 45 & 35 & 42 & 50 & 63 & 40 \\
\hline $\begin{array}{l}\text { Possible side } \\
\text { effects }\end{array}$ & 47 & 41 & 56 & 51 & 50 & 38 & 50 \\
\hline $\begin{array}{l}\text { Management of } \\
\text { side effects }\end{array}$ & 37 & 24 & 23 & 28 & 0 & 0 & 24 \\
\hline $\begin{array}{l}\text { Ability to protect } \\
\text { from sexually } \\
\text { transmitted } \\
\text { diseases }\end{array}$ & 21 & 10 & 0 & 4 & 17 & 0 & 5 \\
\hline Date for follow-up & 0 & 0 & 2 & 6 & 0 & 0 & 2 \\
\hline Total (N) & 19 & 49 & 94 & 53 & 6 & 8 & 229 \\
\hline
\end{tabular}

Source: Interviews with Service Providers. 
At the "Help" stage, another responsibility of the service provider is to refer the client to another facility if her problem cannot be solved at the current one. Moreover, while referring the client, the service provider should provide her with adequate information such as location and address, expected travel and costs, to be prepared and access the facility with minimal trouble. During interviews, service providers were asked what information they provided clients at the time of referral. An overview of their replies is provided in Table 3.12.

Generally, service providers do not provide their clients many details of the facilities they are being referred to. However, half of the providers, particularly female providers, inform their clients about the location and address of the facility and give their clients referral slips. While female doctors, LHVs and FWW/FWCs provide the most information (such as, travel time and cost and using the SP's reference), the proportion of these cadres that gives this information is not satisfactory.

Table 3.12: Information Provided by SPs When Referring a Client to another Facility ( $\mathbf{N}=\mathbf{2 3 1}$ )

\begin{tabular}{|c|c|c|c|c|c|c|c|}
\hline & \multicolumn{4}{|c|}{ Female Staff } & \multicolumn{2}{|c|}{ Male Staff } & \multirow{3}{*}{$\begin{array}{c}\text { Total } \\
\% \text { of SPs }\end{array}$} \\
\hline & Gynaecologist & WMO & LHV/FHT & FWW/FWC & MO & $\begin{array}{l}\text { Dispenser/ } \\
\text { MHT/PHT }\end{array}$ & \\
\hline & $\%$ & $\%$ & $\%$ & $\%$ & $\%$ & $\%$ & \\
\hline $\begin{array}{l}\text { Cost/Fee for } \\
\text { medicine }\end{array}$ & 56 & 28 & 40 & 36 & 43 & 25 & 37 \\
\hline Travel time & 17 & 37 & 26 & 32 & 43 & 25 & 29 \\
\hline Travel cost & 6 & 35 & 30 & 18 & 29 & 13 & 25 \\
\hline Discuss barriers & 11 & 22 & 24 & 22 & 29 & 38 & 23 \\
\hline Accompany her & 22 & 17 & 33 & 32 & 29 & 25 & 28 \\
\hline $\begin{array}{l}\text { Explain } \\
\text { address/location }\end{array}$ & 50 & 48 & 50 & 46 & 43 & 13 & 47 \\
\hline $\begin{array}{l}\text { Tell her to use my } \\
\text { reference }\end{array}$ & 44 & 26 & 18 & 22 & 0 & 38 & 23 \\
\hline Referral slip & 67 & 46 & 36 & 42 & 29 & 38 & 42 \\
\hline Mode of transport & 0 & 0 & 1 & 6 & 0 & 13 & 2 \\
\hline Don't refer & 6 & 4 & 2 & 2 & 0 & 13 & 3 \\
\hline Total (N) & 18 & 46 & 88 & 50 & 7 & 8 & 217 \\
\hline
\end{tabular}

Source: Interviews with Service Providers.

\section{Reassurance}

At the end of the interaction, the service provider should ideally reassure the client by checking that she has understood what was advised, informing her that the solution may be reconsidered, and discussing a future follow-up. Table 3.13 depicts the extent to which trained and untrained service providers practice the protocols of reassurance. It is a matter of concern that about half of the service providers are not following the reassurance protocols. SPs do not ask clients to repeat instructions, and do not reassure them that the solution given is not the last one and can be discussed again. Above all, the practice of suggesting a follow-up, which can help a client feel secure, is not common, particularly among untrained providers. Generally, trained providers are better at practicing reassurance than untrained ones, endorsing the need of trainings in general and of behavioural trainings in particular. 
Table 3.13: Proportion of SPs following Reassurance Protocols by whether they were trained $(\mathrm{N}=432)$

\begin{tabular}{|c|c|c|c|}
\hline & \multicolumn{2}{|c|}{$\%$ of SPs who followed Reassurance protocols } & \multirow{2}{*}{$\begin{array}{c}\text { Total } \\
\% \text { of SPs }\end{array}$} \\
\hline & Trained & Untrained & \\
\hline Asked the client to repeat instructions & 28 & 26 & 28 \\
\hline $\begin{array}{l}\text { Reassured client that the present solution is not } \\
\text { the last solution and it can be discussed again }\end{array}$ & 48 & 38 & 45 \\
\hline $\begin{array}{l}\text { Informed the client to return for follow-up if } \\
\text { necessary }\end{array}$ & 58 & 49 & 55 \\
\hline Informed the client when to return for follow-up & 41 & 30 & 38 \\
\hline Total (N) & 244 & 68 & 312 \\
\hline
\end{tabular}

Source: Observation of interactions between service providers and clients.

\section{Views of Clients Visiting Static Facilities}

As mentioned earlier, apart from interviews with SPs and observations of their interactions with clients, exit interviews were conducted with 436 clients as they left the visited facilities to find out the purpose of their visit and the extent to which they were satisfied with the services they received.

Table 3.14 describes the socio-demographic profiles of these clients (all female). The mean age of the respondents was 31 years, almost all of them were currently married, and the mean number of their children was 4. Half of them were breastfeeding a child and 53 percent did not want to have more children. The majority of the women who mentioned a desire to have more children wanted spacing of at least one or two years.

Table3.14: Socio-demographic Characteristics of Clients Interviewed

\begin{tabular}{|c|c|c|}
\hline & Percent & Total $(\mathbf{N})$ \\
\hline \multicolumn{3}{|l|}{ Marital status } \\
\hline Currently married & 98 & 426 \\
\hline Separated & 2 & 7 \\
\hline Total & 100 & 433 \\
\hline Mean age of respondents (years) & 31 & 433 \\
\hline Mean number of children & 4 & 433 \\
\hline \multicolumn{3}{|l|}{ Currently breastfeeding } \\
\hline Yes & 50 & 138 \\
\hline No & 50 & 139 \\
\hline \multicolumn{3}{|l|}{ Want to have any (more) children } \\
\hline Yes & 47 & 207 \\
\hline No & 53 & 229 \\
\hline Total & 100 & 436 \\
\hline \multicolumn{3}{|c|}{ When would you like to have your next child } \\
\hline Within one year & 36 & 74 \\
\hline In one to two years & 32 & 66 \\
\hline After two years or later & 32 & 64 \\
\hline
\end{tabular}

Source: Exit interviews with clients. 
Table 3.15 indicates the type of SPs clients sought to visit and the purpose of their visit to the health facility. The main purpose mentioned by most (41 percent) of the respondents was general healthcare, while 32 percent visited the facility for antenatal care, a tetanus injection, delivery, or postnatal care. Very few respondents (8.5 percent) visited the facility specifically for FP related issues such as accepting a new method, restarting FP, getting FP supplies, others.

As the table shows, LHVs and FWCs are dealing more with respondents visiting for supplies of FP methods and antenatal care, while qualified gynaecologists and female doctors deal more with antenatal, delivery and postnatal care as well as general health clients. It is interesting that the only purpose reported for visits to male doctors was general healthcare; however, women visit dispensers, (who are usually men), to adopt new FP methods or get more supplies for an existing method, indicating the potential of dispensers in providing FP services, particularly when they practice in rural areas where no other FP facilities are readily available.

Table3.15: Client's Purpose of Visiting Health Facility on Day of Interview by type of provider ( $N=436)$

\begin{tabular}{|c|c|c|c|c|c|c|c|}
\hline & \multicolumn{4}{|c|}{ Female Staff } & \multicolumn{2}{|c|}{ Male Staff } & \multirow{3}{*}{$\begin{array}{c}\text { Total } \\
\% \text { of Clients }\end{array}$} \\
\hline & Gynaecologist & WMO & LHV/FHT & FWW/FWC & MO & $\begin{array}{l}\text { Dispenser/ } \\
\text { MHT/PHT }\end{array}$ & \\
\hline & $\%$ & $\%$ & $\%$ & $\%$ & $\%$ & $\%$ & \\
\hline New FP acceptor & 6 & 2 & 4 & 6 & 0 & 20 & 5 \\
\hline Restart & 4 & 3 & 3 & 6 & 0 & 0 & 4 \\
\hline Resupply & 0 & 7 & 12 & 27 & 0 & 7 & 11 \\
\hline $\begin{array}{l}\text { Resupply or repeat visit } \\
\text { (having problem with method } \\
\text { but continuing the method) }\end{array}$ & 6 & 6 & 9 & 15 & 0 & 0 & 8 \\
\hline $\begin{array}{l}\text { Repeat visit (having problem } \\
\text { with method and wanting to } \\
\text { change method) }\end{array}$ & 2 & 3 & 3 & 3 & 0 & 0 & 3 \\
\hline $\begin{array}{l}\text { Repeat visit (having problem } \\
\text { with method and wanting to } \\
\text { discontinue FP);Referral } \\
\text { slip/card }\end{array}$ & 2 & 1 & 1 & 0 & 0 & 0 & 1 \\
\hline $\begin{array}{l}\text { Family planning method(s) } \\
\text { information }\end{array}$ & 4 & 7 & 2 & 6 & 0 & 0 & 4 \\
\hline $\begin{array}{l}\text { Antenatal/Delivery/ } \\
\text { Postnatal/ TT Short }\end{array}$ & 34 & 37 & 40 & 14 & 0 & 13 & 32 \\
\hline General healthcare & 48 & 42 & 37 & 25 & 100 & 80 & 41 \\
\hline $\begin{array}{l}\text { Child illness/health/ } \\
\text { Immunization }\end{array}$ & 0 & 2 & 6 & 1 & 20 & 0 & 3 \\
\hline $\begin{array}{l}\text { Sterilization case having } \\
\text { problem }\end{array}$ & 6 & 3 & 2 & 3 & 0 & 0 & 3 \\
\hline Others & 10 & 10 & 3 & 3 & 0 & 0 & 6 \\
\hline Total $(\mathrm{N})$ & 50 & 122 & 156 & 71 & 10 & 15 & 424 \\
\hline
\end{tabular}

Source: Exit interviews with clients.

Note: Multiple responses are possible. 
During the exit interviews, respondents were also asked about their satisfaction with the particular interaction they had just had with their service provider. Almost all respondents ( 94 percent) reported that they were satisfied. This is surprising because, as mentioned earlier, the behaviour of service providers was not observed by interviewers to score high on client-centered behaviour. A possible reason for this contrast between SPs' observed behaviour and the positive perception of them by clients could be that the latter are generally unaware about their rights as clients as well as the standards or quality of care that should be provided.

\section{Knowledge among Lady Health Workers}

This section presents an overview of the knowledge of LHWs based on interviews with 23 LHWs from the study districts. Table 3.16 presents a basic socio-demographic profile of the randomly selected interviewees. LHWs from Sindh and Balochistan were relatively younger than those from Punjab and KP. All LHWS fulfilled the basic educational criteria for their position, and the majority had completed grades 10 to 12 and was married. The mean work experience of the interviewees was 10 years.

Table 3.16: Socio-demographic Profile of Lady Health Workers Interviewed

\begin{tabular}{lcccc|c}
\hline & Punjab & Sindh & KP & Balochistan & Total \\
\hline $\begin{array}{l}\text { Mean age (years) } \\
\text { Level of education }\end{array}$ & 38 & 34 & 37 & 31 & 35 \\
$\quad$ Middle & 1 & 1 & 3 & 0 & 5 \\
$\quad$ Matric & 2 & 1 & 2 & 3 & 8 \\
FA & 3 & 3 & 0 & 2 & 8 \\
BA & 0 & 0 & 1 & 1 & 2 \\
Marital status & & & & & \\
$\quad$ Currently married & 4 & 5 & 4 & 4 & \\
$\quad$ Unmarried & 0 & 0 & 2 & 2 & 4 \\
$\quad$ Widow & 1 & 0 & 0 & 0 & 17 \\
Work experience & 11 & 8 & 11 & 7 & 10 \\
$\quad$ Mean years & $\mathbf{6}$ & $\mathbf{5}$ & $\mathbf{6}$ & $\mathbf{6}$ & $\mathbf{2 3}$ \\
Total (N) & & &
\end{tabular}

Source: Interviews with LHWs.

Since all LHWs receive trainings on family planning and related issues as part of their job, a number of questions were asked about healthy timing and spacing and FP methods to assess their level of knowledge. Overall, LHWs from KP have better knowledge than their peers in other provinces, as shown in Table 3.17. A substantial number of LHWs across the provinces know that couples should wait for at least two years after the last child's birth before attempting the next pregnancy; in fact, all LHWs from KP and Sindh have this knowledge.

In Sindh, Punjab and Balochistan, LHWs generally lack knowledge that married women who have undergone a miscarriage or abortion should wait for at least 6 months before attempting the next pregnancy, and that the age of a woman should not be less than 18 years for pregnancy. The fact that becoming pregnant after 35 years of age can be dangerous for the health and life of the mother and baby is better known by LHWs from Punjab; their peers in KP, Sindh and Balochistan are lacking in this knowledge. Generally, there is a vast margin for improvement in knowledge of LHWs about healthy timing and spacing. 
Table 3.17: Knowledge of LHWs about Healthy Timing and Spacing of Pregnancy by Province $(\mathrm{N}=23)$

\begin{tabular}{|c|c|c|c|c|c|}
\hline & Punjab & Sindh & $\mathrm{KP}$ & Balochistan & \multirow{2}{*}{$\begin{array}{c}\text { Total } \\
\% \text { of LHWs }\end{array}$} \\
\hline & $\%$ & $\%$ & $\%$ & $\%$ & \\
\hline $\begin{array}{l}\text { Couples should wait for at least } 2 \\
\text { years after last child birth before } \\
\text { attempting next pregnancy }\end{array}$ & 83 & 100 & 100 & 83 & 91 \\
\hline $\begin{array}{l}\text { Married women who have undergone } \\
\text { miscarriage or abortion should wait for } \\
\text { at least } 6 \text { months before attempting } \\
\text { next pregnancy }\end{array}$ & 17 & 25 & 83 & 17 & 36 \\
\hline $\begin{array}{l}\text { Age of a woman for pregnancy should } \\
\text { not be less than } 18 \text { years }\end{array}$ & 50 & 75 & 100 & 33 & 64 \\
\hline $\begin{array}{l}\text { Becoming pregnant after } 35 \text { years of } \\
\text { age can be dangerous for the health } \\
\text { and life of mother and baby }\end{array}$ & 67 & 25 & 17 & 17 & 32 \\
\hline Total (N) & 6 & 4 & 6 & 6 & 22 \\
\hline
\end{tabular}

Source: Interviews with LHWs.

Note: Multiple responses are possible.

Since almost all interviewed LHWs (91 percent) are providing injectables in their respective communities, they ought to have comprehensive knowledge about this method. When asked about the appropriate timing for giving a Depo-Provera injection, almost all LHWs from all provinces knew that it should be given between the first and seventh day of the menstrual cycle; however, there is some gap in LHWs' knowledge, particularly in Balochistan and KP, regarding the fact that a woman can be given injectables at any time during the menstrual cycle if they are reasonably sure she is not pregnant. LHWs from all districts in general and from Balochistan in particular did not know that injectables can be given immediately after delivery if a woman is not breastfeeding. Table 3.18 indicates that LHWs know only about administering injections in the first two listed situations, and their knowledge for third situation is limited.

Table3.18: Knowledge of LHWs regarding Timing of Depo-Provera Injection, by Province $(\mathrm{N}=\mathbf{2 3})$

\begin{tabular}{|c|c|c|c|c|c|}
\hline & Punjab & Sindh & $\mathrm{KP}$ & Balochistan & \\
\hline & $\%$ & $\%$ & $\%$ & $\%$ & $\%$ of LHWs \\
\hline Day 1 to 7 of the menstrual cycle & 100 & 100 & 100 & 67 & 91 \\
\hline $\begin{array}{l}\text { Anytime during the menstrual cycle when } \\
\text { you can be reasonably sure the client is } \\
\text { not pregnant }\end{array}$ & 83 & 75 & 50 & 33 & 59 \\
\hline $\begin{array}{l}\text { Immediately after delivery if not } \\
\text { breastfeeding }\end{array}$ & 33 & 25 & 50 & 0 & 27 \\
\hline Total $(\mathrm{N})$ & 6 & 4 & 6 & 6 & 22 \\
\hline
\end{tabular}

Source: Interviews with LHWs.

Note: Multiple responses are possible.

LHWs were asked further about the possible side effects of injectables. Table 3.19 shows that respondents were aware of the main side effects, such as heavy and irregular bleeding; however, they also perceived weight loss and infection as side effects of injectables, although these are not actual side effects. LHWs also mentioned dizziness and pain in the body in the "Other" category of side effects. This is worrying since, if LHWs have the wrong knowledge about any method, women in their community are also likely to develop the same misconceptions. 
Table 3.19: Knowledge of LHWs regarding Side Effects of Injectables, by Province $(\mathrm{N}=\mathbf{2 3})$

\begin{tabular}{|c|c|c|c|c|c|}
\hline & Punjab & Sindh & $\mathrm{KP}$ & Balochistan & \\
\hline & $\%$ & $\%$ & $\%$ & $\%$ & $\%$ of LHWs \\
\hline Heavy bleeding & 83 & 75 & 83 & 100 & 86 \\
\hline Irregular bleeding & 100 & 100 & 100 & 67 & 91 \\
\hline Weight loss* & 17 & 0 & 17 & 17 & 14 \\
\hline Infection* & 17 & 25 & 17 & 17 & 18 \\
\hline Others & 17 & 25 & 0 & 33 & 18 \\
\hline Total $(\mathrm{N})$ & 6 & 4 & 6 & 6 & 22 \\
\hline
\end{tabular}

Source: Interviews with LHWs.

Notes: Multiple responses are possible.

* Weight loss and infection are not actual but perceived side effects.

Since the LHW is a main source of oral contraceptive pills at the community level, she should have some knowledge about how to handle and manage side effects if a client experiences them. As irregular bleeding is a common side effect of oral pills, LHWs were asked about their knowledge regarding the management of this particular side effect. Table 3.20 shows that 64 percent of providers, mainly from Sindh and Punjab, know that they should ask the client to continue taking the pills regularly and at the same time every day in this situation. Secondly, half of the LHWs know that they can assure the client that the side effect is not a danger to her health. LHWs from Balochistan lacked knowledge regarding these management measures.

Another measure is a short course of non-steroidal analgesics to control bleeding. This management measure was mainly known to LHWs from Balochistan while LHWs from Punjab and Sindh were completely unaware of it. Only three LHWs knew that they could suggest all of the above-mentioned management measures to clients.

Table 3.20: Knowledge of LHWs regarding Management of Irregular Bleeding while on Oral Contraceptive Pills, by Province $(\mathrm{N}=23)$

\begin{tabular}{|c|c|c|c|c|c|}
\hline & Punjab & Sindh & KP & Balochistan & \\
\hline & $\%$ & $\%$ & $\%$ & $\%$ & $\%$ of LHWs \\
\hline $\begin{array}{l}\text { Reassuring the client that the side } \\
\text { effect is not a danger to her health }\end{array}$ & 67 & 100 & 33 & 17 & 50 \\
\hline $\begin{array}{l}\text { Instructing the client to take her pills } \\
\text { regularly and at the same time every day }\end{array}$ & 83 & 100 & 67 & 17 & 64 \\
\hline $\begin{array}{l}\text { Using a short course of non-steroidal } \\
\text { analgesics to control bleeding }\end{array}$ & 0 & 0 & 17 & 67 & 23 \\
\hline All of the above & 17 & 0 & 17 & 17 & 14 \\
\hline Total $(\mathrm{N})$ & 6 & 4 & 6 & 6 & 22 \\
\hline
\end{tabular}

Source: Interviews with LHWs.

Note: Multiple responses are possible.

Like the other service providers, the LHWs were also given multiple choice questions to gauge the level of their technical knowledge for responding to different situations. Table 3.21 shows the proportion of right answers given by LHWs in different provinces. By and large, the knowledge of LHWs is satisfactory. LHWs from KP, Punjab and Balochistan have better knowledge than LHWs in Sindh. The most common understanding of LHWs is about condoms; a substantial number have knowledge that condoms can be used as a backup method. 
Overall, the same proportion of LHWs (74 percent), with some provincial variations (particularly for Sindh), have accurate knowledge about the fact that emergency contraceptive pills are most effective within the first five days of unprotected intercourse; injectables cannot be used for clients who have cardiovascular disease, cancer or liver disease; and a woman who is breastfeeding a baby can use injectable contraceptive and progestin-only pills.

Two areas of concern emerge, specifically related to the method of pills, which LHWs provide frequently: about half of the LHWs do not have correct knowledge that a woman does not require to have a pelvic examination before she can start or continue using pills. Similarly, 70 percent have incorrect knowledge that progestin-only pills can be used for emergency contraception after unprotected sex. The table clearly identifies the methodspecific gaps in the knowledge of LHWs that can be reduced by proper training.

Table3.21: Proportion of Correct Answers Given by LHWs about Contraceptives by Province $(\mathrm{N}=\mathbf{2 3})$

\begin{tabular}{|c|c|c|c|c|c|}
\hline & Punjab & Sindh & KP & Balochistan & \multirow{2}{*}{$\begin{array}{l}\text { Total } \\
\% \text { of LHWs }\end{array}$} \\
\hline & $\%$ & $\%$ & $\%$ & $\%$ & \\
\hline Condom can be used as a backup method & 83 & 80 & 100 & 100 & 91 \\
\hline $\begin{array}{l}\text { Emergency contraception pills are most effective } \\
\text { within first five days of unprotected intercourse }\end{array}$ & 67 & 60 & 100 & 67 & 74 \\
\hline $\begin{array}{l}\text { Injectable cannot be used for clients having } \\
\text { cardiovascular disease, cancer, liver disease }\end{array}$ & 100 & 40 & 100 & 50 & 74 \\
\hline $\begin{array}{l}\text { A woman does not need a pelvic examination } \\
\text { before she can start or continue using the Pills }\end{array}$ & 83 & 40 & 50 & 33 & 52 \\
\hline $\begin{array}{l}\text { A woman who is breastfeeding a baby can use } \\
\text { Injectable contraceptive after six weeks of delivery }\end{array}$ & 83 & 60 & 67 & 83 & 74 \\
\hline $\begin{array}{l}\text { A woman who is breastfeeding a baby can take } \\
\text { progestin-only pills after six weeks of delivery }\end{array}$ & 83 & 20 & 67 & 100 & 70 \\
\hline $\begin{array}{l}\text { Progestin-only pills can be used for emergency } \\
\text { contraception after unprotected sex }\end{array}$ & 33 & 40 & 33 & 17 & 30 \\
\hline Total (N) & 6 & 5 & 6 & 6 & 22 \\
\hline
\end{tabular}

Source: Interviews with LHWs.

Note: Multiple responses are possible. 


\section{Conclusions}

While it appears, at first glance, that the majority of providers do have some training in family planning, greater scrutiny reveals that certain critical areas related to both technical and communication skills have been overlooked. Overall, gaps in knowledge among service providers indicate their limited ability to provide FP counselling and services.

The overall situation suggests a significant need for training, particularly behavioural training, of service providers at static facilities, so they can play a more positive role in providing quality care. Training in providing IUCDs to clients is treated as a critical part of family planning provider skills since it requires a certain level of technical expertise, and it can be assumed that it encompasses abilities to provide less technically demanding methods such as pills and injectables. About 60 percent of service providers interviewed had technical training for IUCD insertion and removal. However, this training was restricted to LHVs and gynaecologists.

Although service providers who knew about general topics related to family planning, knowledge of some specific methods was weak. Surprisingly, the cadres of gynaecologists, WMOs, MOs and dispensers generally had better knowledge about IUCDs than injectables and pills, whereas LHVs and FWWs/FWCs had better knowledge about injectables than IUCDs and pills. Furthermore, knowledge about contraindications of pills and about use of progestin-only pills as emergency contraception was generally better than progestin-only pills. A slightly higher proportion of SPs had the right knowledge regarding injectables, while less than half had the right knowledge about how emergency contraceptive pills and vasectomy work to prevent conception.

An essential part of family planning services is appropriate counselling, including a client-centered approach which gives respect and importance to clients' choices, concerns and values. Findings from observations indicate that while providers are generally better in the initial stages of icebreaking and salutation, they are less competent in assessing client needs and responding to them. Additional training for family planning service providers must include an element of behaviour and communications training. Although we identified gaps in SPs' dealings with family planning clients during observations, clients themselves reported they were satisfied. This discrepancy could be due to the fact that clients are unaware of their rights and expect low standards of quality of care.

LHWs play a very important role in being the first point of contract and information and services at the community level. However, while they are better informed about healthy timing and spacing of births, they are less knowledgeable about method-specific side effects and their management. In particular, there is a clear gap in their knowledge about oral pills, a method they frequently provide. LHWs should be provided refresher trainings for comprehensive knowledge and management of initial side effects of the methods they provide. Their training should have a specific protocol for referrals to nearby public and private health facilities for methods they cannot provide. Adding emergency contraceptive pills and injectables to their service delivery options may also be considered. 



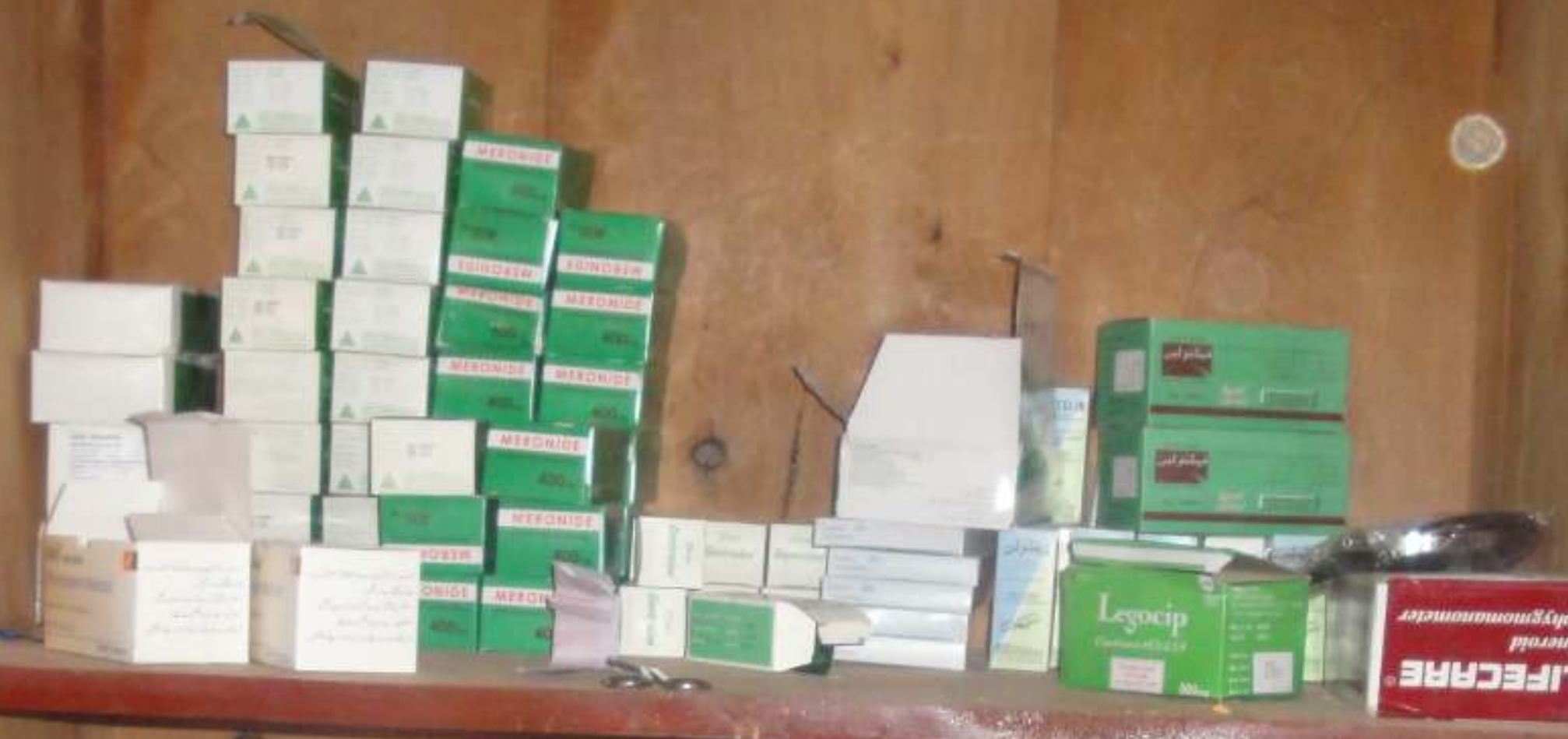

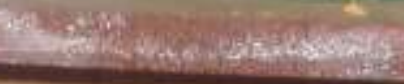

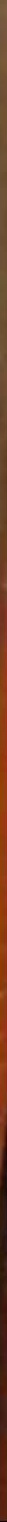




\section{Availability of Contraceptive Stock}

- Public sector facilities associated with the Department of Health suffer from frequent and prolonged shortages of all four methods. There is no single method out of the standard four (condoms, pills, injectables and IUCDs) that is available at all health facilities.

- All four methods were found to be available at only $33 \%$ of sample facilities in Balochistan, $\mathbf{5 0} \%$ of facilities in $\mathbf{K P}, \mathbf{5 1} \%$ of facilities in Sindh, and $\mathbf{5 3} \%$ of facilities in Punjab.

- Public district headquarters (DHQ) hospitals have the least availability of contraceptive methods, which seems to be due to an administrative issue. This oversight has a major share in the "missed opportunity" to provide contraceptives to potential new users.

- The private sector manages its supply of contraceptives independently, and sometimes refers clients to stores and pharmacies.

- Large stocks of IUCDs and injectables remain unutilized at rural health centers (RHCs): $67 \%$ of RHCs have stocks of IUCDs but only $7 \%$ report IUCD dispensing, and similarly, $\mathbf{7 3} \%$ of RHCs have stocks of injectables but only $13 \%$ report their utilization.

- There is frequent shortage of contraceptive stocks and disruptions in supplies. During stock-outs, LHWs usually manage by borrowing from other LHWs or by referring clients to a health facility. 


\section{Availability of Contraceptive Stock}

A necessary condition for the success of family planning apart from accessible and competent service providers is the consistent availability of the full range of modern contraceptive methods. Breaks and inconsistencies in supply translate into non-availability or unreliable access for users, and when stock-outs of contraceptives are frequent or prolonged, users may be forced to switch to less preferred methods simply due to poor management of the contraceptive supply chain. Given the already high incidence of discontinuation of modern contraceptive use in Pakistan, this is a serious concern.

The availability and access to a choice of family planning methods through an effective contraceptive supply system which includes both the private and public sectors can only be ensured through the continuous supply of sufficient quantities of high-quality contraceptives at all service delivery points. ${ }^{17}$ The system, referred to as "the supply chain", has to ideally ensure that the end-user receives the right product in the right quantity in the right condition at the right time for the right cost. ${ }^{18}$

As mentioned earlier, the fourth study conducted by the Population Council as part of its investigation into the reasons for low modern contraceptive use in Pakistan focused on the availability of contraceptive stock. The objectives and methodology of the study are outlined in the section on Methodology. This section presents the study's findings on the situation of the availability of contraceptives, focusing on facilities and LHWs in the eight study districts. It responds to the research questions regarding factors that affect the availability of contraceptives from the districts and downwards to the service delivery points and down to clients. It assesses availability of stocks in the public and private sector, focusing on specific contraceptives most commonly used in Pakistan, i.e., IUCDs, pills, injectables and condoms.

\section{Flow of Contraceptives}

The supply of contraceptives to most delivery points in Pakistan begins from the "Central Warehouse" (CWH), the country's largest warehouse for contraceptives, which is located in Karachi and currently headed by the Population and Planning Wing of the Federal Ministry of National Health Services Regulation and Coordination. Figure 4.1 presents the flow of contraceptives from $\mathrm{CWH}$ to the district stores and from there to service delivery points (SDPs) in the district facilities of the health and population department and to LHWs.

Supplies from the $\mathrm{CWH}$ are requisitioned by the districts through a specific form submitted jointly by the Executive District Officer-Health (EDO-H) and the Population Welfare Department. The requisition form, called the CLR-6, reflects the combined quarterly demand of the two concerned departments, PWD and DoH, and is usually filled during a monthly District Technical Committee (DTC) meeting. In the private sector, a major proportion of outlets manage contraceptives through independent procurement of services by clients from stores and pharmacies, or services provided by independent healthcare providers. There are some private NGO facilities that receive contraceptives from their provincial warehouses on a quarterly basis.

The CWH supplies directly to different public- and private-sector providers at the district level, including the District Population Welfare Officer (DPWOs); EDO-H; People's Primary Healthcare Initiative/Punjab Rural

\footnotetext{
17USAID-DELIVER Project, “Why is logistics important?” (n.d.), available at http://deliver.

jsi.com/dhome/topics/supplychain/logistics/logisticsimportant (accessed October 20, 2008); European Commission, Reproductive Health Commodity Security Study: Key Findings and Recommendations for the European Commission, Final report (Brussels: European Commission, 2007).

18USAID-DELIVER Project, “Contraceptive Security Index 2009: A Tool for Priority Setting and Planning,” Task Order 1 (Arlington, VA: USAIDDELIVER, 2009).
} 
Support Program (PPHI/PRSP) and a limited number of public private sector organizations (PPSOs), as well as two large non-government organizations (NGOs), the Family Planning Association of Pakistan (FPAP) and Marie Stopes Society (MSS). Supply arrangements are discussed further later in this section.

At the district level, the DoH maintains two stores, one for the distribution of commodities to all DoH SDPs and the other for LHWs; stores, the latter are District Project Implementation Units (DPIUs). The PPHI/PRSP and PWD have their own district stores where contraceptives are stored for supply to respective SDPs on a monthly or quarterly basis, as required. Arrangements for distribution of contraceptives from the district stores to SDPs vary across provinces and sectors, and are discussed later in this section. The overall responsibility for distribution to LHWs rests with the District Coordinator from the Provincial LHW Program through Lady Health Supervisors.

The types of delivery points associated with different district stores are listed in Table 4.1. As the table indicates, the SDPs of the Department of Health also serve as source of distribution to LHWs.

Table 4.1: Types of Service Delivery Points Served by Different Sectors' District Stores

\begin{tabular}{|c|c|c|}
\hline District Store/Sector & Associated SDPs & Sources for LHWs \\
\hline Department of Health & $\begin{array}{l}\text { DHQ and THQ hospitals, RHC, Maternal } \\
\text { and Child Health Care }\end{array}$ & Yes* \\
\hline $\begin{array}{l}\text { People's Primary Healthcare } \\
\text { Initiative/Punjab Rural Support } \\
\text { Program }\end{array}$ & $\mathrm{BHU}, \mathrm{RHC}$ & Yes* \\
\hline Department of Population & Family Welfare Center (FWC), Mobile & \\
\hline Welfare & $\begin{array}{l}\text { Service Units (MSU), Social Mobilizers } \\
\text { (SM), Reproductive Health Services of } \\
\text { Type A centers (RHS-A) }\end{array}$ & No \\
\hline
\end{tabular}

* The facilities are only used as contraceptive distribution points, while LHWs receive commodities from their DPIU through LHS

As shown in Figure 4.1, private wholesalers are also engaged in supplying contraceptives, although they operate on a much more limited scale, catering exclusively to private pharmacies and non-governmental organizations.

Figure 4.1: Flow of Contraceptives to Public and Private Health Facilities and Clients

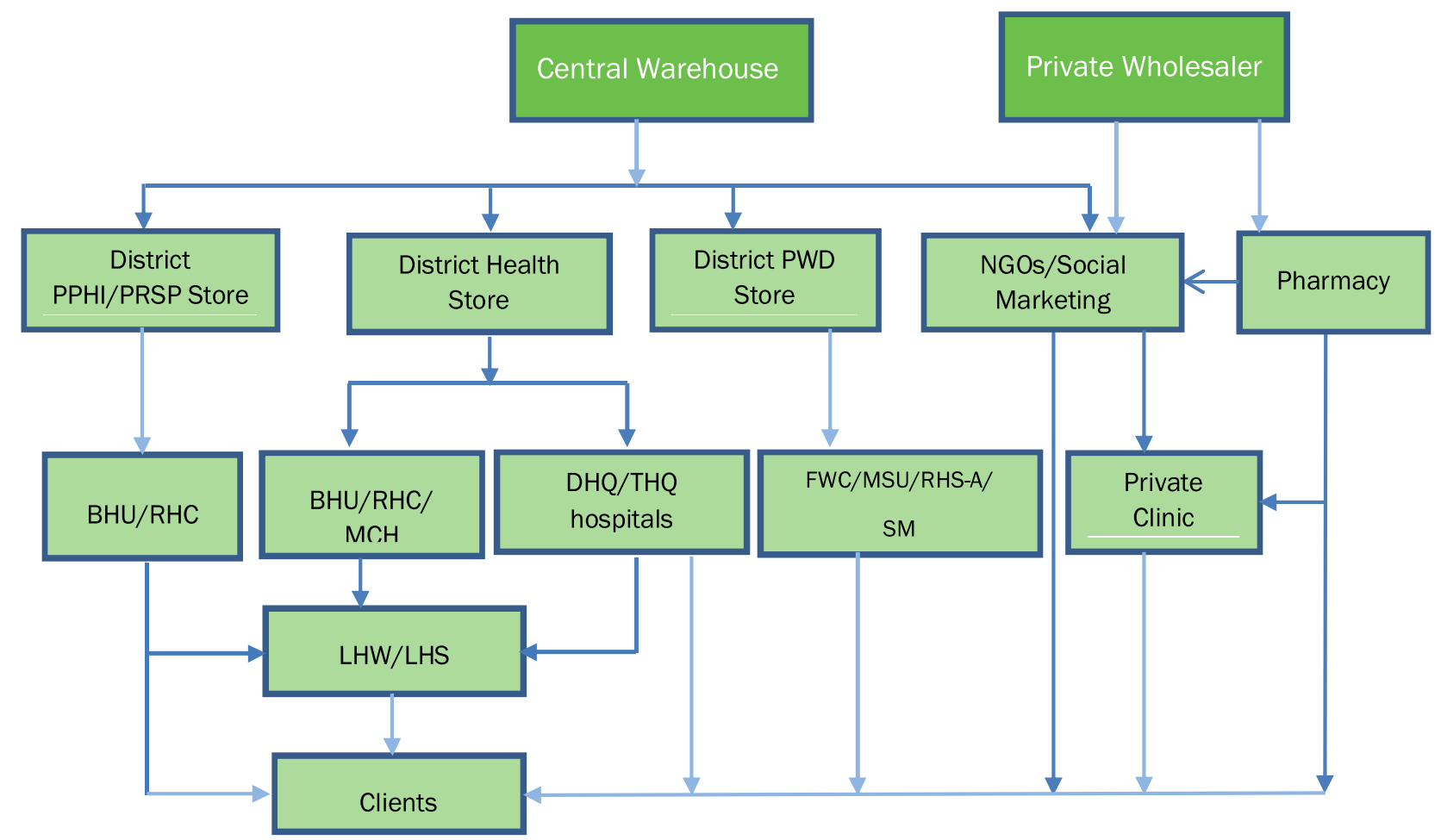




\section{Central Warehouse}

Currently, major procurement of contraceptives by CWH is being carried out through the USAID-DELIVER Project, which began operations in Pakistan in August 2009 and will provide support until June 2015. The study team visited the Central Warehouse in Karachi. On the day of the study team's visit, a minimum of one year's stock of condoms, pills, injectables and IUCDs was available at the warehouse, kept in proper storage condition.

USAID-DELIVER is also supporting the introduction of modern technology in contraceptive supply chain management. At $\mathrm{CWH}$, it has introduced bar-coding, an automated inventory control system, and a web-based Logistics Management Information System (LMIS), which is being used for management, record-keeping, procurement and distribution of contraceptives. However, this system is only functional at a third of the publicsector district facilities.

In accordance with the Manual of Contraceptive Logistics of the Government of Pakistan, the CWH usually provides a maximum of six months' stock of contraceptives to the public-sector district facilities, which are supposed to supply a three-month buffer stock down to their SDPs. ${ }^{19}$ The only reason for delay or late supply of contraceptives from $\mathrm{CWH}$ to the districts was identified as incorrect or late submission of the requisition form, CLR-6, from districts facilities to $\mathrm{CWH}$.

\section{District Stores}

As mentioned in Section 2.3, the study team visited a total of 30 district-level stores, all of which belonged to the public sector, since no private district-level stores are operating.

All public stores submit their demand for contraceptive commodities to $\mathrm{CWH}$ and it takes, on average, two months for them to receive the supplies. USAID has committed to bear costs of quarterly transportation of contraceptives from $\mathrm{CWH}$ to all district stores until the end of the DELIVER project. ${ }^{20}$ However, the supply from district stores to facilities is the responsibility of the respective departments. All the DoH district stores visited in all four provinces, and all PWD stores in Punjab receive their contraceptive supply through USAID-DELIVER support and do not pay any transportation charges. However, the district store facilities of PWD and PPHI in Sindh, KP and Balochistan receive contraceptive supplies through public transport and pay all transportation charges.

Slightly more than one-half of the public-sector district stores had more than four months' stock available. About one in four stores that the team visited had experienced a stock-out of more than one contraceptive method during the previous year.

Among the 30 stores visited, approximately three in four PWD stores and two-thirds of DoH stores did not deliver contraceptives to the SDPs. In these cases, the SDPs collected contraceptive commodities from the store and were not provided any payment for transportation.

\footnotetext{
${ }^{19}$ Government of Pakistan, Manual of Contraceptive Logistics (Islamabad: Ministry of Population Welfare, Monitoring and Statistics Wing, 2007).

20 USAID, “Pakistan: Stock Analysis at Service Delivery Points for USAID Supported Contraceptives” (Final Report).
} 


\section{Service Delivery Points}

We utilized four major indicators to assess the stock position of contraceptives at service delivery points which is what would affect clients' uptake of modern contraception. They are:

- Stock-out of a contraceptive method experienced during the preceding one year;

- Alternative sources for contraceptive methods;

- Availability of one or more contraceptive methods and previous month's contraceptive utilization; and

- Number of available contraceptive methods.

The findings are presented below. In addition, the study also looked at the availability of contraceptives with mobile health services, specifically, lady health workers. The findings about LHWs are discussed later in this section.

\section{Contraceptive Stock-outs}

Irregular supply of contraceptive commodities from the major sources described above leads to contraceptive stock-outs. When a facility experiences one or more stock-outs, its consistency in FP service delivery is affected, and clients either seek services at other facilities considered more reliable, or may discontinue contraceptive use. ${ }^{21}$

As mentioned earlier, one in four district stores had faced contraceptive stock-outs during the preceding one year. Stock-out of almost all methods appeared to be more of an issue in the private sector (including NGO clinics) than the public sector in all provinces except Balochistan. Among public sector facilities, stock-out was observed more in Khanewal and Pishin than other districts. Table 4.2 shows that, on average, 30 percent of DoH SDPs in Pishin and 25 percent of DoH SDPs in Khanewal had experienced stock-outs of all methods during the preceding year. The highest stock-outs were reported for IUCDs (71 percent), followed by injectables at DoH facilities in Sibi (57 percent).

The Population Welfare Department did not experience any contraceptive stock-outs during the year preceding our visit with the exception of pills, which remained out of stock in one-fourth of its SDPs in Pishin. The relatively low incidence of stock-outs at PWD facilities is due to the fact that the department usually maintains a three-month buffer stock at its SDPs and a six-month stock at district stores, ${ }^{22}$ which, to a large extent, reduces the risk of stocks running out. On the other hand, DoH facilities in Balochistan had the highest stockout among public-sector SPDs, specifically for IUCDs and injectables, which remained out of stock at a large number of SDPs in this sector.

Among the private sector SDPs, 56 percent in Khanewal and 50 percent in Mansehra reported the highest stock-out of all four contraceptive methods during the previous year. Private SDPs do not have a formal structure to receive contraceptive supplies from the public or private sector and may run out of stock because private suppliers have deficient stock. Private sector facilities in Punjab and KP also reported stock-outs although the majority managed supplies through procurement from pharmacies.

\footnotetext{
${ }^{21}$ MEASURE, A User's Guide for Monitoring Quality of Care in Family Planning, MEASURE Evaluation Manual Series, No. 2 (Carolina Population Center, University of North Carolina at Chapel Hill, 2001).

22Government of Pakistan. 2007. Manual of Contraceptive Logistics. Islamabad: Ministry of Population Welfare, Monitoring and Statistics Wing, Islamabad.
} 
Table 4.2: Contraceptive Stock-outs in the Past Year by Sector across Districts

\begin{tabular}{|c|c|c|c|c|c|c|}
\hline & & \multicolumn{4}{|c|}{$\%$ of Facilities with Stock-out } & \multirow[b]{2}{*}{$\begin{array}{l}\text { Total Number of } \\
\text { Facilities }\end{array}$} \\
\hline & & Condoms & Pills & Injectables & IUCD & \\
\hline \multirow[t]{2}{*}{ Punjab } & & 21 & 23 & 23 & 23 & 53 \\
\hline & DoH & 20 & 30 & 30 & 30 & 10 \\
\hline \multirow[t]{2}{*}{ Khanewal } & PWD & 0 & 0 & 0 & 0 & 8 \\
\hline & Private & 56 & 56 & 56 & 56 & 9 \\
\hline \multirow{3}{*}{$\begin{array}{l}\text { Rahim Yar } \\
\text { Khan }\end{array}$} & DoH & 10 & 10 & 10 & 10 & 10 \\
\hline & PWD & 0 & 0 & 0 & 0 & 8 \\
\hline & Private & 38 & 38 & 38 & 38 & 8 \\
\hline \multirow{5}{*}{ Khairpur } & & 14 & 14 & 14 & 14 & 51 \\
\hline & $\mathrm{DoH}$ & 10 & 10 & 10 & 10 & 10 \\
\hline & PWD & 0 & 0 & 0 & 0 & 6 \\
\hline & Private & 33 & 33 & 33 & 22 & 9 \\
\hline & $\mathrm{DoH}$ & 0 & 0 & 0 & 10 & 10 \\
\hline \multirow[t]{2}{*}{ Umerkot } & PWD & 0 & 0 & 0 & 0 & 8 \\
\hline & Private & 38 & 38 & 38 & 38 & 8 \\
\hline \multirow[t]{2}{*}{ KP } & & 14 & 14 & 14 & 14 & 48 \\
\hline & DoH & 18 & 18 & 18 & 27 & 11 \\
\hline \multirow[t]{3}{*}{ Mardan } & PWD & 0 & 0 & 0 & 0 & 5 \\
\hline & Private & 13 & 13 & 13 & 13 & 8 \\
\hline & $\mathrm{DoH}$ & 10 & 30 & 20 & 10 & 10 \\
\hline \multirow[t]{2}{*}{ Mansehra } & PWD & 0 & 0 & 0 & 0 & 6 \\
\hline & Private & 50 & 50 & 50 & 50 & 8 \\
\hline \multirow[t]{2}{*}{ Balochistan } & & 15 & 18 & 21 & 27 & 33 \\
\hline & DoH & 30 & 30 & 30 & 30 & 10 \\
\hline \multirow[t]{3}{*}{ Pishin } & PWD & 0 & 25 & 0 & 0 & 4 \\
\hline & Private & 0 & 0 & 0 & 0 & 5 \\
\hline & $\mathrm{DoH}$ & 29 & 29 & 57 & 71 & 7 \\
\hline \multirow[t]{2}{*}{ Sibi } & PWD & 0 & 0 & 0 & 20 & 5 \\
\hline & Private & 0 & 0 & 0 & 0 & 2 \\
\hline Total $(\mathbf{N})$ & & 17 & 19 & 19 & 20 & 185 \\
\hline
\end{tabular}

Source: Inventory of health facilities.

Note: DoH facilities include BHUs attached with PPHI in KP, Sindh and Balochistan, and with PRSP in Punjab.

A comparison of stock-outs by types of facilities in the major sectors is shown in Table 4.3. It indicates that all facilities of PWD are efficient in contraceptive supplies: almost none of the FWCs and RHS-As reported stockout of any method during the previous year. On the other hand, all DHQ hospitals, which are under DoH jurisdiction, reported ever stock-out of IUCDs and nearly nine in ten reported ever stock-out for the remaining three methods (condoms, pills, and injectables). This might be because all RHS-A centres of PWD are located within the premises of public DHQ and THQ hospitals, except in Pishin and Sibi, and therefore, clients are largely referred to the nearby RHS-A centre for family planning services. This is why they neither request contraceptive supplies from the EDO-H nor do they submit any separate requisitions to the $\mathrm{CWH}$.

Private facilities equivalent to THQ hospitals (in terms of number of beds) have the highest level of stock-outs for all methods, which could be due to irregular or low contraceptive supply from their provincial warehouse or 
the absence of a contraceptive stocking mechanism at such facilities. As discussed, seven in ten private THQequivalent facilities had stock-outs of condoms, pills and injectables.

Table 4.3: Contraceptive Stock-outs in Past Year by Type of Facility and Sector

\begin{tabular}{lccccc}
\hline & \multicolumn{5}{c}{ \% of Facilities with Stock-outs in the Last Year } \\
\cline { 2 - 5 } & Condom & Pills & Injectables & IUCD & $\begin{array}{c}\text { Total Number of } \\
\text { Facilities }\end{array}$ \\
\hline DoH & 88 & 88 & 88 & 100 & 8 \\
DHQ & 0 & 0 & 14 & 0 & 7 \\
THQ & 13 & 13 & 13 & 13 & 15 \\
RHC & 3 & 9 & 12 & 18 & 33 \\
BHU* & 13 & 20 & 13 & 13 & 15 \\
MCH & 0 & & & & \\
\hline PWD & 0 & 2 & 0 & 0 & 9 \\
RHS-A & 0 & 0 & 2 & 41 \\
FWC & & & & \\
\hline Private(Equivalent)** & 33 & 33 & 33 & 33 & 3 \\
DHQ & 71 & 71 & 71 & 57 & 7 \\
THQ & 25 & 25 & 25 & 25 & 16 \\
RHC & 29 & 29 & 29 & 29 & 31 \\
BHU & 17 & 19 & 19 & 20 & 185 \\
Total (N) & & & & & \\
\hline
\end{tabular}

Source: Inventory of health facilities.

*BHUs are attached with PPHI in KP, Sindh and Balochistan and with PRSP in Punjab.

** Private facilities were categorized by number of beds: $0-4$ bed $\equiv$ BHU, $5-19$ beds $\equiv$ RHC, $20-80$ beds $\equiv T H Q, 81$ and more beds $\equiv$ DHQ.

Figure 4.2 shows the level of stock-outs faced by different types of public facilities during the previous one year. The largest DHQ hospitals had the highest reported ever stock-outs.

Figure 4.2: Stock-out of Any or More than One Contraceptive in the Past Year at Different Types of Facilities (Public Sector), \% of Facilities

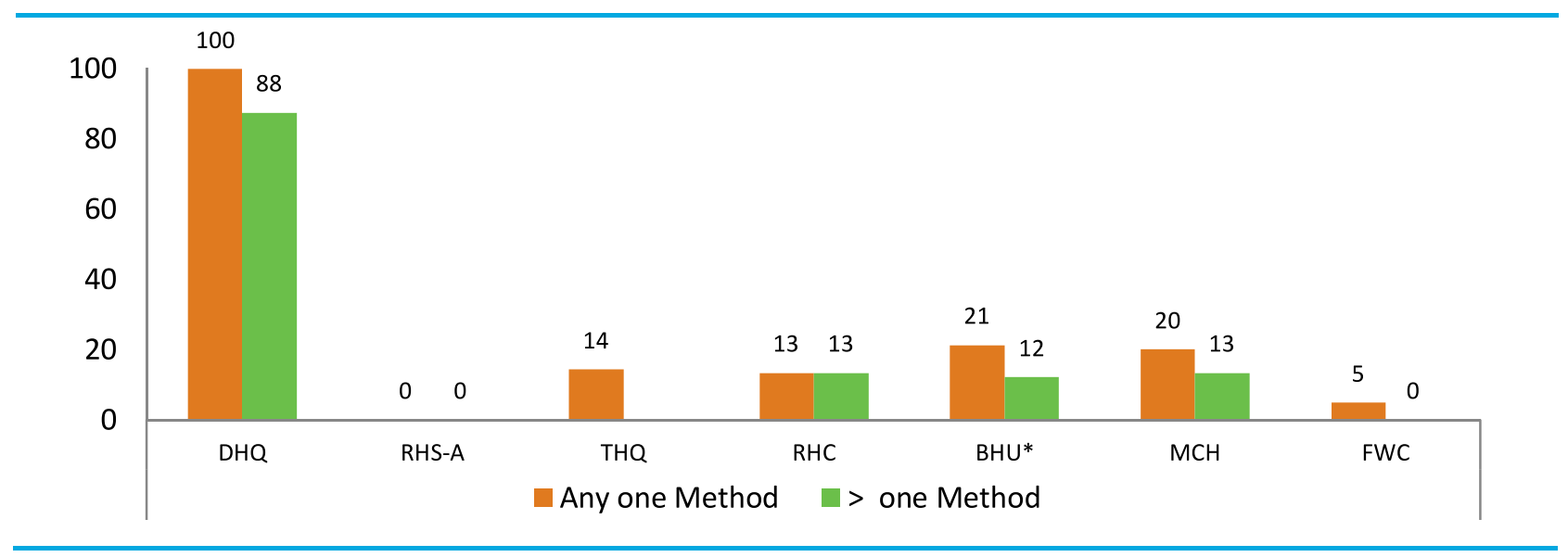

Source: Inventory of health facilities. *BHUs are attached with PPHI in KP, Sindh and Balochistan and with PRSP in Punjab. 
Figure 4.3 compares stock-outs by type of facility across the provinces. DHQ hospitals reported the most stockouts in all four provinces. In Balochistan, all SDPs except THQ hospitals had experienced stock-outs of one or more contraceptive methods. On the other hand, in Sindh, no facility except DHQ hospitals, reported any stockout, which could be because the SDPs received a regular supply throughout the year, or because their utilization was less than what was ordered. In Punjab, apart from DHQ hospitals, stock-outs occurred at MCHs, and to a lesser extent at BHUs. In KP, RHC-level facilities reported stock-outs of more than one method, while stock-outs of one method were reported at THQ hospitals, MCHs and BHUs.

Figure 4.3: Stock-out of Contraceptives in Past Year by Type of Facility (Public Sector) and Province, \% of Facilities

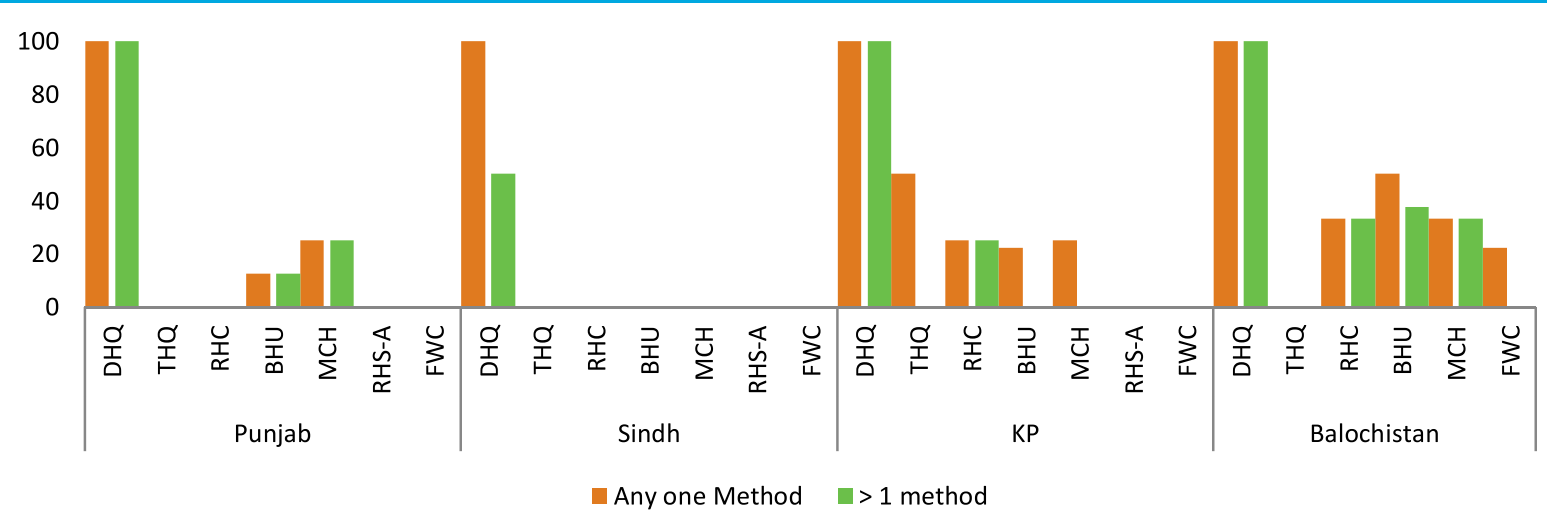

Source: Inventory of health facilities.

*BHUs are attached with PPHI in KP, Sindh and Balochistan and with PRSP in Punjab.

\section{Additional Contraceptive Sources}

For the most part, all public-sector SDPs receive contraceptives from their respective district stores, while in the private sector, except for a few cases, most facilities procure contraceptives from pharmacies and general stores. Compared to the demand that they present, public-sector SDPs usually receive a lower supply from their respective district stores. This may be because the contraceptives are usually evenly distributed rather than based on demand expressed, and the actual need of the facility is ignored. When demand exceeds supply, even some public SDPs end up either arranging the remaining methods from other sources, specifically pharmacies and general stores, or refer their clients to other facilities, such as RHS-As or FWCs of PWD, where sufficient contraceptive stocks are usually available.

Table 4.4 shows the percentage of public and private facilities that say that they arrange additional supplies of contraceptives from suppliers other than their primary source. While pharmacies are the major source for most of the private SDPs, a few private-sector facilities, including Marie Stopes Society and the Family Planning Association of Pakistan, receive a monthly or quarterly supply from their regional warehouses as well. These supplies are sometimes interrupted or lower than the actual demand, in which case the SDPs procure from pharmacies or other public (such as PWD) entities, or refer their clients to another facility. The highest incidence of additional supply arrangements seems to be at private THQ-equivalent facilities, which procure a large proportion of injectables from pharmacies. The next highest incidence of special procurement occurs at THQ-equivalent private hospitals, 57 percent of which arrange additional supplies of condoms and pills from pharmacies.

Although public DHQ hospitals report the highest level of contraceptive stock-outs, a relatively low proportion of them (38 percent)-refer their clients. This could be because most of them have annexed RHS-A centers, and they are likely to refer their clients to these centers for all four methods.

Slightly more than a fourth of public sector $\mathrm{MCH}$ facilities and more than a fifth of BHUs arrange additional supplies of condoms, injectables and IUCDs from the private sector (pharmacies/general stores). 
Table 4.4: Facilities that Arrange Supplies from Additional Sources by Type of facility and Sector

\begin{tabular}{|c|c|c|c|c|c|c|c|c|c|c|c|c|c|}
\hline & \multicolumn{3}{|c|}{ Condom } & \multicolumn{3}{|c|}{ Pills } & \multicolumn{3}{|c|}{ Injectables } & \multicolumn{3}{|c|}{ IUCD } & \multirow[b]{2}{*}{$\begin{array}{c}\text { Total } \\
\text { Number } \\
\text { of } \\
\text { Facilities }\end{array}$} \\
\hline & $\begin{array}{c}\text { Pharmacies } \\
\text { or General } \\
\text { Stores }\end{array}$ & $\begin{array}{l}\text { Other } \\
\text { Public } \\
\text { Sources }\end{array}$ & $\begin{array}{l}\text { Refer to } \\
\text { Other } \\
\text { Facilities }\end{array}$ & $\begin{array}{c}\text { Pharmacies } \\
\text { or General } \\
\text { Stores }\end{array}$ & $\begin{array}{c}\text { Other } \\
\text { Public } \\
\text { Sources }\end{array}$ & $\begin{array}{c}\text { Refer to } \\
\text { Other } \\
\text { Facilities }\end{array}$ & $\begin{array}{c}\text { Pharmacies } \\
\text { or General } \\
\text { Stores }\end{array}$ & $\begin{array}{c}\text { Other } \\
\text { Public } \\
\text { Sources }\end{array}$ & $\begin{array}{l}\text { Refer to } \\
\text { Other } \\
\text { Facilities }\end{array}$ & $\begin{array}{c}\text { Pharmacies } \\
\text { or General } \\
\text { Stores }\end{array}$ & $\begin{array}{c}\text { Other } \\
\text { Public } \\
\text { Sources }\end{array}$ & $\begin{array}{l}\text { Refer to } \\
\text { Other } \\
\text { Facilities }\end{array}$ & \\
\hline \multicolumn{14}{|l|}{ DoH } \\
\hline $\mathrm{DHQ}$ & 0 & 0 & 38 & 0 & 0 & 38 & 0 & 0 & 38 & 0 & 0 & 38 & 8 \\
\hline THQ & 14 & 0 & 0 & 0 & 14 & 0 & 0 & 14 & 0 & 0 & 14 & 29 & 7 \\
\hline $\mathrm{RHC}$ & 7 & 7 & 0 & 7 & 13 & 0 & 7 & 13 & 0 & 0 & 7 & 13 & 15 \\
\hline $\mathrm{BHU*}$ & 9 & 3 & 3 & 9 & 3 & 0 & 6 & 3 & 3 & 3 & 3 & 21 & 33 \\
\hline $\mathrm{MCH}$ & 27 & 0 & 0 & 20 & 0 & 0 & 27 & 0 & 0 & 27 & 0 & 7 & 15 \\
\hline \multicolumn{14}{|l|}{ PWD } \\
\hline RHS-A & 0 & 0 & 0 & 0 & 0 & 0 & 11 & 0 & 0 & 0 & 0 & 0 & 9 \\
\hline FWC & 0 & 5 & 0 & 0 & 5 & 0 & 0 & 5 & 0 & 0 & 7 & 2 & 41 \\
\hline \multicolumn{14}{|c|}{ Private (Equivalent)** } \\
\hline DHQ & 33 & 0 & 0 & 33 & 0 & 0 & 33 & 0 & 0 & 0 & 0 & 0 & 3 \\
\hline $\mathrm{THQ}$ & 57 & 0 & 0 & 57 & 0 & 0 & 71 & 0 & 0 & 43 & 0 & 0 & 7 \\
\hline $\mathrm{RHC}$ & 56 & 0 & 0 & 44 & 0 & 0 & 44 & 0 & 0 & 44 & 0 & 0 & 16 \\
\hline $\mathrm{BHU}$ & 32 & 6 & 3 & 23 & 3 & 0 & 32 & 3 & 0 & 26 & 3 & 3 & 31 \\
\hline Total (N) & 18 & 3 & 3 & 14 & 4 & 2 & 17 & 4 & 2 & 12 & 4 & 9 & 185 \\
\hline
\end{tabular}

Source: Inventory of health facilities.

*BHUs are attached with PPHI in KP, Sindh and Balochistan and with PRSP in Punjab.

* *Private facilities were categorized by number of beds: 0-4 bed $\equiv$ BHU, 5-19 beds $\equiv \mathrm{RHC}, 20-80$ beds $\equiv \mathrm{THQ}, 81$ and more beds $\equiv \mathrm{DHQ}$. 


\section{Stock Availability and Reporting}

It was important to assess the level of contraceptive stocks of different methods available in facilities in the districts of our study. Almost all public district stores had considerable stocks of contraceptives; more than half had a buffer stock for more than three months. However, a number of SDPs were actually out of stock. In case of private facilities, this was quite common since the facilities usually procure contraceptives from other private sources, such as pharmacies, as and when required. In general, contraceptive stocks are available at public SDPs, although large SDPs of DoH in all four provinces also reported non-availability of methods on the day of the visit.

Another way of gauging utilization of facility for family planning methods was by looking at the previous month's reporting of contraceptives.

Table 4.5 shows the contraceptive availability and previous month's reporting for each service delivery point on the day of the visit. Contraceptive availability and past-month reporting were highest at PWD facilities (RHS-A and FWCs) for all four methods in all four provinces. Among provincial differences, 71 percent of SDPs in KP, followed by 65 percent in Sindh had available stocks of condoms. IUCDs were available at 73 percent of SDPs in Sindh and 66 percent of SDPs in Punjab. Generally, DoH facilities in Sindh had high availability of methods while their reporting was very low: despite availability of IUCDs, in 80 percent of DoH SDPs in Khairpur and 60 percent in Umerkot, only 10 percent of their SDPs reported utilization of IUCDs.

Although all methods were available, only 29 percent of DoH facilities in Sibi reported any utilization of pills and none of them reported utilization of the remaining three methods (condoms, injectables and IUCDs) for the month preceding the survey. However, compared with other provinces, SDPs in Balochistan's private health sector seem to be performing better in terms of stocking and utilization for all methods. 
Table 4.5: Availability and Reporting of Stocks of Contraceptives by District

\begin{tabular}{|c|c|c|c|c|c|c|c|c|c|c|c|c|c|c|}
\hline & & \multicolumn{12}{|c|}{$\%$ of Facilities with Stock Availability and Monthly Reporting } & \multirow{3}{*}{$\begin{array}{c}\text { Total } \\
\text { Number } \\
\text { of } \\
\text { Facilities }\end{array}$} \\
\hline & & \multicolumn{3}{|c|}{ Condom } & \multicolumn{3}{|c|}{ Pills } & \multicolumn{3}{|c|}{ Injectables } & \multicolumn{3}{|c|}{ IUCD } & \\
\hline & & $\begin{array}{c}\text { Stock } \\
\text { Available }\end{array}$ & $\begin{array}{l}\text { Reported. } \\
\text { Utilization }\end{array}$ & Difference & $\begin{array}{c}\text { Stock } \\
\text { Available }\end{array}$ & $\begin{array}{l}\text { Reported. } \\
\text { Utilization }\end{array}$ & Difference & $\begin{array}{c}\text { Stock } \\
\text { Available }\end{array}$ & $\begin{array}{l}\text { Reported. } \\
\text { Utilization }\end{array}$ & Difference & $\begin{array}{c}\text { Stock } \\
\text { Available }\end{array}$ & $\begin{array}{l}\text { Reported. } \\
\text { Utilization }\end{array}$ & Difference & \\
\hline Punjab & & 58 & 55 & 3 & 62 & 55 & 7 & 62 & 57 & 5 & 66 & 57 & 9 & 53 \\
\hline \multirow[t]{3}{*}{ Khanewal } & $\mathrm{DoH}$ & 60 & 50 & 10 & 50 & 40 & 10 & 40 & 30 & 10 & 40 & 30 & 10 & 10 \\
\hline & PWD & 100 & 100 & 0 & 100 & 100 & 0 & 88 & 88 & 0 & 100 & 100 & 0 & 8 \\
\hline & Private & 11 & 11 & 0 & 33 & 22 & 11 & 33 & 22 & 11 & 33 & 22 & 11 & 9 \\
\hline \multirow[t]{3}{*}{$\begin{array}{l}\text { Rahim } \\
\text { Yar Khan }\end{array}$} & $\mathrm{DoH}$ & 80 & 70 & 10 & 80 & 70 & 10 & 80 & 70 & 10 & 80 & 50 & 30 & 10 \\
\hline & PWD & 100 & 100 & 0 & 100 & 100 & 0 & 100 & 100 & 0 & 100 & 100 & 0 & 8 \\
\hline & Private & 0 & 0 & 0 & 13 & 0 & 13 & 38 & 38 & 0 & 50 & 50 & 0 & 8 \\
\hline Sindh & & 65 & 49 & 16 & 67 & 51 & 16 & 78 & 63 & 15 & 73 & 45 & 28 & 51 \\
\hline \multirow[t]{3}{*}{ Khairpur } & DoH & 80 & 30 & 50 & 90 & 60 & 30 & 90 & 70 & 20 & 80 & 10 & 70 & 10 \\
\hline & PWD & 100 & 100 & 0 & 83 & 83 & 0 & 100 & 100 & 0 & 100 & 100 & 0 & 6 \\
\hline & Private & 11 & 11 & 0 & 22 & 11 & 11 & 22 & 22 & 0 & 67 & 56 & 11 & 9 \\
\hline \multirow[t]{3}{*}{ Umerkot } & DoH & 90 & 60 & 30 & 90 & 50 & 40 & 100 & 60 & 40 & 60 & 10 & 50 & 10 \\
\hline & PWD & 100 & 100 & 0 & 100 & 100 & 0 & 100 & 100 & 0 & 88 & 88 & 0 & 8 \\
\hline & Private & 13 & 13 & 0 & 13 & 13 & 0 & 63 & 38 & 25 & 50 & 38 & 13 & 8 \\
\hline
\end{tabular}




\begin{tabular}{|c|c|c|c|c|c|c|c|c|c|c|c|c|c|c|}
\hline & & \multicolumn{12}{|c|}{$\%$ of Facilities with Stock Availability and Monthly Reporting } & \multirow{3}{*}{$\begin{array}{c}\text { Total } \\
\text { Number } \\
\text { of } \\
\text { Facilities }\end{array}$} \\
\hline & & \multicolumn{3}{|c|}{ Condom } & \multicolumn{3}{|c|}{ Pills } & \multicolumn{3}{|c|}{ Injectables } & \multicolumn{3}{|c|}{ IUCD } & \\
\hline & & $\begin{array}{c}\text { Stock } \\
\text { Available }\end{array}$ & $\begin{array}{l}\text { Reported. } \\
\text { Utilization }\end{array}$ & Difference & $\begin{array}{c}\text { Stock } \\
\text { Available }\end{array}$ & $\begin{array}{l}\text { Reported. } \\
\text { Utilization }\end{array}$ & Difference & $\begin{array}{c}\text { Stock } \\
\text { Available }\end{array}$ & $\begin{array}{l}\text { Reported. } \\
\text { Utilization }\end{array}$ & Difference & $\begin{array}{c}\text { Stock } \\
\text { Available }\end{array}$ & $\begin{array}{l}\text { Reported. } \\
\text { Utilization }\end{array}$ & Difference & \\
\hline KP & & 71 & 52 & 19 & 73 & 54 & 19 & 75 & 63 & 12 & 65 & 50 & 15 & 48 \\
\hline \multirow[t]{3}{*}{ Mardan } & $\mathrm{DoH}$ & 73 & 45 & 27 & 82 & 45 & 36 & 73 & 64 & 9 & 45 & 27 & 18 & 11 \\
\hline & PWD & 100 & 80 & 20 & 100 & 60 & 40 & 100 & 80 & 20 & 100 & 80 & 20 & 5 \\
\hline & Private & 63 & 50 & 13 & 75 & 75 & 0 & 75 & 75 & 0 & 75 & 75 & 0 & 8 \\
\hline \multirow[t]{3}{*}{ Mansehra } & DoH & 80 & 40 & 40 & 70 & 40 & 30 & 70 & 40 & 30 & 60 & 30 & 30 & 10 \\
\hline & PWD & 100 & 100 & 0 & 100 & 100 & 0 & 100 & 100 & 0 & 100 & 100 & 0 & 6 \\
\hline & Private & 25 & 25 & 0 & 25 & 25 & 0 & 50 & 38 & 13 & 38 & 25 & 13 & 8 \\
\hline Balochistan & & 61 & 45 & 16 & 79 & 61 & 18 & 73 & 55 & 18 & 42 & 27 & 15 & 33 \\
\hline \multirow[t]{3}{*}{ Pishin } & DoH & 50 & 50 & 0 & 60 & 50 & 10 & 70 & 60 & 10 & 10 & 0 & 10 & 10 \\
\hline & PWD & 75 & 75 & 0 & 75 & 75 & 0 & 75 & 75 & 0 & 75 & 75 & 0 & 4 \\
\hline & Private & 40 & 40 & 0 & 100 & 100 & 0 & 80 & 80 & 0 & 60 & 60 & 0 & 5 \\
\hline \multirow[t]{3}{*}{ Sibi } & DoH & 57 & 0 & 57 & 71 & 29 & 43 & 43 & 0 & 43 & 29 & 0 & 29 & 7 \\
\hline & PWD & 100 & 100 & 0 & 100 & 100 & 0 & 100 & 100 & 0 & 80 & 60 & 20 & 5 \\
\hline & Private & 50 & 0 & 50 & 100 & 0 & 100 & 100 & 0 & 100 & 50 & 0 & 50 & 2 \\
\hline Total (N) & & 64 & 51 & 13 & 69 & 55 & 15 & 72 & 59 & 12 & 63 & 46 & 17 & 185 \\
\hline
\end{tabular}

Source: Inventory of health facilities.

Note: DoH facilities include BHUs attached with PPHI in KP, Sindh and Balochistan and with PRSP in Punjab.

** Private facilities were categorized by number of beds: $0-4$ bed $\equiv$ BHU, $5-19$ beds $\equiv$ RHC, $20-80$ beds $\equiv T H Q, 81$ and more beds $\equiv D H Q$. 
Table 4.6 provides details about the availability of different types of contraceptives at different types of public and private facilities of different sectors. Condoms, pills and IUCDs are available at all SDPS of PWD (RHS-A and FWCs). The availability of stock varies across levels of facilities. THQ hospitals seem to be performing better than other types of facilities in terms of contraceptive availability and utilization: all public THQ hospitals had stocks of pills available and slightly less than four-fifths had condom stocks. Utilization of pills seems very high at public THQ hospitals (86 percent), while 71 percent of these facilities report utilization of injectables and of IUCDs.

Public RHCs appear to be better at stocking rather than consuming contraceptives: 73 percent of RHCs had available stocks of pills and injectables, while only slightly more than one-tenth reported utilization of these methods. Similarly, IUCDs are available in more than two-thirds of RHCs but only 7 percent of these facilities reported their utilization.

Amongst the private sector SDPs, condoms and pills were not available at any private DHQ-equivalent facilitystocks of injectables were available at two-thirds these facilities, and IUCDS were available at one-third of facilities only. Contraceptives are more widely available at lower-level private facilities. Both injectables and IUCDs were available at slightly more than half the private RHC-equivalent facilities and more than half of the BHUs under PPHI/PRSP. 
Table 4.6: Availability of Stocks and Reporting of Specific Contraceptive Methods by Type of Facility

\begin{tabular}{|c|c|c|c|c|c|c|c|c|c|c|c|c|c|}
\hline & \multicolumn{12}{|c|}{$\%$ of Facilities with Stock Availability and Monthly Reporting } & \multirow{3}{*}{$\begin{array}{c}\text { Total } \\
\text { Number } \\
\text { of } \\
\text { Facilities }\end{array}$} \\
\hline & \multicolumn{3}{|c|}{ Condoms } & \multicolumn{3}{|c|}{ Pills } & \multicolumn{3}{|c|}{ Injectables } & \multicolumn{3}{|c|}{ IUCDs } & \\
\hline & $\begin{array}{c}\text { Stock } \\
\text { Available }\end{array}$ & $\begin{array}{l}\text { Reported } \\
\text { Utilization }\end{array}$ & Difference & $\begin{array}{c}\text { Stock } \\
\text { Available }\end{array}$ & $\begin{array}{l}\text { Reported } \\
\text { Utilization }\end{array}$ & Difference & $\begin{array}{c}\text { Stock } \\
\text { Available }\end{array}$ & $\begin{array}{l}\text { Reported } \\
\text { Utilization }\end{array}$ & Difference & $\begin{array}{c}\text { Stock } \\
\text { Available }\end{array}$ & $\begin{array}{l}\text { Reported } \\
\text { Utilization }\end{array}$ & Difference & \\
\hline \multicolumn{14}{|l|}{$\mathrm{DOH}$} \\
\hline DHQ & 13 & 0 & 13 & 13 & 0 & 13 & 13 & 0 & 13 & 0 & 0 & 0 & 8 \\
\hline THQ & 86 & 71 & 14 & 100 & 86 & 14 & 71 & 71 & 14 & 43 & 43 & 0 & 7 \\
\hline $\mathrm{RHC}$ & 67 & 27 & 40 & 73 & 13 & 60 & 73 & 13 & 40 & 67 & 7 & 60 & 15 \\
\hline $\mathrm{BHU*}$ & 82 & 52 & 30 & 85 & 64 & 21 & 85 & 70 & 30 & 58 & 24 & 33 & 33 \\
\hline $\mathrm{MCH}$ & 80 & 60 & 20 & 73 & 60 & 13 & 73 & 67 & 20 & 53 & 27 & 27 & 15 \\
\hline \multicolumn{14}{|l|}{ PWD } \\
\hline RHS-A & 100 & 100 & 0 & 89 & 78 & 11 & 89 & 89 & 0 & 100 & 89 & 11 & 9 \\
\hline FWC & 98 & 95 & 2 & 98 & 95 & 2 & 98 & 95 & 2 & 93 & 90 & 2 & 41 \\
\hline \multicolumn{14}{|c|}{ Private (Equivalent)** } \\
\hline DHQ & 0 & 0 & 0 & 0 & 0 & 0 & 67 & 33 & 0 & 33 & 0 & 33 & 3 \\
\hline THQ & 14 & 14 & 0 & 14 & 14 & 0 & 14 & 14 & 0 & 43 & 43 & 0 & 7 \\
\hline $\mathrm{RHC}$ & 25 & 19 & 6 & 50 & 44 & 6 & 63 & 56 & 6 & 63 & 56 & 6 & 16 \\
\hline BHU & 26 & 23 & 3 & 42 & 29 & 13 & 52 & 39 & 3 & 52 & 42 & 10 & 31 \\
\hline Total (N) & 64 & 51 & 13 & 69 & 55 & 15 & 72 & 59 & 13 & 63 & 46 & 17 & 185 \\
\hline
\end{tabular}

Source: Inventory of health facilities.

*BHUs are attached with PPHI in KP, Sindh and Balochistan and with PRSP in Punjab.

* * Private facilities were categorized by number of beds: $0-4$ beds $\equiv$ BHU, $5-19$ beds $\equiv \mathrm{RHC}, 20-80$ beds $\equiv \mathrm{THQ}, 81$ and more beds $\equiv \mathrm{DHQ}$. 


\section{Number of Available Methods}

Availability of the full range of contraceptives is important to optimize clients' ability to choose their preferred family planning method from the facility that they visit. We expect each facility to stock four methodscondoms, pills, injectables, and IUCDs. Table 4.6 shows the availability of these four modern methods at the visited SDPs on the day they were visited. There is quite a divergence across provinces. All four methods were available in only 33 percent of SDPs in Balochistan, 50 percent of facilities in KP, 51 percent of facilities in Sindh, and at 53 percent of facilities in Punjab.

All four methods were available in PWD facilities of Rahim Yar Khan, Mardan and Mansehra. None of the DoH facilities in Pishin had all four methods available; in Sibi only 29 percent of DoH SDPs had all four methods available. On the other hand, 80 percent of DoH facilities in both Rahim Yar Khan and Khairpur had all four methods available on the day of the visit.

Table 4.7: Range of Contraceptive Methods available at Facilities by District

\begin{tabular}{|c|c|c|c|c|c|}
\hline & & \multicolumn{3}{|c|}{$\%$ of Facilities with Availability of Method Mix } & \multirow{2}{*}{$\begin{array}{c}\text { Total Number o } \\
\text { Facilities }\end{array}$} \\
\hline & & Any Two & Any Three & All Four & \\
\hline Punjab & & 74 & 68 & 53 & 53 \\
\hline \multirow[t]{3}{*}{ Khanewal } & $\mathrm{DoH}$ & 70 & 50 & 40 & 10 \\
\hline & PWD & 100 & 100 & 88 & 8 \\
\hline & Private & 33 & 33 & 11 & 9 \\
\hline \multirow[t]{3}{*}{ Rahim Yar Khan } & $\mathrm{DoH}$ & 90 & 90 & 80 & 10 \\
\hline & PWD & 100 & 100 & 100 & 8 \\
\hline & Private & 50 & 38 & 0 & 8 \\
\hline Sindh & & 80 & 67 & 51 & 51 \\
\hline \multirow[t]{3}{*}{ Khairpur } & $\mathrm{DoH}$ & 90 & 80 & 80 & 10 \\
\hline & PWD & 100 & 100 & 83 & 6 \\
\hline & Private & 33 & 22 & 11 & 9 \\
\hline \multirow[t]{3}{*}{ Umerkot } & DoH & 100 & 90 & 50 & 10 \\
\hline & PWD & 100 & 100 & 88 & 8 \\
\hline & Private & 63 & 13 & 0 & 8 \\
\hline KP & & 81 & 73 & 50 & 48 \\
\hline \multirow[t]{3}{*}{ Mardan } & $\mathrm{DoH}$ & 82 & 73 & 36 & 11 \\
\hline & PWD & 100 & 100 & 100 & 5 \\
\hline & Private & 88 & 88 & 38 & 8 \\
\hline \multirow[t]{3}{*}{ Mansehra } & DoH & 90 & 70 & 40 & 10 \\
\hline & PWD & 100 & 100 & 100 & 6 \\
\hline & Private & 38 & 25 & 25 & 8 \\
\hline Balochistan & & 82 & 64 & 33 & 33 \\
\hline \multirow[t]{3}{*}{ Pishin } & $\mathrm{DoH}$ & 60 & 60 & 0 & 10 \\
\hline & PWD & 100 & 75 & 75 & 4 \\
\hline & Private & 100 & 80 & 20 & 5 \\
\hline \multirow[t]{3}{*}{ Sibi } & $\mathrm{DoH}$ & 71 & 29 & 29 & 7 \\
\hline & PWD & 100 & 100 & 80 & 5 \\
\hline & Private & 100 & 50 & 50 & 2 \\
\hline Total (N) & & 79 & 68 & 48 & 185 \\
\hline
\end{tabular}

Source: Inventory of health facilities.

Note: DoH facilities include BHUs attached with PPHI in KP, Sindh and Balochistan and with PRSP in Punjab. 
Figure 4.4 shows the availability of contraceptive choice (of one or more methods) at different types of facilities. None of the DHQ hospitals had more than one method available. In general, SDPs linked with the PWD, particularly FWCs, offered more choices. However, other DoH facilities (THQs and BHUs) performed better, having at least one method, while a large number of these SDPs had a shortage of all four methods.

Figure 4.4: Distribution of Public Sector Facilities by Number of Contraceptive Methods Available on Day of Visit

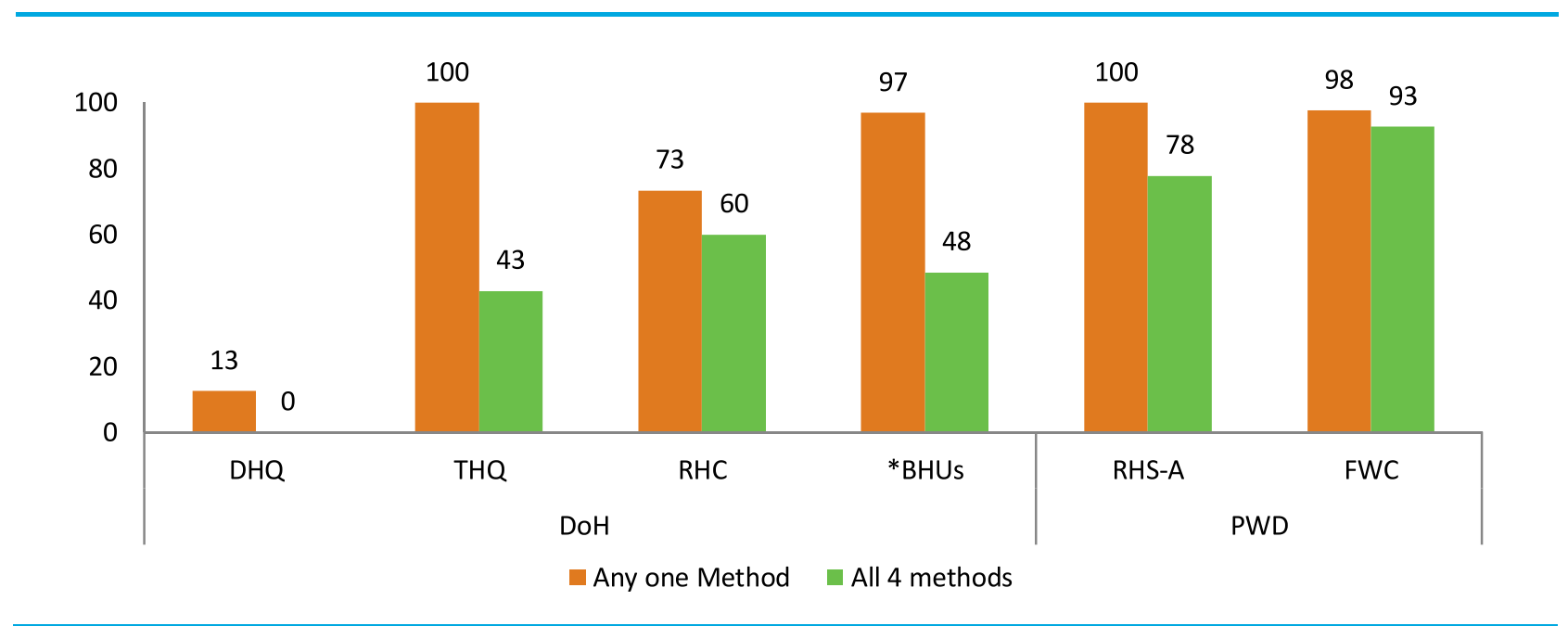

Source: Inventory of health facilities.

*BHUs are attached with PPHI in KP, Sindh and Balochistan and with PRSP in Punjab.

Figure 4.5 shows the wide range in availability of choice of contraceptive methods at different private sector facilities. However, multiple methods were rarely available at other. All smaller level facilities and DHQequivalent SDPs had at least one method available on the day of the study team's visit. Only 13 percent RHCequivalent facilities and slightly less than one fifth of the BHU-equivalent facilities had all four methods available.

Figure 4.5: Distribution of Private Sector Facilities by Number of Contraceptive Methods Available on Day of Visit

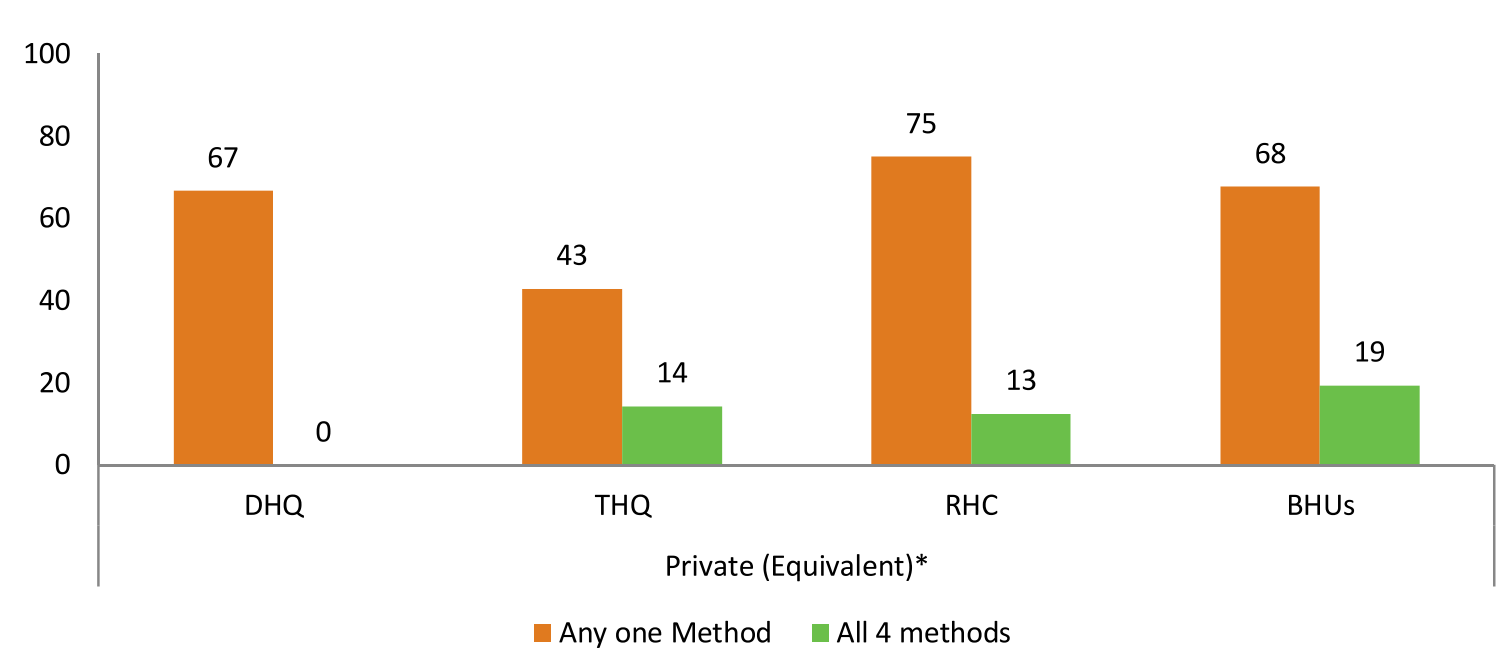

Source: Inventory of health facilities.

* Private facilities were categorized by number of beds: 0-4 bed $\equiv \mathrm{BHU}, 5-19$ beds $\equiv \mathrm{RHC}, 20-80$ beds $\equiv \mathrm{THQ}, 81$ and $\mathrm{more}$ beds $\equiv \mathrm{DHQ}$. 


\section{Lady Health Workers Program}

The LHW program is considered very effective especially in the past in delivering family planning services in Pakistan. ${ }^{23}$ The primary task of LHWs is to provide family planning services and three contraceptive methodscondoms, pills and injectables-at the grassroots level. We looked at contraceptive availability with LHWs as they serve directly in providing contraceptives, particularly to the poorest women and underserved communities in rural areas. We also examined the sources, availability and range of contraceptives for LHWs.

In general, LHWs receive their commodities from the nearest public sector facilities (THQs, RHCs and BHUs) through Lady Health Supervisors (LHSs) who are responsible for receiving contraceptives from the District Project Implementation Units and distributing them among their respective LHWs. Three LHWs were interviewed in each district to understand the pattern of contraceptive supply to LHWs. Only 2 LHWs could be interviewed in Khairpur. The data obtained from the $23 \mathrm{LHWs}$ is presented below.

The DPIUs located in the District Health Offices directly distribute to the first-level care facility (THQs/RHCs and BHUs) and the LHSs often take the contraceptive supplies for their assigned LHWs when they visit for monthly meetings. They distribute contraceptives to LHWs at the nearest public facility during monthly progress sharing meetings.

Figure 4.6 shows the different sources from where LHWs receive contraceptives from their department for provision to their clients. Different patterns prevail across the provinces. In KP and Sindh, the public health facilities (BHUs, RHCs and THQ hospitals) are the main contraceptive distribution points for LHWs when they receive a monthly supply. In Punjab, 17 percent of LHWs do not attend monthly progress sharing meetings but the LHS supplies them at their doorstep. A third of LHWs visit the DPIU to collect contraceptives, and the remaining half collect contraceptives from health facilities. In Balochistan, half the LHWs obtain contraceptives from DPIUs directly, and the other half follows the actual procedure, collecting them from health facilities during monthly progress sharing meetings.

Figure 4.6: Sources of Contraceptives for LHWs, by Province

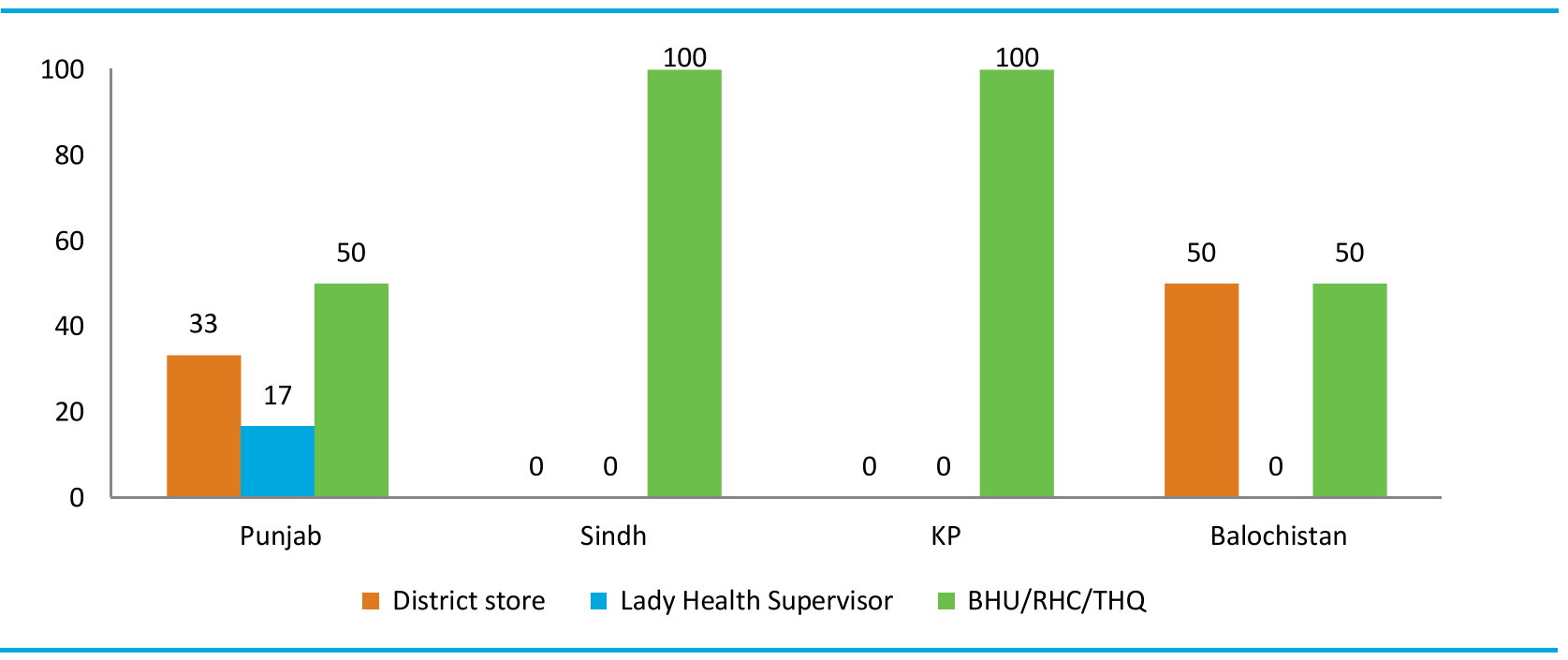

Source: Interviews with LHWs.

\footnotetext{
${ }^{23}$ Oxford Policy Management, “Lady Health Worker Programme: External Evaluation of the National Programme for Family Planning and Primary Health Care," 2002, available at http://www.opml.co.uk/document.rm?id=690 (accessed December 5, 2014).
} 


\section{Contraceptive Stock-outs}

A continuous problem of stock-out of contraceptives was reported by almost all LHWs in all four provinces. They seem to be affected by the same problems of interrupted or insufficient supply that appear to underlie the high reported stock-out of methods in facilities. Figure 4.7 shows the incidence of contraceptive stock-out among LHWs during the preceding one year. All LHWs in Balochistan reported that they had experienced stockouts of all three methods. All LHWs in Sindh and more than four-fifths of LHWs in Punjab reported they experienced stock-outs of condoms. In KP, the supply of pills remained sufficient, with a relatively lower 17 percent of LHWs reporting stock-out, while one-third reported ever stock-out of condoms. On the other hand, all LHWs in Punjab and Balochistan had faced stock-outs of pills at some point, while injectables stock outs were faced by more than two-thirds of LHWs in Punjab, three-fifths of LHWs in Sindh, and half of LHWs in KP.

Figure 4.7: Stock-outs of Contraceptives Experienced by LHWs, by Province

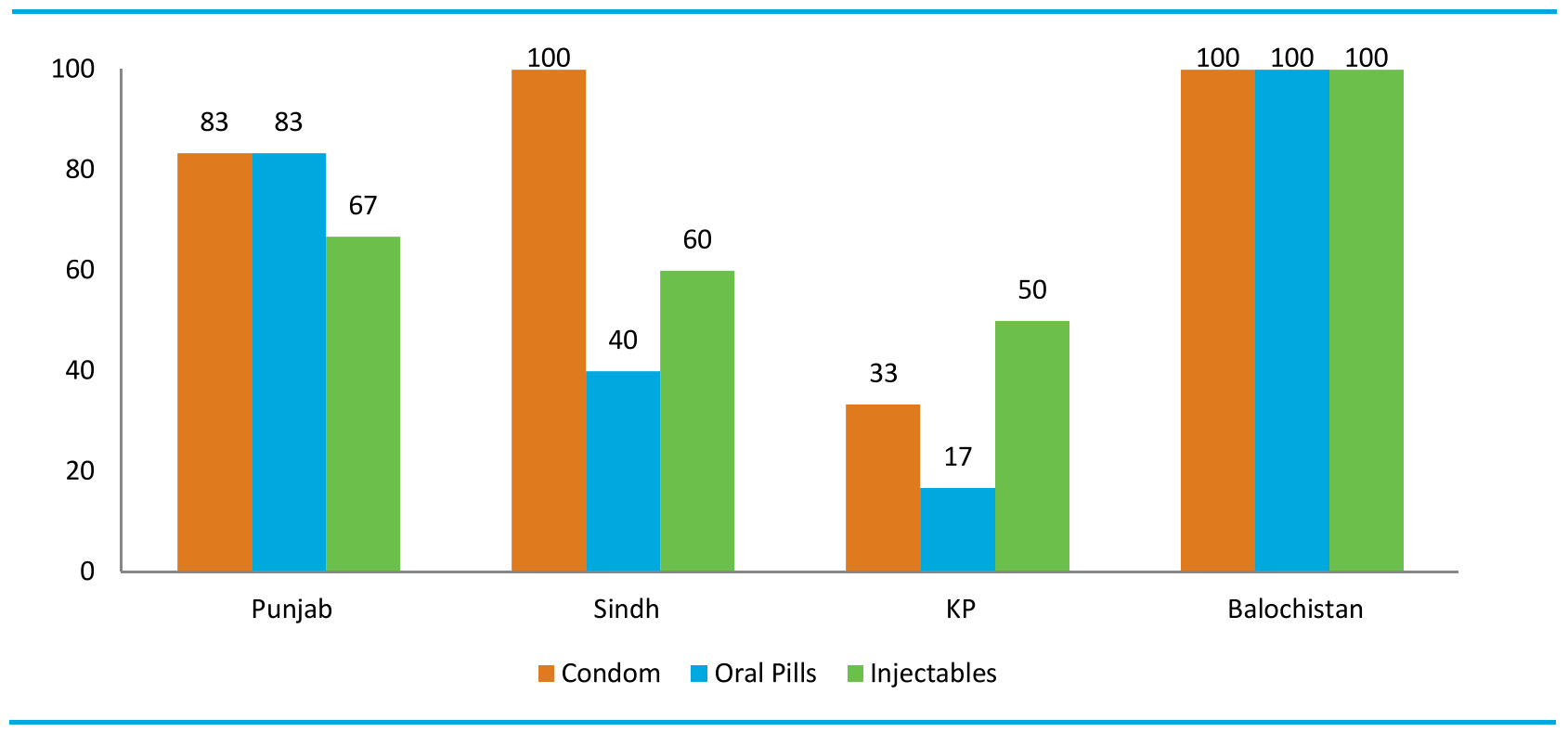

Source: Interviews with LHWs.

Figure 4.8 shows the number of methods-one, two or all three-for which LHWs had ever experienced stockouts in the preceding year. All interviewed LHWs in Balochistan and Sindh and more than two-thirds of LHWs in Punjab reported that they had experienced stock-outs of all three methods. Supply to LHWs in KP was comparatively sufficient: only 17 percent of LHWs reported stock-outs for all three methods, the lowest proportion across provinces. 


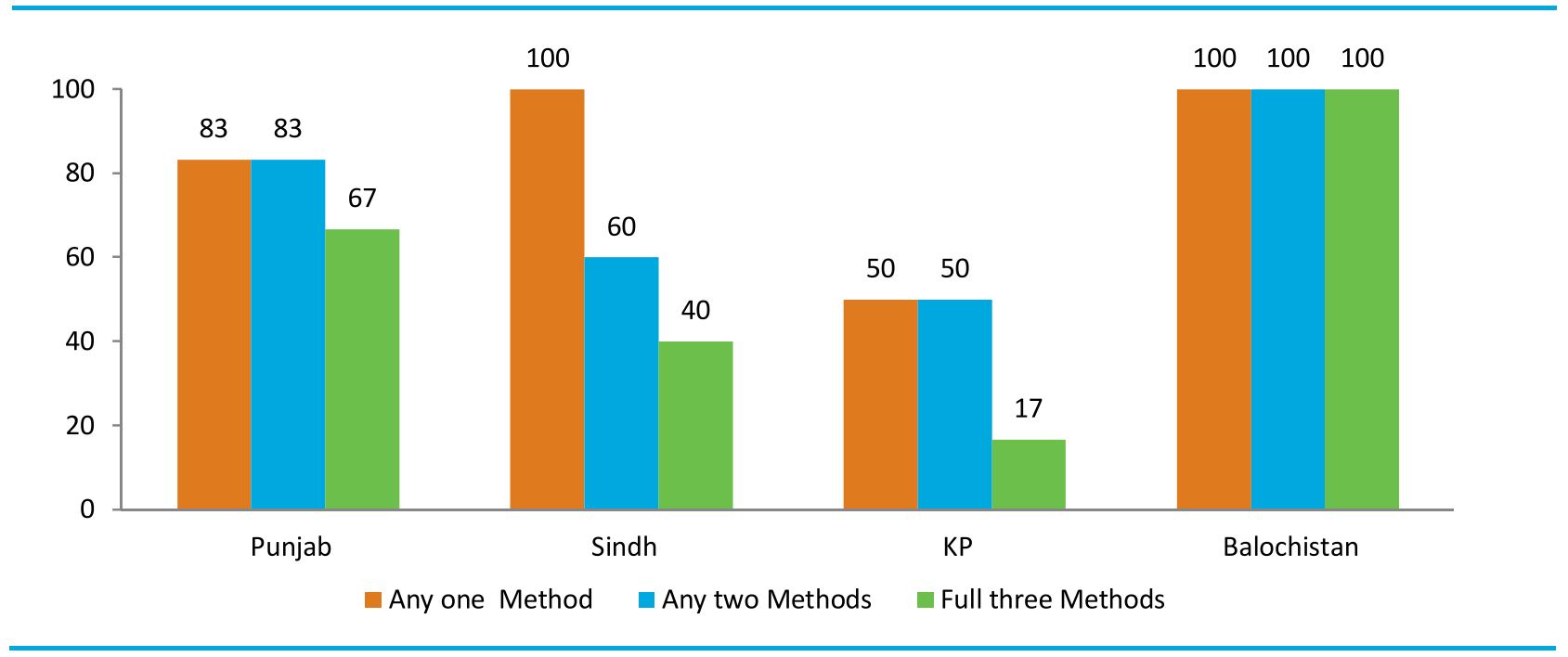

Source: Interviews with LHWs.

\section{Stock Availability by Number of Methods}

Since LHWs are the primary sources of condoms, injectables and oral contraceptive pills for some of the poorest and most underserved communities, it is very important that sufficient stocks of these commodities be available with them at all times and stock-outs be minimized.

Figure 4.9 shows the availability of contraceptive stocks across 23 LHWs included in this study. LHWs from Punjab appear to be best equipped with stocks of pills and injectables across the provinces. KP follows, with slightly more than four-fifths of LHWs having stocks of condoms and pills available. However, only a third of LHWs in Balochistan had condoms and injectables; the rest were out of stock of both commodities. Almost half the LHWs in KP and three-fifths of LHWs in Sindh had stock-outs of injectables.

Figure 4.9: Availability of Contraceptives with LHWs on the Day of the Visit

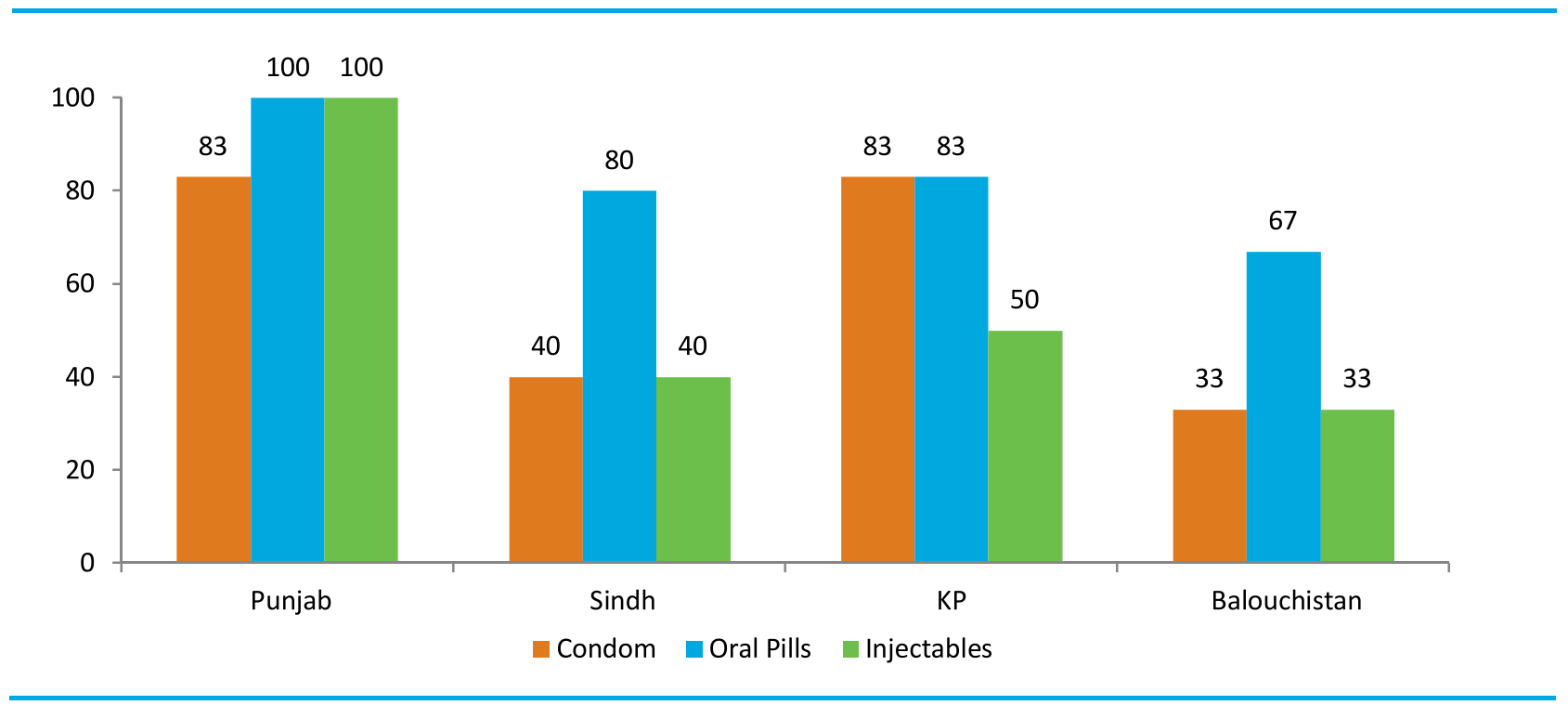

Source: Interviews with LHWs. 
Availability of all three contraceptive methods with LHWs should have a great impact on their performance by offering their clients significantly more choice. Figure 4.10 shows that none of the LHWs interviewed had all three methods available in Balochistan. All LHWs in Punjab, 83 percent in KP, and 60 percent in Sindh did have two methods available, compared to 67 percent in Balochistan.

Figure 4.10: Choice of Contraceptive Method Mix Available with LHWs on the Day of Visit, by Province

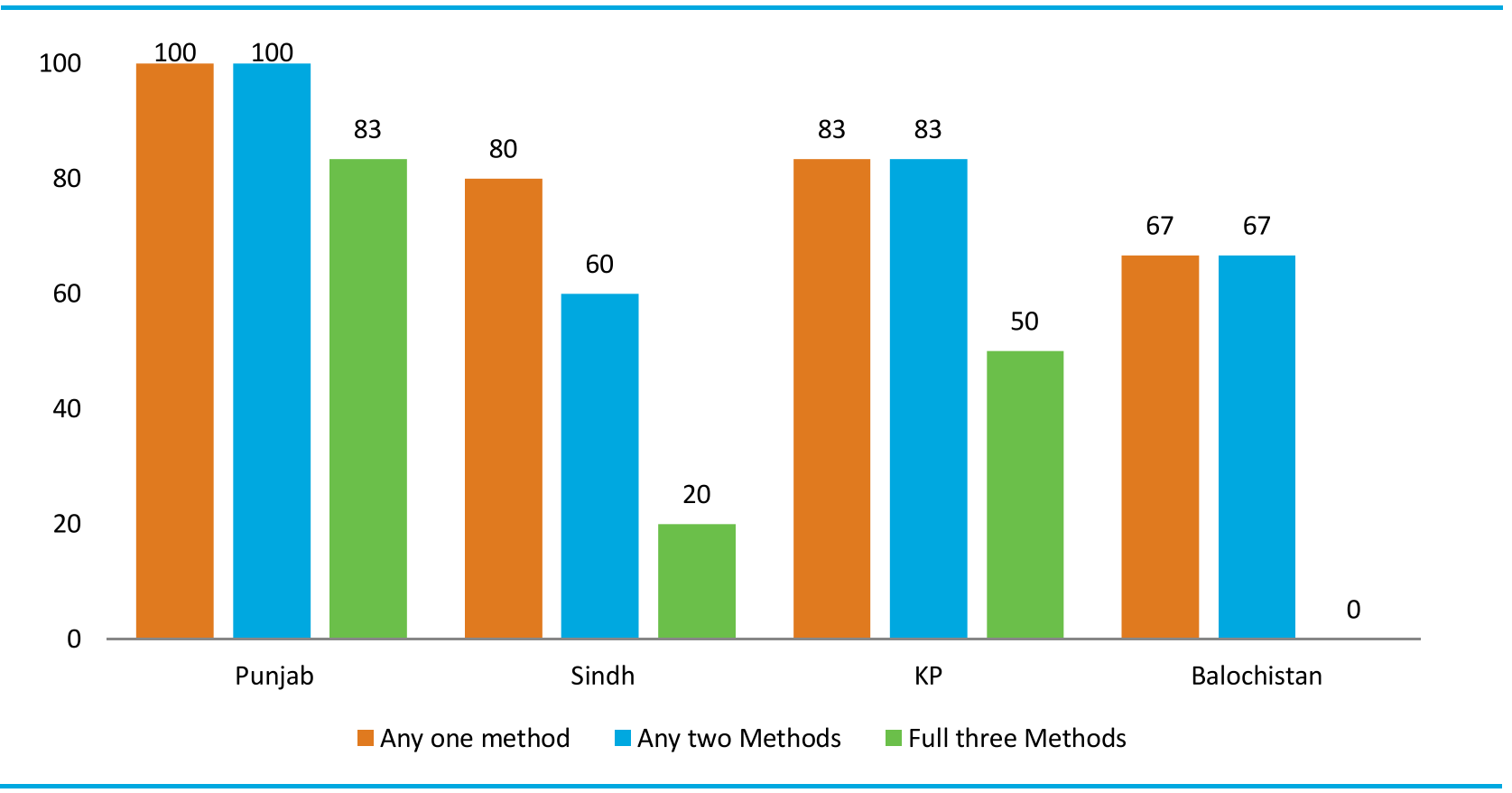

Source: Interviews with LHWs.

\section{Conclusions}

The reason for late supply of contraceptives to district stores was identified as incorrect or late submission of the requisition form, CLR-6, from districts facilities to the Central Warehouse. In the majority of the public district stores, commodities are not delivered to the SDPs but their representatives do visit and collect these methods from district stores, which is a major issue for SDPs located in remote areas. Private SDPs do not have a formal structure for receiving contraceptive supplies from the public sector, except a few NGOs, which receive contraceptives at their regional stores from the Central Warehouse and supply these onwards to their facilities. Pharmacies are the major contraceptive source for most private sector SDPs.

The survey revealed that despite availability of sufficient contraceptive stocks at most of the district stores, breakdown in supply for all four methods was reported at public SDPs of DoH, specifically in Pishin and Sibi in Balochistan, and Khanewal in Punjab. In Punjab, apart from DHQ hospitals, stock-outs for more than one method occurred at $\mathrm{MCH}$ centres, In KP, RHC-level facilities reported stock-out of more than one method, while stock-outs of one method was reported at THQ hospitals, MCHs and BHUs. The poor contraceptive requisitioning and distribution mechanism is considered to be the main reason for irregular and insufficient supply to facilities. Public DHQ hospitals have the least availability of contraceptive methods. This seems to be an administrative issue as DHQ hospitals are not under jurisdiction of the EDO-H but the Medical

Superintendent in charge of the hospital. Medical Superintendents neither request contraceptive supplies from the EDO-H nor do they submit any separate requisitions to $\mathrm{CWH}$.

In some situations, public sector facilities are forced to arrange supplies from the alternative sources. The highest incidence of such arrangements for all methods was reported by public $\mathrm{MCH}$ centres, which procured 
from pharmacies, while public DHQ and THQ hospitals facing contraceptive stock-outs refer their clients to other facilities, especially RHS-A centres located in their premises even where there is availability of contraceptive methods at public SDPs, the reported rate of utilization is low, especially at RHCs, which only seem to stock but not to record utilization of contraceptive methods.

The availability of the full range of contraceptives is important to optimize clients' ability to choose and continue their preferred family planning method. Despite availability of a full range of all four methods at District stores in Pishin and Sibi (Balochistan), none of the DoH facilities in Pishin had all four methods. In Sibi only 29 percent of DoH SDPs had all four methods available. Similarly a large number of DoH facilities in the other three provinces had a similar problem of non-availability of the full range of all four methods.

The supply of contraceptives to LHWs seems significantly deficient, as all interviewed LHWs in Balochistan and Sindh had experienced stock-outs of all three methods during the year preceding the survey. Moreover, none of the interviewed LHWs had all three methods available on the day they were visited by the study team. This finding indicates that supply issues are likely to be an important factor impeding the ability of the LHWs to ensure that clients are able to start and continue with a modern method of their choice. 


\section{Readiness of Health Facilities for Family Planning Service Provision}

- Public health facilities often maintain short working hours, which minimize the time window available to users to access services. This is a serious concern in rural areas, where the heavy workloads, restricted mobility and lower availability of transportation can make it nearly impossible for women to reach facilities before 2:00 PM, when the facilities close.

- RHCs are mandated to provide round-the-clock services seven days a week. However, far from working $24 / 7$, nearly half of them do not even provide services in the evenings.

- LHVs are the most available cadre for catering to women's family planning needs at all types of public health facilities. Their availability is $100 \%$ at DHQ and THQ hospitals, and $91 \%$ at RHCs.

- A large proportion of sanctioned posts for Women Medical Officers (WMOs) is currently vacant at all types of public health facilities. This leaves health facilities with a gap of female providers as well as technical expertise.

- In the public sector, female service providers are mainly present in the morning sessions; their presence shrinks to a minimal level in the evening sessions.

- In the evenings, far more private sector facilities are available to meet family planning needs than public sector facilities. However, not everyone can afford private care. 


\section{Readiness of Health Facilities for Family Planning Service Provision}

The availability of certain elements, such as qualified staff, basic amenities, equipment, and infection prevention arrangements, is a prerequisite for provision of health and family planning services by health facilities. In its situation analysis of 185 public- and private-sector health facilities in 8 districts, ranging in scale from basic health units to DHQ hospitals, the study team assessed the facilities' readiness for FP service provision in terms of the following indicators:

- Availability of basic infrastructure, such as electricity;

- Availability of general medical equipment;

- Infection prevention arrangements;

- Availability of IUCD insertion kits;

- Appointment of technical staff; and

- Facility timings and availability of technical staff.

The objective of this assessment, presented in the first part of this section, is to learn about the capacities of health facilities and identify the gaps that affect service provision. The analysis has been carried out at the level of facilities, by district as well as by sector (private or public). Notably, public sector facilities are mainly associated with one of two provincial departments: the Department of Health (DoH) and the Population Welfare Department (PWD). Where applicable, the analysis looks at DoH- and PWD-affiliated facilities separately.

In the second part of the section, the findings concerning the availability of infrastructure, staff, systems and equipment, are correlated with the findings indicated in section of availability of contraceptive Stock, regarding availability of contraceptives, to develop a complete picture of overall readiness of health facilities for family planning service provision.

\section{Infrastructure}

Infrastructure and amenities affect facility readiness and performance. An uninterrupted electric supply is imperative for a facility to be fully functional, especially in emergency cases. Running water is another must. Sometimes, clients have to wait for a long time for consultations and examinations, so the waiting area must be protected from the sun and rain; since purdah remains a norm in many parts of the country, a separate waiting area for women is also essential. In addition, toilets for patients, especially women, are necessary.

Table 5.1 shows the status of infrastructure availability at different levels of health facilities in the public and private sectors. The data suggests that the private sector is performing better in this respect than the public sector at all levels. In the public sector, large facilities, including DHQ hospitals, RHS-As and THQ hospitals, have most of the amenities available, while RHCs, BHUs, MCHs and FWCs have relatively fewer amenities available. It is also notable that RHCs, despite being higher-level facilities than BHUs, have fewer amenities, which is because BHUs are attached with different public entities, i.e., PPHI/PRSP. Generally, a separate waiting area for females is less available at public $\mathrm{DoH}$ facilities. 
Table 5.1: Availability of Necessary Infrastructure and Amenities for Family Planning by Type of Facility and Sector

\begin{tabular}{|c|c|c|c|c|c|c|}
\hline & \multicolumn{5}{|c|}{$\%$ of Health Facilities } & \multirow[b]{2}{*}{$\begin{array}{c}\text { Total } \\
\text { Number of } \\
\text { Facilities }\end{array}$} \\
\hline & $\begin{array}{c}\text { Running } \\
\text { water }\end{array}$ & $\begin{array}{c}\text { Toilet for } \\
\text { clients with } \\
\text { water }\end{array}$ & Electricity & $\begin{array}{c}\text { Waiting } \\
\text { room/veranda }\end{array}$ & $\begin{array}{c}\text { Separate } \\
\text { waiting area } \\
\text { for women }\end{array}$ & \\
\hline \multicolumn{7}{|l|}{ Public } \\
\hline DHQ & 100 & 100 & 100 & 88 & 75 & 8 \\
\hline RHS-A & 100 & 89 & 100 & 100 & 100 & 9 \\
\hline THQ & 100 & 100 & 100 & 100 & 71 & 7 \\
\hline RHC & 73 & 67 & 87 & 93 & 73 & 15 \\
\hline $\mathrm{BHU} *$ & 94 & 79 & 88 & 94 & 73 & 33 \\
\hline $\mathrm{MCH}$ & 93 & 87 & 87 & 93 & 73 & 15 \\
\hline FWC & 93 & 83 & 90 & 73 & 73 & 41 \\
\hline \multicolumn{7}{|c|}{ Private (Equivalent)* * } \\
\hline DHQ & 100 & 100 & 100 & 100 & 100 & 3 \\
\hline THQ & 100 & 86 & 100 & 100 & 86 & 7 \\
\hline RHC & 100 & 100 & 100 & 100 & 88 & 16 \\
\hline BHU & 97 & 90 & 97 & 97 & 77 & 31 \\
\hline Total $(\mathrm{N})$ & 94 & 86 & 93 & 91 & 74 & 185 \\
\hline
\end{tabular}

Source: Inventory of health facilities.

*BHUs are attached with PPHI in KP, Sindh and Balochistan and with PRSP in Punjab.

**Private facilities were categorized by number of beds: $0-4$ beds $\equiv$ BHU, $5-19$ beds $\equiv$ RHC, $20-80$ beds $\equiv$ THQ, 81 and more beds $\equiv$ DHQ.

Table 5.2 indicates the situation of infrastructure at health facilities across districts and sectors. Overall, most of the services related to infrastructure are available. By and large, KP has a high availability of all the infrastructural facilities and amenities in both public and private sectors compared with other provinces. The situation in Punjab and Sindh is also satisfactory in terms of availability of running water, toilets with water, electricity and a general waiting area. In districts of Balochistan, particularly Pishin, the situation is slightly compromised and facilities of running water, toilets with water, electricity, and a waiting area for women are less available than in other districts.

Although, there is a waiting area for clients at all facilities, there is no separate waiting area for females at DoH facilities, particularly in Punjab. The proportion of facilities with a waiting area and a separate area for women is the same for RHS-As and FWCs because only women can visit these facilities.

In most districts, facilities under PWD and DoH have nearly the same level of amenities available. Compared to the public sector, the private sector offers better infrastructure availability across all districts, except in the case of separate waiting areas for women in the two districts of Punjab. While amenities are lacking at PWD and DoH facilities in Balochistan, they are almost all available at private sector facilities in the province.

In terms of availability of all elements of infrastructure by district and sector, PWD facilities in Khanewal top the list. The highest proportion of DoH facilities with all five amenities is in Khairpur. In KP and Balochistan, no facility has all five elements of infrastructure available, which indicates the shortage of amenities in specific districts and sectors. 
Table 5.2: Availability of Necessary Infrastructure and Amenities for Family Planning by Sector, and District

\begin{tabular}{|c|c|c|c|c|c|c|c|c|}
\hline & & & & $\%$ of Health & acilities & & & \\
\hline & & $\begin{array}{l}\text { Running } \\
\text { water }\end{array}$ & 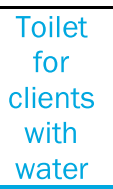 & Electricity & $\begin{array}{c}\text { Waiting } \\
\text { room/veranda }\end{array}$ & $\begin{array}{c}\text { Separate } \\
\text { waiting } \\
\text { area for } \\
\text { females }\end{array}$ & $\begin{array}{c}\text { All } 5 \\
\text { amenities } \\
\text { available, } \\
\% \text { of } \\
\text { facilities }\end{array}$ & $\begin{array}{c}\text { Total } \\
\text { Number } \\
\text { of } \\
\text { Facilities }\end{array}$ \\
\hline \multicolumn{9}{|l|}{ Punjab } \\
\hline \multirow[t]{3}{*}{ Khanewal } & $\mathrm{DoH}^{*}$ & 90 & 90 & 90 & 80 & 60 & 10 & 10 \\
\hline & PWD & 100 & 88 & 100 & 63 & 75 & 38 & 8 \\
\hline & Private & 100 & 89 & 100 & 100 & 67 & 33 & 9 \\
\hline \multirow[t]{3}{*}{ Rahim Yar Khan } & DoH & 100 & 100 & 100 & 100 & 70 & 0 & 10 \\
\hline & PWD & 88 & 75 & 88 & 75 & 63 & 0 & 8 \\
\hline & Private & 88 & 75 & 88 & 88 & 50 & 13 & 8 \\
\hline \multicolumn{9}{|l|}{ Sindh } \\
\hline \multirow[t]{3}{*}{ Khairpur } & DoH & 100 & 90 & 90 & 100 & 80 & 30 & 10 \\
\hline & PWD & 100 & 100 & 83 & 100 & 50 & 17 & 6 \\
\hline & Private & 100 & 89 & 100 & 100 & 89 & 22 & 9 \\
\hline \multirow[t]{3}{*}{ Umerkot } & DoH & 80 & 70 & 90 & 100 & 80 & 10 & 10 \\
\hline & PWD & 100 & 88 & 88 & 75 & 50 & 0 & 8 \\
\hline & Private & 100 & 100 & 100 & 100 & 100 & 25 & 8 \\
\hline \multicolumn{9}{|l|}{ KP } \\
\hline \multirow[t]{3}{*}{ Mansehra } & DoH & 100 & 100 & 100 & 90 & 70 & 0 & 10 \\
\hline & PWD & 100 & 83 & 100 & 100 & 100 & 0 & 6 \\
\hline & Private & 100 & 100 & 100 & 100 & 75 & 0 & 8 \\
\hline \multirow[t]{3}{*}{ Mardan } & DoH & 100 & 91 & 100 & 100 & 100 & 0 & 11 \\
\hline & PWD & 100 & 100 & 100 & 100 & 100 & 0 & 5 \\
\hline & Private & 100 & 100 & 100 & 100 & 100 & 0 & 8 \\
\hline \multicolumn{9}{|l|}{ Balochistan } \\
\hline \multirow[t]{3}{*}{ Pishin } & DoH & 80 & 40 & 60 & 80 & 30 & 0 & 10 \\
\hline & PWD & 75 & 75 & 100 & 50 & 0 & 0 & 4 \\
\hline & Private & 100 & 100 & 100 & 100 & 100 & 0 & 5 \\
\hline \multirow[t]{3}{*}{ Sibi } & DoH & 71 & 71 & 86 & 100 & 100 & 0 & 7 \\
\hline & PWD & 80 & 60 & 80 & 60 & 60 & 0 & 5 \\
\hline & Private & 100 & 100 & 100 & 100 & 100 & 0 & 2 \\
\hline Total (N) & & 94 & 86 & 93 & 91 & 74 & 9 & 185 \\
\hline
\end{tabular}

Source: Inventory of health facilities.

*DoH also includes BHUs attached with PPHI in KP, Sindh and Balochistan and with PRSP in Punjab. 


\section{General Medical Equipment}

It is essential that some general equipment for physical examination be available, including a weighing scale, stethoscope, blood pressure (BP) measuring apparatus, and examination lamp and table for any facility to provide sound health care and family planning services. In particular, for readiness for FP service provision, a lamp is vital for pelvic examination and IUCD insertion, while BP apparatus is necessary to check blood pressure and identify contraindications before dispensing hormonal methods.

Table 5.3 describes the situation of availability of this basic functional equipment at the health facilities visited comparing public and private facilities. It is important to note that physical availability of any equipment does not serve the purpose unless it is in a functional form; thus, the figures shown below are for functional equipment only.

Generally, private facilities are well equipped, except in terms of examination lamps, which are lacking at all levels of facilities. Most public facilities have available stethoscopes and examination tables/couches.

However, other necessary equipment, such as examination lamps and adult weighing scales, is less available throughout the facilities, even at DHQ level. Availability of BP apparatus is also low, particularly at RHCs and MCHs. BHUs attached with PPHI/PRSP are again better than RHCs in having availability of adult weighing scales, stethoscopes and BP apparatus and only lack examination lamps. Facilities of PWD, including both RHS-As and FWCs, have a conspicuous deficiency of examination lamps and BP apparatus, indicating that they are not fully prepared to provide family planning services.

For both the public and the private sectors, the non-availability of examination lamps and BP apparatus is a concern because it signifies that a client who needs an IUCD or a hormonal method will either be provided the required method without screening or will return without having receiving services.

Table 5.3: Availability of Functional General Examination Equipment by Level of Facilities

\begin{tabular}{|c|c|c|c|c|c|c|}
\hline \multicolumn{6}{|c|}{$\%$ of Health Facilities } & \multirow[b]{2}{*}{$\begin{array}{c}\text { Total } \\
\text { Number of } \\
\text { Facilities }\end{array}$} \\
\hline & $\begin{array}{l}\text { Examination } \\
\text { lamp }\end{array}$ & $\begin{array}{c}\text { Adult } \\
\text { weighing scale }\end{array}$ & Stethoscope & $\begin{array}{c}\text { BP } \\
\text { apparatus }\end{array}$ & $\begin{array}{l}\text { Examination } \\
\text { table/couch }\end{array}$ & \\
\hline \multicolumn{7}{|l|}{ Public } \\
\hline $\mathrm{DHQ}$ & 75 & 75 & 100 & 100 & 100 & 8 \\
\hline RHS-A & 67 & 67 & 100 & 56 & 100 & 9 \\
\hline THQ & 57 & 71 & 100 & 100 & 100 & 7 \\
\hline $\mathrm{RHC}$ & 60 & 73 & 80 & 73 & 100 & 15 \\
\hline $\mathrm{BHU} *$ & 36 & 79 & 97 & 91 & 94 & 33 \\
\hline $\mathrm{MCH}$ & 33 & 73 & 80 & 67 & 93 & 15 \\
\hline FWC & 71 & 61 & 90 & 71 & 93 & 41 \\
\hline \multicolumn{7}{|c|}{ Private (Equivalent)** } \\
\hline $\mathrm{DHQ}$ & 67 & 67 & 100 & 100 & 100 & 3 \\
\hline THQ & 71 & 100 & 100 & 100 & 100 & 7 \\
\hline $\mathrm{RHC}$ & 81 & 100 & 100 & 100 & 100 & 16 \\
\hline $\mathrm{BHU}$ & 42 & 52 & 81 & 84 & 87 & 31 \\
\hline Total (N) & 56 & 71 & 91 & 82 & 95 & 185 \\
\hline
\end{tabular}

Source: Inventory of health facilities.

*BHUs are attached with PPHI in KP, Sindh and Balochistan and with PRSP in Punjab.

** Private facilities were categorized by number of beds: $0-4$ beds $\equiv$ BHU, $5-19$ beds $\equiv$ RHC, $20-80$ beds $\equiv T H Q, 81$ and more beds $\equiv$ DHQ. 
Table 5.4 provides a picture of the availability of functional basic medical equipment in provinces and districts. Overall, health facilities from almost all provinces have stethoscopes and examination tables, but regional and sectorial variation is observed in the availability of examination lamps and BP apparatus. Health facilities of PWD and the private sector in KP are better equipped than other provinces. Availability of both lamps and BP apparatus is also better in DoH facilities in Punjab. However, DoH facilities in all other provinces lack these essential components, particularly in Pishin. Moreover, the majority of PWD facilities do not have these two pieces of equipment in Rahim Yar Khan, Umerkot, and Pishin.

Unexpectedly, private sector facilities in Punjab and Sindh are also less equipped, although their situation in $\mathrm{KP}$ and Balochistan is satisfactory. The proportion of facilities that have all five items of general equipment available is highest among private facilities in Sibi, followed by private facilities in Pishin, Mansehra and Mardan.

Table 5.4: Availability of Functional General Examination Equipment by District and Sector

\begin{tabular}{|c|c|c|c|c|c|c|c|c|}
\hline \multicolumn{9}{|c|}{$\%$ of Health Facilities } \\
\hline & & $\begin{array}{l}\text { Examination } \\
\text { lamp }\end{array}$ & $\begin{array}{c}\text { Adult } \\
\text { weighing } \\
\text { scale }\end{array}$ & Stethoscope & $\begin{array}{c}\text { BP } \\
\text { apparatus }\end{array}$ & $\begin{array}{l}\text { Examination } \\
\text { table/couch }\end{array}$ & $\begin{array}{c}\text { All } 5 \\
\text { components, } \\
\% \text { of } \\
\text { facilities }\end{array}$ & $\begin{array}{c}\text { Total } \\
\text { Number } \\
\text { of } \\
\text { Facilities }\end{array}$ \\
\hline \multicolumn{9}{|l|}{ Punjab } \\
\hline \multirow[t]{3}{*}{ Khanewal } & $\mathrm{DoH}^{*}$ & 70 & 70 & 80 & 80 & 100 & 60 & 10 \\
\hline & PWD & 88 & 63 & 100 & 50 & 100 & 25 & 8 \\
\hline & Private & 67 & 56 & 78 & 78 & 78 & 56 & 9 \\
\hline \multirow{3}{*}{$\begin{array}{l}\text { Rahim Yar } \\
\text { Khan }\end{array}$} & DoH & 60 & 90 & 100 & 100 & 90 & 60 & 10 \\
\hline & PWD & 50 & 13 & 100 & 50 & 100 & 0 & 8 \\
\hline & Private & 50 & 50 & 75 & 75 & 75 & 38 & 8 \\
\hline \multicolumn{9}{|l|}{ Sindh } \\
\hline \multirow[t]{3}{*}{ Khairpur } & DoH & 0 & 60 & 80 & 80 & 100 & 0 & 10 \\
\hline & PWD & 83 & 100 & 100 & 67 & 100 & 67 & 6 \\
\hline & Private & 22 & 78 & 100 & 100 & 100 & 22 & 9 \\
\hline \multirow[t]{3}{*}{ Umerkot } & DoH & 60 & 90 & 90 & 90 & 90 & 40 & 10 \\
\hline & PWD & 50 & 63 & 75 & 75 & 75 & 25 & 8 \\
\hline & Private & 25 & 63 & 75 & 88 & 100 & 25 & 8 \\
\hline \multicolumn{9}{|l|}{ KP } \\
\hline \multirow[t]{3}{*}{ Mansehra } & $\mathrm{DoH}$ & 70 & 90 & 100 & 90 & 100 & 60 & 10 \\
\hline & PWD & 83 & 67 & 100 & 100 & 100 & 67 & 6 \\
\hline & Private & 75 & 88 & 100 & 100 & 100 & 75 & 8 \\
\hline \multirow[t]{3}{*}{ Mardan } & DoH & 55 & 100 & 100 & 91 & 100 & 45 & 11 \\
\hline & PWD & 80 & 60 & 100 & 100 & 100 & 40 & 5 \\
\hline & Private & 88 & 75 & 100 & 100 & 100 & 75 & 8 \\
\hline \multicolumn{9}{|l|}{ Balochistan } \\
\hline \multirow[t]{3}{*}{ Pishin } & DoH & 20 & 30 & 90 & 70 & 90 & 20 & 10 \\
\hline & PWD & 25 & 75 & 75 & 75 & 75 & 25 & 4 \\
\hline & Private & 80 & 100 & 100 & 100 & 100 & 80 & 5 \\
\hline \multirow[t]{3}{*}{ Sibi } & DoH & 29 & 71 & 86 & 71 & 100 & 29 & 7 \\
\hline & PWD & 100 & 80 & 80 & 40 & 100 & 40 & 5 \\
\hline & Private & 100 & 100 & 100 & 100 & 100 & 100 & 2 \\
\hline Total (N) & & 56 & 71 & 91 & 82 & 95 & 42 & 185 \\
\hline
\end{tabular}

Source: Inventory of health facilities.

* DoH facilities include BHUs attached with PPHI in KP, Sindh and Balochistan and with PRSP in Punjab. 


\section{Infection Prevention Measures}

Adequate infection prevention measures are essential for good service provision by health facilities, and are indicated by the availability of at least a container for chlorine solution, disinfection solution, and a sterilizer. If a facility offers surgery services, it must also have an autoclave. Facilities lacking these elements are technically not fully prepared to provide health services.

Table 5.5 shows the proportion of facilities that have infection prevention measure available. Overall, private health facilities, particularly those equivalent to DHQ hospitals, THQ hospitals and RHCs, exhibit better availability of infection prevention equipment than public health facilities of the same level.

Among public health facilities, RHS-As have most of the required infection prevention arrangements available, with over three-fourths of the facilities having sterilizers and autoclaves, and almost all of them having disinfection solution and chlorine containers. However, other larger health facilities, such as DHQ and THQ hospitals, significantly lack in these measures, particularly in availability of autoclaves and containers for chlorine solutions. Most importantly, the situation at the level of RHCs as well as PPHI/PRSP facilities (BHUs) is even worse, with more than half of the facilities lacking all elements of infection prevention measures.

Table 5.5: Availability of Infection Prevention Arrangements by Facility Level

\begin{tabular}{lccc|c}
\hline & \multicolumn{3}{c|}{ \% of Health Facilities } & \\
\hline Level of Facilities: & Autoclave & Disinfection solution & Sterilizer & $\begin{array}{c}\text { Total Number of } \\
\text { Facilities }\end{array}$ \\
\hline Public & & & & \\
DHQ & 50 & 88 & 75 & 8 \\
RHS-A & 78 & 89 & 78 & 9 \\
THQ & 71 & 86 & 71 & 7 \\
RHC & 40 & 47 & 47 & 15 \\
BHU* & 27 & 55 & 48 & 33 \\
MCH & 27 & 60 & 60 & 15 \\
FWC & 10 & 73 & 73 & 41 \\
Private (Equivalent)** & & & & \\
DHQ & 100 & 67 & 67 & 3 \\
THQ & 86 & 100 & 100 & 7 \\
RHC & 75 & 88 & 88 & 16 \\
BHU & 13 & 52 & 48 & 31 \\
Total (N) & 35 & 67 & 64 & $\mathbf{1 8 5}$ \\
\hline
\end{tabular}

Source: Inventory of health facilities.

*BHUs are attached with PPHI in KP, Sindh and Balochistan and with PRSP in Punjab.

**Private facilities were categorized by number of beds: 0-4 beds $\equiv \mathrm{BHU}, 5-19$ beds $\equiv \mathrm{RHC}, 20-80$ beds $\equiv \mathrm{THQ}, 81$ and more beds $\equiv \mathrm{DHQ}$.

Table 5.6 shows the status of availability of infection prevention measures by sector and across districts. No district or province offers a full or even high capacity to provide complete infection prevention measures. Facilities in Balochistan are the least prepared in this respect.

In the public sector, PWD facilities exhibit a relatively better level of infection prevention measures in almost all districts except Pishin, where no facility has an autoclave available. Infection prevention measures are far less available at DoH facilities across all districts, and particularly in Khairpur, Mansehra, Pishin and Sibi. The situation of private facilities is more or less the same across the eight districts, with generally more than half the facilities having infection prevention measures available. 
While the non-availability of an autoclave may be explained by the fact that a facility does not perform surgeries, absence of a sterilizer, disinfection solution and a container this solution is inexcusable for any type of health facility. Yet, Table 5.6 shows that a significant proportion of facilities across all districts and sectors lack sterilizers and even containers for chlorine solution and disinfectant. This points to a serious gap in the quality of existing family planning services in terms of infection prevention.

The highest proportion of facilities having all four infection prevention measures available is to be found in Sindh and KP, mainly due to the private sector. Balochistan lags far behind other provinces in this respect: except for 20 percent of private facilities in Pishin, no health facility has all these measures available.

\section{Table 5.6: Availability of Infection Prevention Arrangements by Sector and Districts}

\begin{tabular}{|c|c|c|c|c|c|c|}
\hline & & & f Health Facili & & & \\
\hline & & Autoclave & $\begin{array}{l}\text { Disinfection } \\
\text { solution }\end{array}$ & Sterilizer & $\begin{array}{l}\text { All } 4 \text { measures } \\
\text { available }\end{array}$ & $\begin{array}{l}\text { Total Number of } \\
\text { Facilities }\end{array}$ \\
\hline \multicolumn{7}{|l|}{ Punjab } \\
\hline \multirow[t]{3}{*}{ Khanewal } & $\mathrm{DoH}^{*}$ & 30 & 60 & 80 & 30 & 10 \\
\hline & PWD & 25 & 100 & 88 & 25 & 8 \\
\hline & Private & 33 & 67 & 56 & 22 & 9 \\
\hline \multirow[t]{3}{*}{$\begin{array}{l}\text { Rahim Yar } \\
\text { Khan }\end{array}$} & DoH & 50 & 70 & 70 & 30 & 10 \\
\hline & PWD & 13 & 100 & 38 & 0 & 8 \\
\hline & Private & 50 & 63 & 38 & 25 & 8 \\
\hline \multicolumn{7}{|l|}{ Sindh } \\
\hline \multirow[t]{3}{*}{ Khairpur } & $\mathrm{DoH}$ & 20 & 70 & 20 & 10 & 10 \\
\hline & PWD & 33 & 67 & 100 & 17 & 6 \\
\hline & Private & 56 & 56 & 67 & 56 & 9 \\
\hline \multirow[t]{3}{*}{ Umerkot } & DoH & 20 & 50 & 50 & 20 & 10 \\
\hline & PWD & 38 & 75 & 75 & 38 & 8 \\
\hline & Private & 38 & 63 & 63 & 38 & 8 \\
\hline \multicolumn{7}{|l|}{ KP } \\
\hline \multirow[t]{3}{*}{ Mansehra } & DoH & 50 & 40 & 50 & 20 & 10 \\
\hline & PWD & 17 & 83 & 83 & 17 & 6 \\
\hline & Private & 25 & 88 & 75 & 25 & 8 \\
\hline \multirow[t]{3}{*}{ Mardan } & DoH & 82 & 73 & 73 & 36 & 11 \\
\hline & PWD & 20 & 60 & 100 & 20 & 5 \\
\hline & Private & 63 & 63 & 88 & 38 & 8 \\
\hline \multicolumn{7}{|l|}{ Balochistan } \\
\hline \multirow[t]{3}{*}{ Pishin } & DoH & 20 & 70 & 50 & 0 & 10 \\
\hline & PWD & 0 & 75 & 75 & 0 & 4 \\
\hline & Private & 60 & 100 & 80 & 20 & 5 \\
\hline \multirow[t]{3}{*}{ Sibi } & DoH & 0 & 43 & 43 & 0 & 7 \\
\hline & PWD & 20 & 20 & 40 & 0 & 5 \\
\hline & Private & 0 & 50 & 100 & 0 & 2 \\
\hline Total (N) & & 35 & 67 & 64 & 22 & 185 \\
\hline
\end{tabular}

Source: Inventory of health facilities.

* DoH facilities also include BHUs attached with PPHI in KP, Sindh and Balochistan and with PRSP in Punjab. 


\section{Availability of IUCD Insertion Kits}

Proper IUCD insertion requires a complete IUCD kit, including an examination lamp on a stand, straight dressing scissors, a vaginal speculum, a vulsellum forceps, a uterine sound, sponge-holding forceps, bowls, a tenaculum, a kidney tray and sterilizers. Where a family planning services facility does not have the complete kit, it should at the very least have the "essential" kit, consisting of the seven of the above-listed items (i.e., all the above except bowls, a tenaculum and a kidney tray).

Table 5.7 shows the situation of availability of both essential and complete IUCD kits at different levels of public and private facilities. Overall, the situation of availability of the complete IUCD kit is alarming: 71 percent of public and private facilities do not have this kit. More than half of the facilities do not even have the essential IUCD kits.

Public facilities lag behind the private sector in this respect. Within different public facilities, RHS-As and FWCs belonging to the PWD, fare slightly better than other facilities. The situation of availability of the essential IUCD kit at PPHI/PRSP facilities also indicates a serious gap: these facilities, where rural women seek services, are not ready to meet their family planning needs. Generally, neither public nor private facilities are fully prepared to provide IUCD services.

Table 5.7: Availability of Essential/Complete IUCD Insertion Kit by Level of Facility

\begin{tabular}{lcc|c}
\hline \multicolumn{2}{c}{$\%$ of Health Facilities } \\
\hline Level of Facilities: & Essential Kit & Complete Kit & Total Number of Facilities \\
\hline Public & 50 & & \\
DHQ & 56 & 38 & 8 \\
RHS-A & 43 & 44 & 9 \\
THQ & 40 & 29 & 7 \\
RHC & 21 & 33 & 15 \\
BHU* & 27 & 12 & 33 \\
MCH & 49 & 27 & 15 \\
FWC & & 27 & 41 \\
Private (Equivalent)** & 33 & & \\
DHQ & 71 & 33 & 3 \\
THQ & 56 & 57 & 7 \\
RHC & 29 & 50 & 16 \\
BHU & 39 & 26 & 31 \\
Total(N) & & 29 & 185 \\
\hline
\end{tabular}

Source: Inventory of health facilities.

*BHUs are attached with PPHI in KP, Sindh and Balochistan and with PRSP in Punjab.

${ }^{* *}$ Private facilities were categorized by number of beds: $0-4$ beds $\equiv \mathrm{BHU}, 5-19$ beds $\equiv \mathrm{RHC}, 20-80$ beds $\equiv \mathrm{THQ}, 81$ and more beds $\equiv \mathrm{DHQ}$.

Table 5.8 depicts an interesting picture of IUCD insertion kit availability across districts. By and large, KP has a better availability of complete and essential kits than other provinces, particularly in PWD facilities. On the other hand, in the two districts of Punjab, DoH facilities are better equipped than their counterparts in KP. Most surprisingly, there seems to be a complete absence of both complete and essential IUCD kits at DoH facilities in Khairpur and Pishin, raising the question of how women with IUCD needs can be served in these 
districts. Across all districts, PWD facilities are relatively better than DoH facilities in having at least essential IUCD kits available. The overall situation indicates a deficiency in the readiness of health facilities to provide IUCD related services.

Table 5.8: Availability of Essential/Complete IUCD Insertion Kits by Sector and Districts

\begin{tabular}{|c|c|c|c|c|c|}
\hline & & \multicolumn{4}{|c|}{$\%$ of Health Facilities } \\
\hline & & Essential Kit & $\begin{array}{c}\text { Complete } \\
\text { Kit }\end{array}$ & $\begin{array}{l}\text { Neither Complete } \\
\text { nor Essential Kit }\end{array}$ & $\begin{array}{c}\text { Total Number of } \\
\text { Facilities }\end{array}$ \\
\hline \multicolumn{6}{|l|}{ Punjab } \\
\hline & DoH & 50 & 40 & 50 & 10 \\
\hline \multirow[t]{3}{*}{ Khanewal } & PWD & 75 & 25 & 25 & 8 \\
\hline & Private & 67 & 33 & 33 & 9 \\
\hline & DoH & 60 & 20 & 40 & 10 \\
\hline \multirow[t]{2}{*}{ Rahim Yar Khan } & PWD & 25 & 0 & 75 & 8 \\
\hline & Private & 38 & 25 & 63 & 8 \\
\hline \multicolumn{6}{|l|}{ Sindh } \\
\hline & DoH & 0 & 0 & 100 & 10 \\
\hline \multirow[t]{3}{*}{ Khairpur } & PWD & 83 & 67 & 17 & 6 \\
\hline & Private & 22 & 22 & 78 & 9 \\
\hline & DoH & 40 & 30 & 60 & 10 \\
\hline \multirow[t]{2}{*}{ Umerkot } & PWD & 25 & 25 & 75 & 8 \\
\hline & Private & 13 & 0 & 88 & 8 \\
\hline \multicolumn{6}{|l|}{ KP } \\
\hline & DoH & 30 & 30 & 70 & 10 \\
\hline \multirow[t]{3}{*}{ Mansehra } & PWD & 83 & 17 & 17 & 6 \\
\hline & Private & 75 & 63 & 25 & 8 \\
\hline & DoH & 45 & 45 & 55 & 11 \\
\hline \multirow[t]{2}{*}{ Mardan } & PWD & 80 & 60 & 20 & 5 \\
\hline & Private & 75 & 75 & 25 & 8 \\
\hline \multicolumn{6}{|l|}{ Balochistan } \\
\hline & DoH & 0 & 0 & 100 & 10 \\
\hline \multirow[t]{3}{*}{ Pishin } & PWD & 25 & 25 & 75 & 4 \\
\hline & Private & 60 & 40 & 40 & 5 \\
\hline & DoH & 14 & 14 & 86 & 7 \\
\hline \multirow[t]{2}{*}{ Sibi } & PWD & 80 & 40 & 20 & 5 \\
\hline & Private & 50 & 50 & 50 & 2 \\
\hline Total (N) & & 44 & 29 & 56 & 185 \\
\hline
\end{tabular}

Source: Inventory of health facilities.

* DoH also includes BHUs attached with PPHI in KP, Sindh and Balochistan and with PRSP in Punjab. 


\section{Appointment of Technical Staff}

Availability of technical staff is the most crucial factor in enabling health facilities to provide family planning services. A key indicator is the extent to which sanctioned posts for different levels of technical staff are filled through appointment. The number of sanctioned posts for each cadre is determined by the level of the facility and the size of the population that it caters. Whatever the facility's size, unoccupied technical posts reflect gaps in its readiness to provide services.

Table 5.9 depicts the percentage of sanctioned posts filled by different types of service providers at public facilities. This analysis excludes private facilities since there are no defined sanctioned posts and technical staff are posted as per need. There is a notable deficiency of female human health resources and they are critical for family planning services for women in Pakistan, who definitely prefer seeking help from women providers. Almost all PWD sanctioned posts at RHS-As and FWCs are filled. PWD, with which these facilities are associated, has no major staff availability issue. On the other hand, the lowest proportion of filled posts are found for women medical officers (WMOs) and gynaecologists in DoH facilities, although this is the most important cadre in meeting women's family planning needs. A substantial number of sanctioned posts for lady health visitors (LHVs) is filled at all levels of facilities. It is encouraging that at least LHVs are available officially at health facilities as an important source of family planning service provision.

All other categories of paramedical staff are filled at the large facilities, but there is a difference between sanctioned and filled posts at lower level facilities. The situation with human health resources for men is much better. Male staff posts for medical officers (MOs) are almost complete filled at DHQ and BHU level, while there is a significant difference between sanctioned and filled posts at THQ hospitals, RHCs and MCHs. Posts for male health technicians (HTs) are almost all filled at all levels of facilities.

Table 5.9: Filling of Sanctioned Posts for Technical Staff at Public Health Facilities, \% of Facilities ( $N=185)$

\begin{tabular}{ccccccc|cc}
\hline & \multicolumn{7}{c|}{ Female Staff } & \multicolumn{2}{c}{ Male Staff } \\
\cline { 2 - 9 } $\begin{array}{c}\text { Level of } \\
\text { Facilities: }\end{array}$ & Gynaecologist & WMO & LHV & $\begin{array}{c}\text { Nurse/FMT/ } \\
\text { FHT }\end{array}$ & Midwife/CMW & FWC/FWW & MO & $\begin{array}{c}\text { Male(MT/ } \\
\text { HT) }\end{array}$ \\
\hline DHQ & 67 & 72 & 100 & 94 & 97 & na & 89 & 93 \\
RHS-A & 100 & 100 & 0 & 100 & 100 & 88 & na & na \\
THQ & 25 & 31 & 100 & 88 & 80 & na & 48 & 100 \\
RHC & na & 54 & 91 & 78 & 54 & na & 40 & 94 \\
BHU* & na & 70 & 98 & 53 & 62 & na & 100 & 84 \\
MCH & 50 & 89 & 100 & 88 & 82 & na & 67 & 100 \\
FWC & na & na & na & na & na & 80 & na & na \\
Total (\%) & 59 & 64 & 89 & 91 & 75 & 85 & 79 & 90 \\
\hline
\end{tabular}

Source: Inventory of health facilities.

*BHUs are attached with PPHI in KP, Sindh and Balochistan and with PRSP in Punjab. 
Table 5.10 shows the extent of filled posts at public facilities by district. Overall, the situation is better in Punjab and KP, where most of the sanctioned posts are filled, except for WMOs in both provinces. Mainly, posts for gynaecologists and MOs are lying vacant in Sindh, indicating an undue burden on existing staff.

Among all categories of midlevel staff, sanctioned posts are filled across all provinces, indicating that at least LHVs are available to provide FP services and share the burden of the low availability of WMOs in most districts. Most sanctioned posts at PWD facilities are filled in nearly all districts.

Table 5.10: Staffing against Sanctioned Posts for Technical Staff at Public Health Facilities by Sector and Districts, \% of Facilities ( $\mathrm{N}=185)$

\begin{tabular}{|c|c|c|c|c|c|c|c|c|c|}
\hline & & \multicolumn{6}{|c|}{ Female Staff } & \multicolumn{2}{|r|}{ Male Staff } \\
\hline & & \multicolumn{6}{|c|}{ Nurse/FMT } & \multirow[b]{2}{*}{ MO } & \multirow[b]{2}{*}{ Male(MT/HT) } \\
\hline & & Gynaecologist & WMO & LHV & /FHT & Midwife/CMW & FWC/FWW & & \\
\hline \multicolumn{10}{|l|}{ Punjab } \\
\hline \multirow[t]{2}{*}{ Khanewal } & $\mathrm{DoH}$ & 80 & 43 & 100 & 90 & 27 & na & 60 & 33 \\
\hline & PWD & 100 & 0 & 0 & 100 & 0 & 92 & na & na \\
\hline \multirow[t]{2}{*}{$\begin{array}{l}\text { Rahim Yar } \\
\text { Khan }\end{array}$} & $\mathrm{DoH}$ & 50 & 87 & 100 & 98 & 73 & na & 97 & 100 \\
\hline & PWD & 100 & 100 & 0 & 0 & 0 & 85 & na & na \\
\hline \multicolumn{10}{|l|}{ Sindh } \\
\hline \multirow[t]{2}{*}{ Khairpur } & $\mathrm{DoH}$ & 83 & 69 & 100 & 78 & 70 & na & 72 & 80 \\
\hline & PWD & 0 & 100 & 0 & 100 & 0 & 86 & na & na \\
\hline \multirow[t]{2}{*}{ Umerkot } & DoH & 0 & 33 & 97 & 75 & 94 & na & 52 & 100 \\
\hline & PWD & 0 & 100 & 0 & 0 & na & 50 & na & na \\
\hline \multicolumn{10}{|l|}{ KP } \\
\hline \multirow[t]{2}{*}{ Mansehra } & DoH & 50 & 89 & 82 & 87 & 67 & na & 78 & 88 \\
\hline & PWD & 0 & 0 & 0 & 0 & 0 & 100 & na & na \\
\hline \multirow[t]{2}{*}{ Mardan } & DoH & 67 & 36 & 100 & 88 & 100 & na & 50 & 100 \\
\hline & PWD & 0 & 100 & 0 & 0 & 0 & 100 & na & na \\
\hline \multicolumn{10}{|l|}{ Balochistan } \\
\hline \multirow[t]{2}{*}{ Pishin } & DoH & 100 & 79 & 82 & 82 & 50 & na & 62 & 100 \\
\hline & PWD & 0 & 0 & 0 & 0 & 0 & 83 & na & na \\
\hline \multirow[t]{2}{*}{ Sibi } & DoH & 36 & 42 & 67 & 100 & 100 & na & 50 & 50 \\
\hline & PWD & 0 & 0 & 0 & 0 & 0 & 88 & na & na \\
\hline Total (\%) & & 59 & 64 & 98 & 91 & 75 & 85 & 79 & 90 \\
\hline
\end{tabular}

Source: Inventory of health facilities.

*DoH also includes BHUs attached with PPHI in KP, Sindh and Balochistan and with PRSP in Punjab. na $=$ Not applicable. 


\section{Timing and Availability of Technical Staff}

Apart from appointments at key posts, availability of technical staff is depicted by their presence at the facility at the time when they are needed by clients. The timings of technical staff's availability are at least as crucial in determining a health facility's readiness for family planning service provision as the appointment of staff on its team.

Table 5.11 presents the situation of service providers' availability in the morning ( 8 am to $2 \mathrm{pm}$ ) and evening ( 2 to $8 \mathrm{pm}$ ) shifts at the district level. The data suggests that, across the districts, LHVs are the most widely available SPs among all cadres in general and among female providers in particular. LHVs are the most available SPs not only in the morning ( 8 am to $2 \mathrm{pm}$ ) but also in the evening shifts (after $2 \mathrm{pm}$ ). This indicates that LHVs are the main providers current and potential for family planning services.

WMOs are mainly available only in the morning shifts; their number is reduced in the evening shifts. Moreover, although PWD facilities have female SPs, they serve clients only in the mornings and close after $2 \mathrm{pm}$. This greatly limits their availability for women from far-off communities who have to travel long hours to reach them.

Overall, facilities in Punjab and Sindh appear to be better at providing services in both morning and evening shifts. In KP and Balochistan, while SPs of all cadres are available in morning session, they are not frequently available in the evening shifts. This is also the case for male providers.

The sectorial variations in SP availability deserve special attention. While SPs are more likely to be available round the clock in DoH facilities across districts, FP service provision may not be a priority in their work. On the other hand, service providers at PWD facilities, which have an exclusive focus on FP service provision, are only available in the mornings. Both morning and evening availability is provided by SPs in the private sector, but FP is not included in the priority of facilities in this sector. The resultant situation implies that from the point of view of clients the timings of both DoH and PWD facilities need to be expanded in order to widen the options for women with FP needs, particularly those who are poor and have to travel long distances for care.

In addition, the potential of private providers could also be tapped in providing FP services. A study shows that private providers, including male and female MBBS doctors, LHVs and dispensers, have a positive understanding of birth spacing and most provide FP services. Owing to the shortage of LHVs, especially in rural areas, dispensers are providing FP services in rural communities where no other services are available. In fact, dispensers sometimes even provide IUCD services at their clinics, using the services of midwives to deal with female clients. Another important finding of this study is that some private service providers have never provided FP services because they are unsure about their ability to manage side effects, while a few providers used to provide FP services but gave up, mainly due to lack of supply of contraceptives. Such providers can be utilized in the FP effort by providing training in side effect management and contraceptive stocks from the public sector. ${ }^{24}$

\footnotetext{
24 M. Haque, P. Miller, and I. Kamran, Role of Private Sector in Delivering Birth Spacing Services in FALAH Districts (Population Council: Islamabad, 2012).
} 
Table 5.11: Availability of Technical Staff in Morning/Evening Shifts at Health Facilities by Sector and Districts, \% of Facilities ( $N=185$ )

\begin{tabular}{|c|c|c|c|c|c|c|c|c|c|c|c|}
\hline & & \multicolumn{5}{|c|}{ Female Staff } & \multicolumn{4}{|c|}{ Male Staff } & \multirow{3}{*}{$\begin{array}{c}\text { Total } \\
\text { Number } \\
\text { of } \\
\text { Facilities }\end{array}$} \\
\hline & & \multicolumn{2}{|c|}{ WMO } & \multicolumn{2}{|c|}{$\begin{array}{c}\text { LHV/FHT/ } \\
\text { Midwife/Nurse }\end{array}$} & \multirow{2}{*}{$\frac{\text { FWW/FWC/FWA }}{\text { Morning }}$} & \multicolumn{2}{|c|}{ MO } & \multicolumn{2}{|c|}{ Dispenser } & \\
\hline & & Morning & Evening & Morning & Evening & & Morning & Evening & Morning & Evening & \\
\hline \multicolumn{12}{|l|}{ Punjab } \\
\hline \multirow{3}{*}{ Khanewal } & $\mathrm{DoH}$ & 20 & 20 & 100 & 40 & 0 & 70 & 40 & 70 & 40 & 10 \\
\hline & PWD & 13 & 0 & 0 & 0 & 100 & na & na & na & na & 8 \\
\hline & Private & 44 & 33 & 56 & 78 & 0 & 44 & 44 & 33 & 44 & 9 \\
\hline \multirow{3}{*}{$\begin{array}{l}\text { Rahim Yar } \\
\text { Khan }\end{array}$} & DoH & 40 & 30 & 100 & 40 & 0 & 80 & 30 & 80 & 30 & 10 \\
\hline & PWD & 25 & 0 & 0 & 0 & 100 & na & na & na & na & 8 \\
\hline & Private & 38 & 25 & 75 & 50 & 0 & 38 & 38 & 63 & 50 & 8 \\
\hline \multicolumn{12}{|l|}{ Sindh } \\
\hline \multirow{4}{*}{ Khairpur } & DoH & 80 & 10 & 70 & 30 & 0 & 90 & 40 & 80 & 40 & 10 \\
\hline & PWD & 17 & 0 & 17 & 0 & 100 & na & na & na & na & 6 \\
\hline & Private & 33 & 44 & 67 & 56 & 0 & 56 & 56 & 56 & 44 & 9 \\
\hline & $\mathrm{DoH}$ & 30 & 0 & 100 & 50 & 0 & 70 & 20 & 70 & 30 & 10 \\
\hline \multirow[t]{2}{*}{ Umerkot } & PWD & 13 & 0 & 13 & 0 & 100 & na & na & na & na & 8 \\
\hline & Private & 50 & 50 & 75 & 38 & 0 & 63 & 50 & 63 & 50 & 8 \\
\hline \multicolumn{12}{|l|}{ KP } \\
\hline \multirow{4}{*}{ Mansehra } & DoH & 20 & 10 & 70 & 0 & 0 & 70 & 10 & 40 & 10 & 10 \\
\hline & PWD & 0 & 0 & 0 & 0 & 100 & na & na & na & na & 6 \\
\hline & Private & 50 & 25 & 75 & 63 & 0 & 38 & 25 & 38 & 38 & 8 \\
\hline & $\mathrm{DoH}$ & 36 & 9 & 91 & 36 & 0 & 73 & 27 & 55 & 27 & 11 \\
\hline \multirow[t]{2}{*}{ Mardan } & PWD & 20 & 0 & 20 & 0 & 100 & na & na & na & na & 5 \\
\hline & Private & 50 & 13 & 88 & 63 & 0 & 13 & 13 & 50 & 13 & 8 \\
\hline \multicolumn{12}{|l|}{ Balochistan } \\
\hline & $\mathrm{DoH}$ & 60 & 20 & 80 & 30 & 0 & 50 & 20 & 80 & 30 & 10 \\
\hline \multirow[t]{3}{*}{ Pishin } & PWD & 0 & 0 & 0 & 0 & 75 & na & na & na & na & 4 \\
\hline & Private & 80 & 40 & 60 & 60 & 0 & 60 & 20 & 100 & 60 & 5 \\
\hline & $\mathrm{DoH}$ & 29 & 14 & 100 & 0 & 29 & 71 & 14 & 71 & 14 & 7 \\
\hline \multirow[t]{2}{*}{ Sibi } & PWD & 0 & 0 & 60 & 0 & 100 & na & $\mathrm{Na}$ & na & na & 5 \\
\hline & Private & 0 & 50 & 50 & 100 & 0 & 0 & 50 & 50 & 50 & 2 \\
\hline
\end{tabular}

Source: Inventory of health facilities.

*DoH also includes BHUs attached with PPHI in KP, Sindh and Balochistan and with PRSP in Punjab.

na= Not applicable. 
Since women's FP needs can mainly be addressed by female service providers, availability of women medical officers, or at least LHVs, FHTs, midwives and nurses in the morning, and particularly in the evening session, is a strong determinant of whether services are being provided effectively. The following figures focus on the morning and evening availability of women medical officers and paramedics at public and private facilities.

Figure 5.1 suggests that most WMOs are available in morning shifts; much fewer WMOs are present in evening shifts at DHQ and THQ level facilities in both the public and private sectors. At RHCs, MCHs and BHUs, WMOs are hardly available-present at less than 40 percent of public facilities-even in the morning session. This cadre is virtually unavailable in evening shifts in any of the facilities. The low availability of WMOs (even in the mornings) at public RHCs is also matter of serious concern for the public health sector. On the other hand, WMOs are available at about 70 percent of RHC-level private facilities in the morning session and at 60 percent of such facilities in the evening session.

Figure 5.1: Morning and Evening Availability of Women Medical Officers at Public and Private Facilities, \% of Facilities ( $\mathrm{N}=185$ )

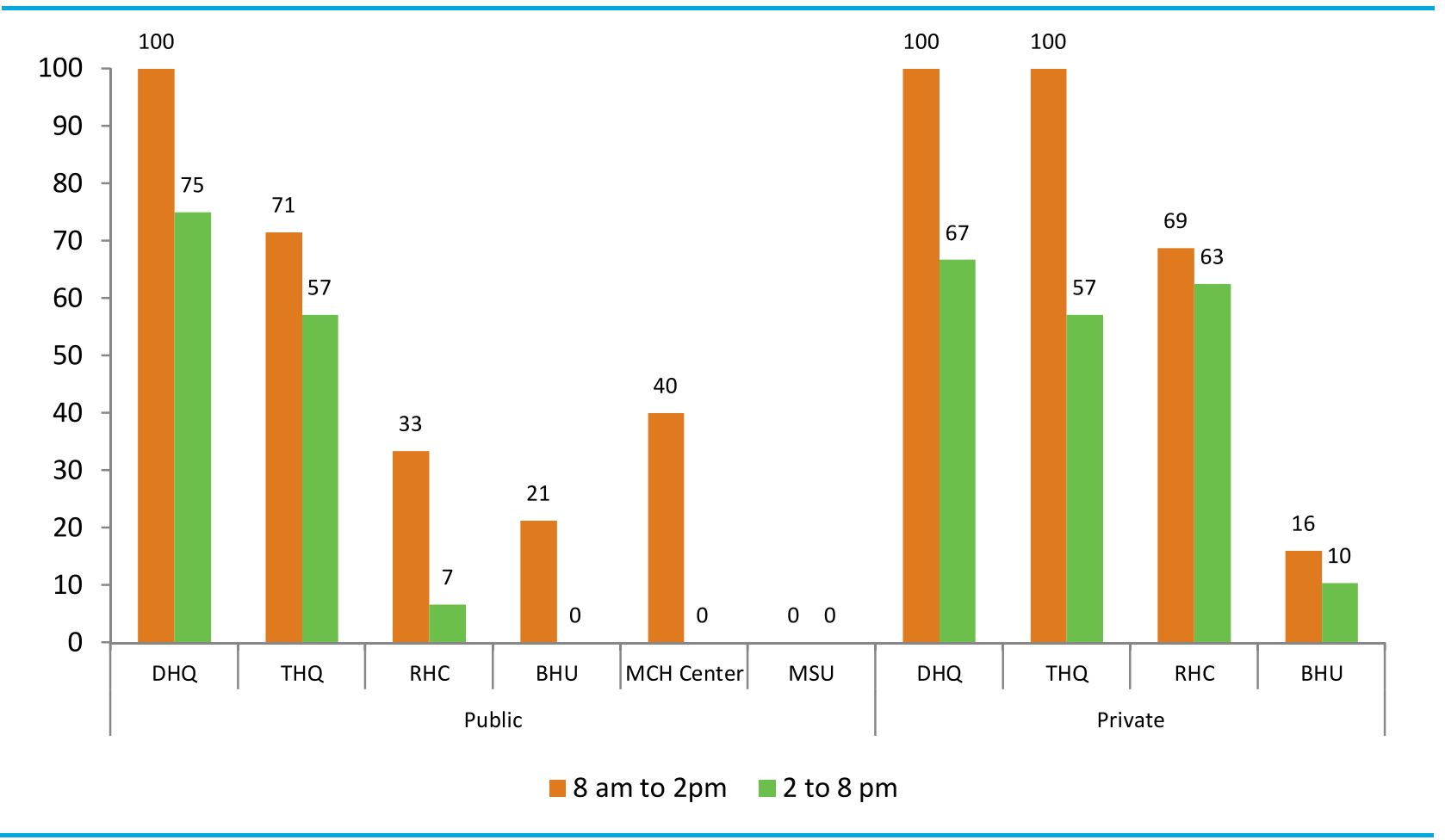

Source: Inventory of health facilities.

*BHUs are attached with PPHI in KP, Sindh and Balochistan and with PRSP in Punjab.

The situation is far more encouraging in terms of availability of female midlevel providers. Figure 5.2 reveals that LHVs and equivalent staff are frequently available to provide services in the morning shifts at the majority of both public and private facilities. Their availability in evening shifts is also quite pervasive in both sectors, except for public-sector RHCs and MCHs. Although LHVs are the main providers of FP services in the public sector, their services could be better utilized for the same purpose in the private sector as well. 
Figure 5.2: Morning and Evening Availability of Female Mid-level providers at Public and Private Facilities, \% of Facilities ( $\mathrm{N}=185)$

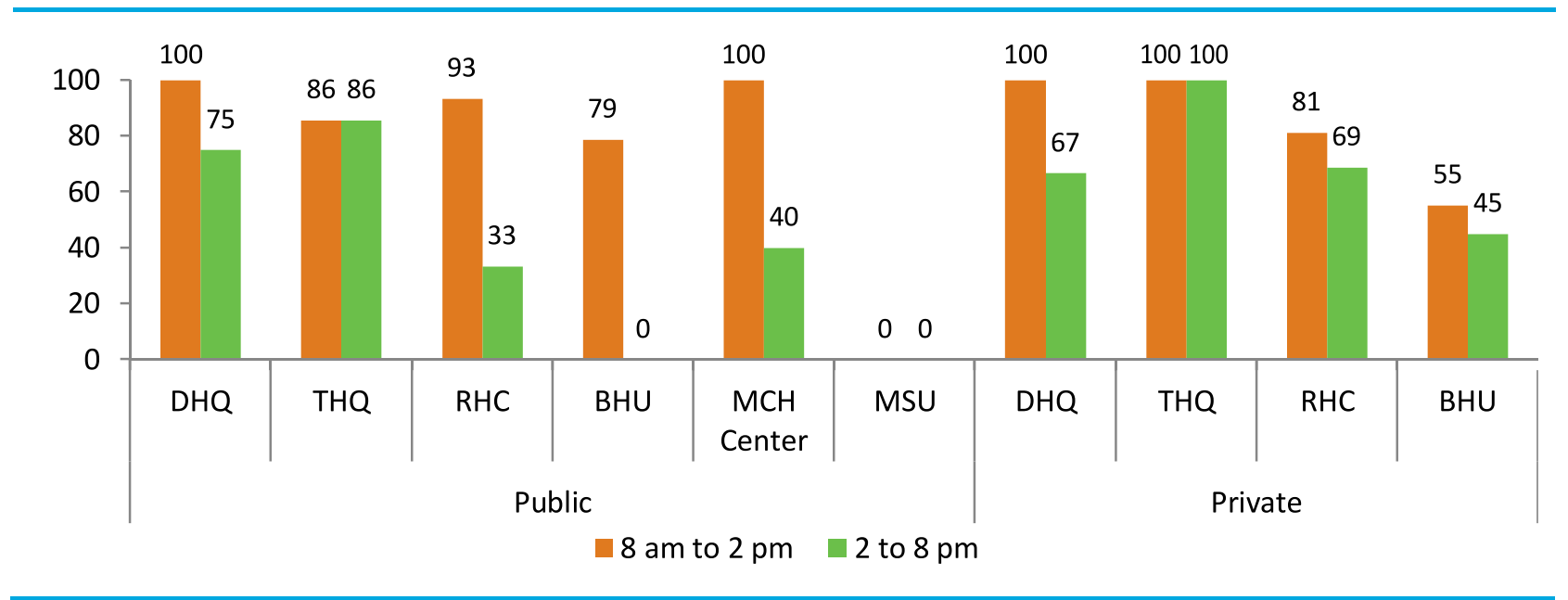

Source: Inventory of health facilities.

*BHUs are attached with PPHI in KP, Sindh and Balochistan and with PRSP in Punjab.

The availability of female service providers in both the morning and evening shifts expands options for women who seek family planning services on flexible timings. In this regard, Figure 5.3 shows the proportion of publicand private-sector facilities that have at least one female SP present in the morning session, in the evening session, and at both times. Nearly all public facilities (96 percent) have at least one female SP present in the morning session; however, only 20 percent of these facilities have a female SP present in the evening, and the same proportion of facilities have at least one female SP present in both shifts.

Among private facilities, however, 77 percent of facilities have at least one female SP in the morning session, and this proportion drops only slightly to 67 percent in the evenings. More than half of the private facilities (54 percent) have at least one female SP present in both shifts. This indicates that the private sector is more ready to provide health and family planning services and provides more options to female clients to schedule their visits at their convenience.

Figure 5.3: Availability of At Least One Female Technical Staff Member in Morning, Evening and Both Shifts at Public and Private Facilities, \% of Facilities $(\mathrm{N}=185)$

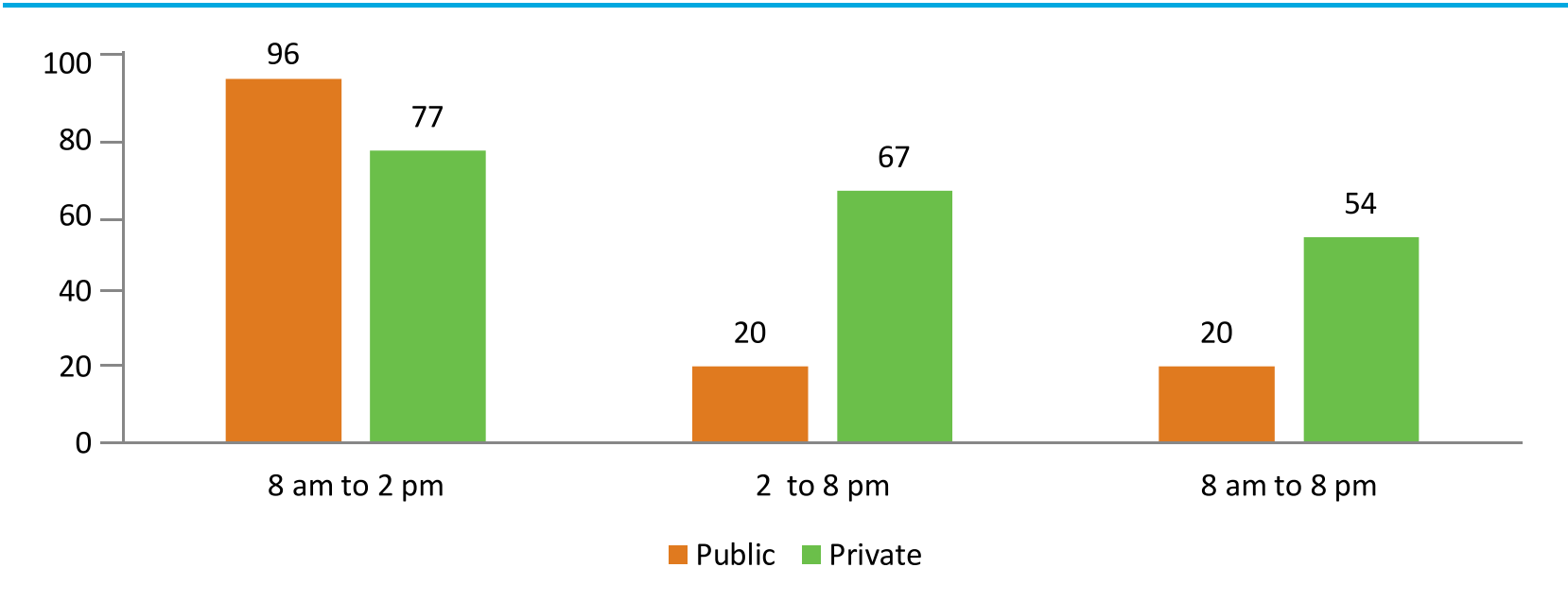

Source: Inventory of health facilities.

*BHUs are attached with PPHI in KP, Sindh and Balochistan and with PRSP in Punjab. 


\section{Combined Availability of Female SPs and Contraceptive Methods}

The readiness of facilities improves with the availability of at least one female provider in morning and especially in the evening shifts. However the female SP's presence cannot be fully utilized without the availability of contraceptive methods at the facility. We have tried to capture the combined availability of both providers and contraceptive stocks to assess the proportion of public- and private-sector facilities that are available to women in the eight study districts. The tables below show the proportion of facilities that have improved readiness by having at least one female staff member as well as a contraceptive method available in the morning, evening and both shifts. Also shown is the further distribution of the facilities into those that have their own contraceptive stocks and those that "manage" supplies by procuring contraceptives from other sources or referring their FP clients to another facility. The readiness to refer clients reflects a dimension of linkages across facilities for family planning service provision.

In terms of detailing specific needs of women who prefer to use injectables, Figure 5.4 suggests that along with availability of at least one female service provider there is a contraceptive supply arrangement in both public and private sectors. These facilities have their own stock of contraceptives and when the face stock-outs, they either purchase contraceptives from elsewhere or refer clients to other facilities. This flexibility is more visible in the private sector and such arrangements increase their readiness to a great extent.

Figure 5.4: Availability of At Least one Female SP and Injectable by Level, \% of Facilities

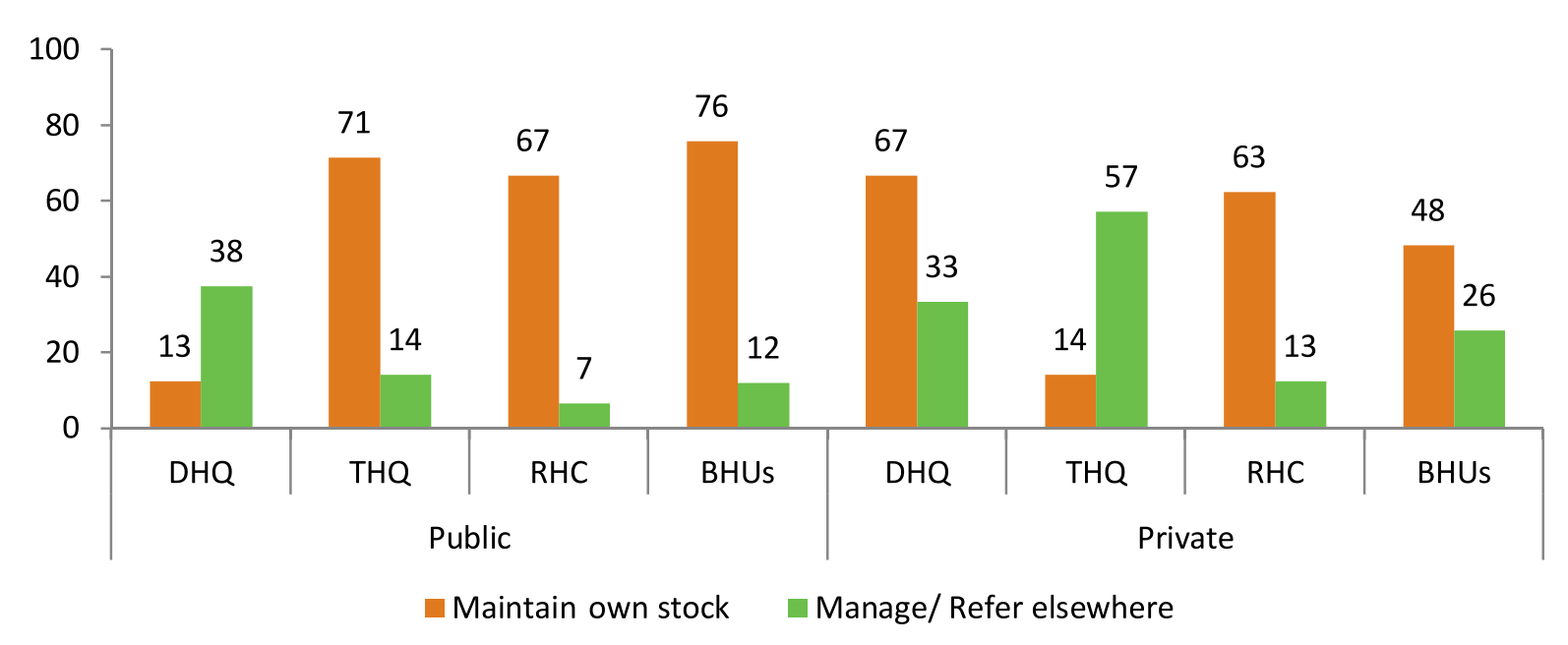

Source: Inventory of health facilities.

*BHUs are attached with PPHI in KP, Sindh and Balochistan and with PRSP in Punjab.

Table 5.12 shows the proportion of both public and private facilities that have available at least one female service provider and injectables in the morning, evening and both shifts by level of facility. In the public sector, the majority of the RHS-As and FWCs have both a female provider and their own stocks of injectables available, indicating readiness, but only in the morning shifts. Likewise, most of the other public facilities having at least one female provider and stocks of injectable available provide services in the morning session. A few DHQ hospitals (13 percent) have at least one female SP and injectables from their own stock available in both shifts; however, their readiness is substantially increased - to 50 percent-when they manage supply from any other source or refer their clients. This applies to all other levels of public health facilities. In the case of THQ hospitals, it is encouraging 
that the same proportions of facilities are available to provide injectables in the morning, evening and both shifts. On the contrary, a higher proportion of RHCs have female providers and injectables available, but the proportion drops significantly for the evening session and for both shifts, mainly due to non-availability of female providers in the evening shifts.

The situation in the private sector is better than at public facilities due to female providers' presence in the evening and both shifts. Unlike the public sector, almost the same proportions of facilities in the private sector have a female provider and stock of injectables available in the evening as in the morning. Another positive aspect of the private sector is that facilities are more likely to manage supply from other sources or through referrals than public sector facilities. This increases the proportion of facilities that have female providers and stock available in all shifts. Table 5.12 suggests that clients seeking injectables can have multiple choices from both the public and private sector in the mornings but are likely to be forced to choose private facilities in the evenings.

Table 5.12: Availability of At Least one Female SP and Injectables by Level, \% of Facilities

\begin{tabular}{|c|c|c|c|c|c|c|c|}
\hline & \multicolumn{2}{|c|}{8 am to $2 \mathrm{pm}$} & \multicolumn{2}{|c|}{2 to $8 \mathrm{pm}$} & \multicolumn{2}{|c|}{$8 \mathrm{am}$ to $8 \mathrm{pm}$} & \multirow[b]{2}{*}{$\begin{array}{c}\text { Total Number } \\
\text { of Facilities }\end{array}$} \\
\hline & $\begin{array}{l}\text { Main } \\
\text { tain } \\
\text { own } \\
\text { stock }\end{array}$ & $\begin{array}{c}\text { Manage/ } \\
\text { Refer } \\
\text { elsewhere }\end{array}$ & $\begin{array}{c}\text { Maintain } \\
\text { own } \\
\text { stock }\end{array}$ & $\begin{array}{c}\text { Manage/ } \\
\text { Refer } \\
\text { elsewhere }\end{array}$ & $\begin{array}{c}\text { Maintain } \\
\text { own stock } \\
\end{array}$ & $\begin{array}{c}\text { Manage/Refer } \\
\text { elsewhere }\end{array}$ & \\
\hline $\mathrm{DHQ}$ & 13 & 37 & 13 & 37 & 13 & 37 & 8 \\
\hline RHS-A & 89 & 0 & na & na & na & na & 9 \\
\hline THQ & 71 & 15 & 71 & 15 & 71 & 15 & 7 \\
\hline $\mathrm{RHC}$ & 67 & 6 & 20 & 7 & 20 & 7 & 15 \\
\hline $\mathrm{BHU*}$ & 76 & 12 & na & na & na & na & 33 \\
\hline $\mathrm{MCH}$ & 73 & 14 & 40 & 27 & 40 & 27 & 15 \\
\hline FWC & 95 & 0 & na & na & na & na & 41 \\
\hline \multicolumn{8}{|c|}{ Private (Equivalent)* * } \\
\hline DHQ & 67 & 33 & 33 & 34 & 33 & 34 & 3 \\
\hline THQ & 14 & 57 & 14 & 57 & 14 & 57 & 7 \\
\hline $\mathrm{RHC}$ & 63 & 12 & 56 & 13 & 56 & 13 & 16 \\
\hline $\mathrm{BHU}$ & 35 & 14 & 26 & 32 & 13 & 32 & 31 \\
\hline
\end{tabular}

Source: Inventory of facilities.

*BHUs are attached with PPHI in KP, Sindh and Balochistan and with PRSP in Punjab.

** Private facilities were categorized by number of beds: $0-4$ bed $\equiv \mathrm{BHU}, 5-19$ beds $\equiv \mathrm{RHC}, 20-80$ beds $\equiv \mathrm{THQ}, 81$ and more beds $\equiv \mathrm{DHQ}$.

na=Not applicable.

Looking at cross-district variability in access to injectables, Table 5.13 describes the proportion of facilities that have at least one female provider and a stock of injectables available in morning, evening and both shifts by district and sector. The table clearly shows that public sector facilities of Khairpur, Umerkot, Pishin and Rahim Yar Khan are far better in having at least one female provider and stock of injectable available (either own or arranged) in the morning session, while the other districts, particularly Khanewal, have fewer facilities with both of these services available, even in the morning session. The table also shows that there is no public facility in Mansehra having at least one female provider and a stock of injectables available in the evening. 
Notably, although the proportion of private facilities with at least one female provider and their own stock of injectables is lower than the public sector in the morning session, in the evening session, this proportion attains the same level as public facilities or even surpasses it when private facilities manage stocks from other sources or their providers refer clients to another facility for injectables. The flexible strategy of the private sector-in terms of being available in both shifts and in managing contraceptives from alternative sources or referrals when their own stocks are not available-makes them more readily available to meet the FP needs of women. This applies to the private sector in all districts, except Pishin, Sibi and Mardan, where private facilities do not manage injectable stocks from any other source but rely on their own stocks.

Table 5.13: Availability of At Least one Female SP and Injectables by Timing and by Sector and Districts, \% of Facilities

\begin{tabular}{|c|c|c|c|c|c|c|c|}
\hline & & \multicolumn{2}{|c|}{$8 \mathrm{am}$ to $2 \mathrm{pm}$} & \multicolumn{2}{|c|}{2 to $8 \mathrm{pm}$} & \multicolumn{2}{|c|}{$8 \mathrm{am}$ to $8 \mathrm{pm}$} \\
\hline & & $\begin{array}{l}\text { Maintain Own } \\
\text { stock }\end{array}$ & $\begin{array}{l}\text { Manage/ } \\
\text { Refer } \\
\text { elsewhere }\end{array}$ & $\begin{array}{l}\text { Maintain Own } \\
\text { stock }\end{array}$ & $\begin{array}{c}\text { Manage/ } \\
\text { Refer } \\
\text { elsewhere }\end{array}$ & $\begin{array}{l}\text { Maintain } \\
\text { Own stock }\end{array}$ & $\begin{array}{l}\text { Manage/ } \\
\text { Refer } \\
\text { elsewhere }\end{array}$ \\
\hline \multicolumn{8}{|l|}{ Punjab } \\
\hline \multirow{2}{*}{ Khanewal } & Public & 56 & 16 & 6 & 22 & 6 & 22 \\
\hline & Private & 33 & 23 & 33 & 23 & 33 & 23 \\
\hline \multirow{2}{*}{$\begin{array}{l}\text { Rahim Yar } \\
\text { Khan }\end{array}$} & Public & 89 & 0 & 17 & 5 & 17 & 5 \\
\hline & Private & 25 & 25 & 0 & 25 & 0 & 25 \\
\hline \multicolumn{8}{|l|}{ Sindh } \\
\hline \multirow{2}{*}{ Khairpur } & Public & 94 & 6 & 13 & 12 & 13 & 12 \\
\hline & Private & 22 & 67 & 22 & 67 & 22 & 67 \\
\hline \multirow{2}{*}{ Umerkot } & Public & 100 & 0 & 28 & 0 & 28 & 0 \\
\hline & Private & 63 & 37 & 38 & 62 & 38 & 62 \\
\hline \multicolumn{8}{|l|}{ KP } \\
\hline \multirow{2}{*}{ Mansehra } & Public & 69 & 0 & 0 & 0 & 0 & 0 \\
\hline & Private & 38 & 25 & 25 & 25 & 13 & 25 \\
\hline \multirow{2}{*}{ Mardan } & Public & 75 & 6 & 13 & 18 & 13 & 18 \\
\hline & Private & 63 & 0 & 50 & 0 & 38 & 0 \\
\hline \multicolumn{8}{|l|}{ Balochistan } \\
\hline \multirow{2}{*}{ Pishin } & Public & 64 & 29 & 14 & 29 & 14 & 29 \\
\hline & Private & 60 & 0 & 60 & 0 & 40 & 0 \\
\hline \multirow{2}{*}{ Sibi } & Public & 67 & 16 & 8 & 17 & 8 & 17 \\
\hline & Private & 50 & 0 & 100 & 0 & 50 & 0 \\
\hline
\end{tabular}

Source: Inventory of health facilities. 
We undertook a similar assessment about the extent of availability of IUCD insertion services for women who seek this method. Figure 5.5 shows that, surprisingly, no public DHQ-level hospital has a female provider and its own stock of IUCDs available; however, by arranging contraceptive supplies from other sources or referring clients to other facilities, these facilities are able to provide IUCD services, albeit to a limited extent. Although less than half of the THQ-level facilities have at least one female provider as well as a stock of IUCDs available, there is a notable increase in their readiness to provide IUCDs when they manage stocks from other sources or refer clients to other facilities; in the private sector, these practices nearly double readiness.

Figure 5.5: Availability of At Least one Female SP and IUCD by Level, \% of Facilities

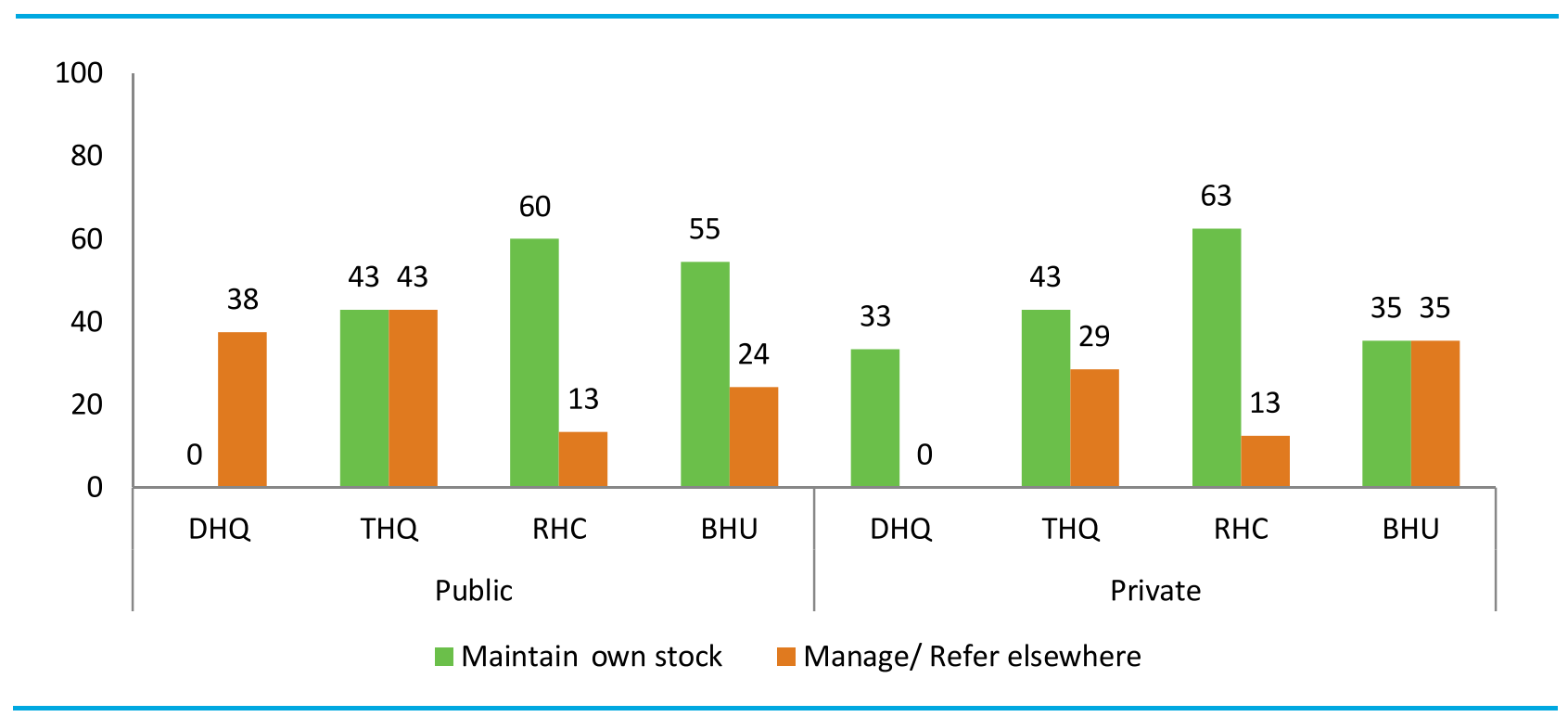

Source: Inventory of health facilities.

As Tables 5.14 and 5.15 show, in the morning session, all RHS-As and the majority of FWCs have both a female service provider and IUCDs available, mostly from their own stock, which is encouraging. The proportion of facilities having both these services available at the same time is lower at THQ, RHC, BHU and MCH level if facilities do not manage to obtain stocks from other sources, which indicates huge gaps in their own stock availability. This clearly shows that public facilities cannot provide IUCD services promptly, even in the morning session, unless they manage shortage or non-availability of contraceptives by obtaining them from another source.

Although facilities equivalent to DHQs in the private sector are not performing well, all other private facilities are better in terms of availability of a female SP and IUCDs available in the morning and evening shifts. The proportion of private facilities equivalent to RHCs with both a female service provider and IUCD services available in the evening and both shifts is higher than in public facilities. 
Table 5.14: Availability of At Least one Female SP and IUCDs in the Morning, Evening and Both Shifts by Level, \% of Facilities

\begin{tabular}{|c|c|c|c|c|c|c|c|}
\hline & \multicolumn{2}{|c|}{8 am to $2 \mathrm{pm}$} & \multicolumn{2}{|c|}{2 to $8 \mathrm{pm}$} & \multicolumn{2}{|c|}{8 am to $8 \mathrm{pm}$} & \multirow{2}{*}{$\begin{array}{c}\text { Total } \\
\text { Number of } \\
\text { Facilities }\end{array}$} \\
\hline & $\begin{array}{l}\text { Maintain } \\
\text { Own stock }\end{array}$ & $\begin{array}{c}\text { Manage/ Refer } \\
\text { elsewhere }\end{array}$ & $\begin{array}{l}\text { Maintain } \\
\text { Own stock }\end{array}$ & $\begin{array}{c}\text { Manage/ Refer } \\
\text { elsewhere }\end{array}$ & $\begin{array}{l}\text { Maintain } \\
\text { Own stock }\end{array}$ & $\begin{array}{c}\text { Manage/Refer } \\
\text { elsewhere }\end{array}$ & \\
\hline \multicolumn{8}{|l|}{ Public } \\
\hline $\mathrm{DHQ}$ & 0 & 38 & 0 & 38 & 0 & 38 & 8 \\
\hline RHS-A & 100 & 0 & na & na & na & na & 9 \\
\hline THQ & 43 & 43 & 43 & 43 & 43 & 43 & 7 \\
\hline $\mathrm{RHC}$ & 60 & 13 & 13 & 14 & 13 & 14 & 15 \\
\hline $\mathrm{BHU} *$ & 55 & 24 & na & na & na & na & 33 \\
\hline $\mathrm{MCH}$ & 53 & 27 & 27 & 33 & 27 & 33 & 15 \\
\hline FWC & 90 & 3 & na & na & na & na & 41 \\
\hline \multicolumn{8}{|c|}{ Private (Equivalent)* * } \\
\hline $\mathrm{DHQ}$ & 33 & 0 & 33 & 0 & 33 & 0 & 3 \\
\hline THQ & 43 & 28 & 43 & 28 & 43 & 28 & 7 \\
\hline $\mathrm{RHC}$ & 63 & 12 & 56 & 13 & 56 & 13 & 16 \\
\hline $\mathrm{BHU}$ & 35 & 23 & 26 & 32 & 13 & 32 & 31 \\
\hline
\end{tabular}

Source: Inventory of health facilities.

**Private facilities were categorized by number of beds: $0-4$ beds $\equiv$ BHU, $5-19$ beds $\equiv$ RHC, $20-80$ beds $\equiv \mathrm{THQ}, 81$ and more beds $\equiv \mathrm{DHQ}$. na=Not applicable.

Table 5.15 shows that public sector facilities generally perform better than the private facilities in the morning shifts, relying on their own stock. In all districts except Khanewal and Mardan, private facilities improve their readiness by managing stocks of IUCDs from any other source. Khairpur, Pishin, Rahim Yar Khan and Sibi have a high proportion of public level facilities with at least one service provider as well as IUCD services available in the morning session, followed by Umerkot and Mardan. Public sector facilities in both districts of Balochistan have the lowest proportion of those having both female providers and own IUCD stocks available; however, this proportion goes up significantly when they manage contraceptive stocks from any other source or refer clients to other facilities. Generally, the concurrent availability of both IUCD stocks (though mostly managed from other sources) and a female service provider is low in the evening shifts in the public sector, which is when the private facilities perform better. 
Table 5.15: Availability of At Least One Female SP and IUCD by timing and by Sector and Districts, \% of Facilities

\begin{tabular}{|c|c|c|c|c|c|c|c|}
\hline & & \multicolumn{2}{|c|}{8 am to $2 \mathrm{pm}$} & \multicolumn{2}{|c|}{2 to $8 \mathrm{pm}$} & \multicolumn{2}{|c|}{8 am to $8 \mathrm{pm}$} \\
\hline & & $\begin{array}{l}\text { Maintain } \\
\text { Own stock }\end{array}$ & $\begin{array}{l}\text { Manage/ Refer } \\
\text { elsewhere }\end{array}$ & $\begin{array}{c}\text { Maintain } \\
\text { Own } \\
\text { stock }\end{array}$ & $\begin{array}{l}\text { Manage/ } \\
\text { Refer } \\
\text { elsewhere }\end{array}$ & $\begin{array}{l}\text { Maintain } \\
\text { Own stock }\end{array}$ & $\begin{array}{l}\text { Manage/Refer } \\
\text { elsewhere }\end{array}$ \\
\hline \multicolumn{8}{|l|}{ Punjab } \\
\hline \multirow[t]{2}{*}{ Khanewal } & Public & 61 & 11 & 6 & 16 & 6 & 16 \\
\hline & Private & 33 & 0 & 33 & 0 & 33 & 0 \\
\hline \multirow[t]{2}{*}{$\begin{array}{l}\text { Rahim Yar } \\
\text { Khan }\end{array}$} & Public & 89 & 0 & 17 & 5 & 17 & 5 \\
\hline & Private & 38 & 12 & 25 & 13 & 25 & 13 \\
\hline \multicolumn{8}{|l|}{ Sindh } \\
\hline \multirow[t]{2}{*}{ Khairpur } & Public & 88 & 12 & 6 & 19 & 6 & 19 \\
\hline & Private & 67 & 11 & 56 & 22 & 56 & 22 \\
\hline \multirow[t]{2}{*}{ Umerkot } & Public & 72 & 6 & 11 & 11 & 11 & 11 \\
\hline & Private & 50 & 50 & 25 & 75 & 25 & 75 \\
\hline \multicolumn{8}{|l|}{ KP } \\
\hline \multirow[t]{2}{*}{ Mansehra } & Public & 69 & 0 & 0 & 6 & 0 & 6 \\
\hline & Private & 25 & 38 & 25 & 38 & 13 & 37 \\
\hline \multirow[t]{2}{*}{ Mardan } & Public & 56 & 19 & 13 & 25 & 13 & 25 \\
\hline & Private & 63 & 0 & 38 & 0 & 25 & 0 \\
\hline \multicolumn{8}{|l|}{ Balochistan } \\
\hline \multirow[t]{2}{*}{ Pishin } & Public & 29 & 64 & 0 & 64 & 0 & 64 \\
\hline & Private & 40 & 40 & 60 & 40 & 40 & 40 \\
\hline \multirow[t]{2}{*}{ Sibi } & Public & 50 & 33 & 8 & 34 & 8 & 34 \\
\hline & Private & 0 & 0 & 50 & 0 & 0 & 0 \\
\hline
\end{tabular}

Source: Inventory of health facilities. 


\section{Districts at a Glance: Variation in FP service availability}

So far, all important factors that enable a facility to provide FP services-infrastructure, availability of general and FP-related equipment, infection prevention measures, availability of staff and contraceptives, and timing of facilities-have been analysed individually at health facility, sector and district level. For each factor, the proportions of facilities that have all sub-services available are presented to see where each district stands in terms of readiness for FP service provision.

In this final part of the section, all districts have been ranked according to their readiness status by combining the analysis of all factors. Table 5.16 shows the position of districts at a glance ranking them from the highest (8) to the lowest (1). Overall, when a combined view is taken of the public and private sectors in each district, Mardan emerges with the highest score and proves its readiness to provide FP services more promptly and effectively than other districts, followed by Khanewal (7) and Mansehra (6). The two districts of Sindh are in the middle of the ranking while Pishin and Sibi seem to be least capable of addressing FP needs of the people at district level. Districts by rank are also shown in Map 1.

Table 5.16: District Index including Both Public and Private Facilities

\begin{tabular}{|c|c|c|c|c|c|c|c|c|c|}
\hline \multicolumn{10}{|c|}{$\%$ of Facilities having } \\
\hline & $\begin{array}{c}\text { All } 5 \\
\text { amenities } \\
\text { available }\end{array}$ & $\begin{array}{l}\text { All } 5 \\
\text { general } \\
\text { equipment } \\
\text { available }\end{array}$ & $\begin{array}{c}\text { All } 4 \\
\text { infection } \\
\text { prevention } \\
\text { measures } \\
\text { in place }\end{array}$ & $\begin{array}{l}\text { Complete } \\
\text { IUCD Kit } \\
\text { available }\end{array}$ & $\begin{array}{l}\text { At least } \\
\text { one } \\
\text { female } \\
\text { staff } \\
\text { available } \\
\text { in } \\
\text { morning } \\
\text { session }\end{array}$ & $\begin{array}{l}\text { At least } \\
\text { one } \\
\text { female } \\
\text { staff } \\
\text { available } \\
\text { in } \\
\text { evening } \\
\text { session }\end{array}$ & $\begin{array}{c}\text { All four } \\
\text { contraceptives } \\
\text { available }\end{array}$ & $\begin{array}{l}\text { Maximum } \\
\text { of all } \\
\text { seven } \\
\text { services } \\
\text { available }\end{array}$ & $\begin{array}{l}\text { Ranking } \\
\text { of the } \\
\text { districts }\end{array}$ \\
\hline \multicolumn{10}{|l|}{ Punjab } \\
\hline Khanewal & 26 & 48 & 26 & 33 & 85 & 41 & 44 & 43 & 7 \\
\hline $\begin{array}{l}\text { Rahim Yar } \\
\text { Khan }\end{array}$ & 4 & 35 & 19 & 15 & 92 & 31 & 62 & 37 & 3 \\
\hline \multicolumn{10}{|l|}{ Sindh } \\
\hline Khairpur & 24 & 24 & 28 & 24 & 92 & 36 & 56 & 41 & 5 \\
\hline Umerkot & 12 & 31 & 31 & 19 & 100 & 38 & 46 & 40 & 4 \\
\hline \multicolumn{10}{|l|}{ KP } \\
\hline Mansehra & 0 & 67 & 21 & 38 & 83 & 29 & 50 & 41 & 6 \\
\hline Mardan & 0 & 54 & 33 & 58 & 92 & 38 & 50 & 46 & 8 \\
\hline \multicolumn{10}{|l|}{ Balochistan } \\
\hline Pishin & 0 & 37 & 5 & 16 & 84 & 32 & 21 & 28 & 1 \\
\hline Sibi & 0 & 43 & 0 & 29 & 93 & 29 & 50 & 35 & 2 \\
\hline
\end{tabular}

Source: Inventory of health facilities.

Table 5.17 uses the same methodology to rank study districts but with a focus on public sector facilities alone. When the public sector facilities are analysed separately, the picture changes. In terms of public sector capacities, Khanewal now ranks at the top (8) while Mardan follows (7), indicating that Mardan's private sector is stronger than its public sector. Public sector facilities of Umerkot (6) and Khairpur (5) also show readiness to provide FP services. Unfortunately, both the lowest-ranking districts are in Balochistan, which indicates the major gaps in capacities of public health facilities that need to be addressed in the province. Districts' ranking for readiness of public-sector facilities is shown in Map 2. 
Table 5.17: District Index and Ranking in Readiness of providing FP services, Public Facilities Only

\begin{tabular}{|c|c|c|c|c|c|c|c|c|c|}
\hline \multicolumn{10}{|c|}{$\%$ of Facilities having } \\
\hline & $\begin{array}{c}\text { All } 5 \\
\text { amenities } \\
\text { available }\end{array}$ & $\begin{array}{l}\text { All } 5 \\
\text { general } \\
\text { equipment } \\
\text { available }\end{array}$ & $\begin{array}{c}\text { All } 4 \\
\text { infection } \\
\text { prevention } \\
\text { measures } \\
\text { in place }\end{array}$ & $\begin{array}{l}\text { Complete } \\
\text { IUCD Kit } \\
\text { available }\end{array}$ & $\begin{array}{l}\text { At least } \\
\text { one } \\
\text { female } \\
\text { staff } \\
\text { available } \\
\text { in } \\
\text { morning } \\
\text { session }\end{array}$ & $\begin{array}{l}\text { At least one } \\
\text { female } \\
\text { staff } \\
\text { available in } \\
\text { evening } \\
\text { session }\end{array}$ & $\begin{array}{c}\text { All four } \\
\text { contracepti } \\
\text { ves } \\
\text { available }\end{array}$ & $\begin{array}{l}\text { All seven } \\
\text { services } \\
\text { available }\end{array}$ & $\begin{array}{l}\text { Ranking } \\
\text { of the } \\
\text { districts }\end{array}$ \\
\hline \multicolumn{10}{|l|}{ Punjab } \\
\hline Khanewal & 22 & 44 & 28 & 33 & 100 & 22 & 61 & 44 & 8 \\
\hline $\begin{array}{l}\text { Rahim Yar } \\
\text { Khan }\end{array}$ & 0 & 33 & 17 & 11 & 100 & 22 & 89 & 39 & 4 \\
\hline \multicolumn{10}{|l|}{ Sindh } \\
\hline Khairpur & 25 & 25 & 13 & 25 & 100 & 19 & 81 & 41 & 5 \\
\hline Umerkot & 6 & 33 & 28 & 28 & 100 & 28 & 67 & 41 & 6 \\
\hline \multicolumn{10}{|l|}{ KP } \\
\hline Mansehra & 0 & 63 & 19 & 25 & 88 & 6 & 63 & 38 & 3 \\
\hline Mardan & 0 & 44 & 31 & 50 & 94 & 25 & 56 & 43 & 7 \\
\hline \multicolumn{10}{|l|}{ Balochistan } \\
\hline Pishin & 0 & 21 & 0 & 7 & 86 & 21 & 21 & 22 & 1 \\
\hline Sibi & 0 & 33 & 0 & 25 & 100 & 17 & 50 & 32 & 2 \\
\hline
\end{tabular}

Source: Inventory of health facilities.

\section{Conclusion}

It may be concluded that, health facilities, especially in the public sector, are generally not fully prepared to provide family planning services. Although most facilities have reasonable infrastructure and amenities, there is a gap in availability of basic equipment, particularly examination lamps and BP apparatus, which are necessary for dispensing IUCDs and hormonal methods. There is also a big gap in availability of both complete and essential IUCD kits. About 50 percent of the facilities have neither complete nor essential IUCD kits available. Further, no district has full infection prevention measures available in its facilities.

Most of the sanctioned posts at public facilities are filled, but the least filled cadres-gynaecologists and male and female medical officers-are also the most important. Posts of LHVs are the most filled across the districts. Service providers from public facilities are mainly available in the morning session and their availability is reduced in the evening session, particularly among women medical officers. The private sector offers better availability of service providers in the evening session, particularly of female providers. The public sector has better performance in having at least one female provider and stock of injectable and IUCD (having own as well managed stock) available in morning while private sector shows its readiness in providing both of these services by having at least one female provider and stock available more in the evening session. Finally, district rankings developed from combining results from both public and private health facilities, find that Mardan followed by Khanewal and Mansehra have the best capacities overall to provide FP services. Analysing the public sector alone shows the district of Khanewal at the highest rank followed by Mardan and Umerkot. In both cases, Pishin and Sibi from Balochistan are the least ready to provide FP services. 
Map1: District Index including Both Public and Private Facilities

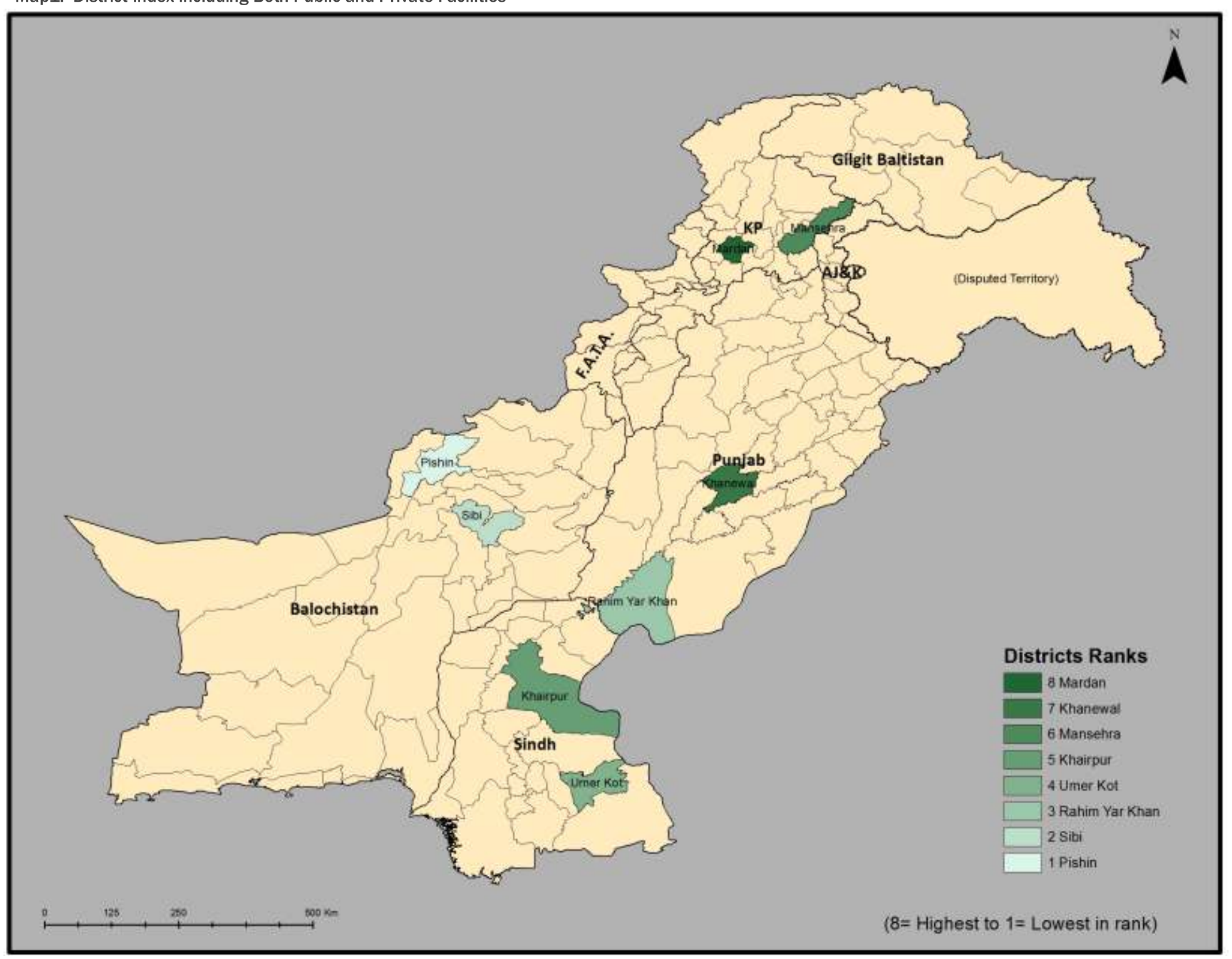


Map 2: District Index including Public Facilities Only







\section{Conclusions and Recommendations}

\section{Conclusions}

This report analyses the readiness of both public and private sector health facilities for providing family planning services in eight fairly representative districts across Pakistan. The analysis encompasses the capacities of service providers, the situation of contraceptive supply and availability, and readiness of health facilities. Readiness has been assessed at the level of service providers, the level of health facilities in both public and private sectors and finally at district level to develop a comprehensive picture of readiness of the health system in eight study districts. Providers including Lady Health Workers were found to have fair levels of knowledge of family planning but there is certainly a need to improve both updated knowledge of specific methods, communication skills and client-centered behaviour through additional training. Staff trained in family planning services, especially those that received a specialized client-centered family planning service training (SAHR) are found to be better in all these respects.

While various cadres of staff are available for providing family planning services, more male than female providers are available and more middle than higher level cadres are likely to be present during afternoons and evenings when clients are more likely to be able to attend facilities. Female providers are most likely to be available in the mornings. For a women-focused program, the presence of female family planning providers at times that suit most women clients is a prerequisite for services to be utilized. Flexibility in terms of task shifting between SPs of the health and population sectors and the private sector could significantly improve the effective availability of family planning services. The current availability of contraceptive stocks especially in public sector outlets is quite sufficient, although its distribution is not entirely efficient. With sufficient stocks available in the Central Warehouse in Karachi and also reaching district stores, the issue that remains is that of stocks reaching service delivery points and providers. The last year did lead to stock-outs across several facilities and among lady health workers. The supply chain from the Central Warehouse to the districts is efficient, but this is not the case for arrangements for supply from the district stores to facilities. Furthermore, the private sector does not have any district store provision for contraceptives and relies mainly on pharmacies and stores for its needs, based on contraceptive methods offered to clients.

When looking at overall family planning service availability across the 8 study districts, we find that the two districts in KP and Khanewal in Punjab have the best rankings and the two districts in Balochistan rank the lowest. If only public service availability is ranked, then Khanewal in Punjab, Mardan in KP, and the two districts of Sind rank highest. The two study districts of Balochistan still rank lowest.

More details of each of the sections are presented below.

\section{Capacities of Service Providers for FP Service Provision}

The assessment of knowledge and behaviour of service providers at static facilities indicates that SPs are more knowledgeable about general topics related to family planning than method-specific issues. Within method specific knowledge, they generally have better knowledge about female hormonal methods such as injectables and pills and have limited knowledge of emergency contraceptive pills. Vasectomy is the least known method. Training when it has been acquired significantly improves their technical knowledge.

Most of the providers generally know about the contraindications of pills and IUCDs. However, their knowledge about technical aspects of these methods is limited. The cadre of lady health visitors, followed by family welfare workers/counsellor (FWWs/FWCs), is more knowledgeable in the use of injectables than even qualified 
gynaecologists. This is probably because administering injectables is a routine practice for them and they are also provided with method-specific trainings.

Overall, the knowledge of providers trained in the client-centered approach is higher than that of providers who have received trainings other than CCA. On the other hand, there is slight difference of knowledge between SPS who are untrained and SPs who have training other than CCA. Facilities in both districts from KP have received this training (except PWD facilities in Mardan) and the data shows a sharp difference in the knowledge level of service providers, particularly regarding the IUCD method. Similarly, knowledge of CCA-trained service providers about injectables and IUCDs in both districts of Punjab is also significantly higher, indicating a positive effect of CCA training on service providers.

Results of observation of interactions between service providers and clients suggest that service providers are relatively better at following client-centeredness protocols at the salutation stage of the interaction when they greet them and start the interaction, but their behaviour in assessing the client's problem, helping her understand and reassure her needs improvement. While our study identified gaps in SPs' dealings with clients during observations, the clients themselves reported they were satisfied. This discrepancy could be due to the fact that clients are unaware of their rights and are used to and expect low standards of quality of care. Among lady health workers, although there is generally sound knowledge about healthy timing and spacing, and method-specific details, there is a clear gap in their knowledge about management of side effects of oral pills, a method they frequently provide.

\section{Contraceptives Supply and Availability at Facilities}

The Central Warehouse is the main source for supply of contraceptive commodities to all public sector facilities at the district level, while a major part of the private sector manages the provision of these methods through independent procurement of services by clients from stores and pharmacies, except a few NGOs that have provincial warehouses.

Contraceptives were widely available at all public district stores of DoH, PWD and PPHI/PRSP. Half the district stores visited had a maximum stock of four months available. Only a few district stores had a current stock-out on the day of the visit. However, one in four visited stores had experienced a stock-out of more than one contraceptive method during the last year. Approximately three in four PWD stores and two-thirds of DoH stores did not deliver contraceptives to the SDPs but the latter's representatives visit and collect these commodities.

Since public sector DHQ hospitals do not receive contraceptives directly, they refer their clients to other facilities. However, 88 percent of public sector DHQs had experienced stock-out of condoms, pills and injectables while all DHQs experienced a stock-out of IUCDs during the year preceding the survey.

Private stores and pharmacies are the major source of contraceptives for most private SDPs. The most common form of arrangement of commodities was their purchase from private stores and pharmacies. This was most prevalent for injectables.

Lady health workers are critical for supply and resupply of three contraceptive methods at the community level. All LHWs interviewed in Balochistan and Sindh had experienced stock-outs of all three methods during the year preceding the survey. None of the interviewed LHWs had all three methods currently available in any of the districts at the time of the interview. 


\section{Readiness of Health Facilities for Family Planning Service Provision}

Health facilities, especially in the public sector, are generally not very well prepared to provide family planning services. Although most facilities generally have reasonable infrastructure and amenities, they lack the availability of basic equipment, particularly examination lamps and BP apparatus, which are necessary for IUCDs insertion and dispensing of hormonal methods, respectively. Non-availability of IUCD kits is a serious issue across health facilities in both private and public sectors. About 50 percent of the facilities have neither complete IUCD kits nor minimum essential equipment available. Further, basic infection prevention measures are not completely in place in any of the provinces.

Most of the sanctioned posts for male technical staff at public health facilities are filled; but among female posts, the LHVs are the most likely to be in place across the districts. The least filled cadres are also the most important-i.e. the shortage of gynaecologists and female medical officers.

Even more crucial may be the timings that service providers are available for clients since many of them are unable to set out to seek services in the mornings due to household duties and work. Service providers from public facilities are mainly available in the morning session and their availability in the evening session is minimal, particularly among women medical officers. The private sector offers a better availability of service providers in the evening session, particularly of female providers. Though the public sector performs better in terms of having at least one female provider and stocks of injectables and IUCD available (having own or managed stock) in morning however,, facilities of private sector show their readiness in providing injectables and IUCD services by having at least one female provider and stock available in the evening session.

We have ranked the 8 study districts according to combined indices of essential components of readiness to provide family planning services such as: (1) all five basic amenities; (2) all five components of general equipment; (3) all four infection prevention measures; (4) a complete IUCD kit; (5) at least one female staff available in the morning session; (6) at least one female staff available in the evening session; and (7) all four contraceptive methods. Among the top ranking districts are Mardan, KP; Khanewal, Punjab; and Mansehra, KP. However, when the ranking is conducted taking into consideration only availability of family planning in public-sector facilities, Khanewal emerges at the top, followed by Mardan and then Umerkot, Sindh. In both rankings, the two districts from Balochistan, Pishin and Sibi, emerge as having the least capacity to provide family planning services. 


\section{Recommendations}

Trainings and Refreshers Method-specific trainings and regular refreshers are needed to improve the technical skills, knowledge and management of side effects of contraceptives particularly IUCD insertion among all service providers (especially) doctors to improve quality of care.

Behavioural Trainings There should be a series of behavioural trainings for service providers to enforce clientfriendly attitudes and a client-friendly, welcoming environment at health facilities.

FP counselling as Priority Agenda It should be mandatory for all service providers at public health facilities to provide FP counselling to potential FP clients even if they visit the facility for antenatal, natal or postnatal care and even if women come for general healthcare to avoid missing any opportunity.

Availability of Equipment Health facilities need to be fully equipped, particularly with medical examination equipment and infection prevention measures, to ensure quality of care in both DoH and PWD facilities.

Availability of IUCD Kits Complete IUCD kits or essential equipment for insertion need to be provided at all public level facilities, particularly at BHUs, which cater to the FP needs of rural areas. IUCD s should be supplied on a regular basis to ensure uninterrupted service provision.

Timings of health facilities The timing factor needs to be critically reviewed. Availability of services in the evening (after 2:00 pm), particularly at public facilities, is urgently required to maximize the utilization of FP services by women.

All RHCs at 24/7 All of the RHCs should be made fully functional as per mandate where it should be ensured that they provide services $24 / 7$ so that family planning needs of women are met and utilization of services could be maximized.

LHWs' Training in Management of Side Effects LHWs should be provided trainings for comprehensive knowledge and management of initial side effects of the methods they provide. This is important to address high levels of discontinuation.

Strengthening of the Referral Linkages Both the Health and Population Welfare Departments should develop strong referral linkages between the two departments which can be the key to enhancing geographical coverage and expanding the range of services in the rural and marginalized areas.

Regular supply of contraceptives Supply of the full range of contraceptives should be regular and should be properly distributed as per demand to the health facilities and to LHWs. This can prevent stock-outs and improve the efficiency FP service provision.

Accountability, Monitoring and supervision A system of accountability, monitoring and facilitative supervision needs to be implemented at all levels, not only to ensure methods' availability, but also to check the utilization of these methods and for prevision of quality family planning services.

Timely Requisition There is a need for district administrations to send correctly filled contraceptive requisition forms (CLR-6) on time to the Central Warehouse in Karachi so delays in supply to district facilities, and the consequent stock-outs at district stores as well as SDPs can be avoided.

Private sector should be involved The potential of skilled and qualified LHVs and even dispensers should be utilized where there are no public services available by providing them contraceptives from public sector stocks and trainings for method-specific knowledge and management of side effects. 


\section{Annex -A: List of Technical Advisory Group (TAG)}

\begin{tabular}{ll}
\hline Name & Designation, Department and Province \\
\hline Dr. Syeda Batool Mazhar & Head of Department, Gynacologist, PIMS, Islamabad \\
Dr. Nasir Mohyuddin & Director (HRD \& Coordination), NIPS, Islamabad \\
Dr. Ayesha Qureshi & Deputy Secretary (Technical), PWD, Punjab \\
Dr. Shabina Raza & Provincial Coordinator \\
& $\begin{array}{l}\text { National Program for Family Planning and Primary Healthcare, } \\
\text { KP }\end{array}$ \\
Dr. Huma Zubair & Director Technical, PWD, KP \\
Dr. Ayaz Hussain & Deputy Director, MNCH, Sindh \\
Dr. Azmat Waseem & Additional Secretary, PWD, Sindh \\
Dr. Amir Bakhsh & Director Health Services, Balochistan \\
\hline
\end{tabular}




\section{Annex-B: Names and designations of field staff}

\begin{tabular}{|c|c|c|}
\hline \multicolumn{3}{|c|}{ QUANTITATIVE TEAM } \\
\hline \multirow[t]{10}{*}{ Punjab } & Designation & Name \\
\hline & Field Coordinator & Ashfa Hashmi \\
\hline & \multirow[t]{2}{*}{ Field Supervisor } & Noreen Ramzan \\
\hline & & Nosheen Rasheed \\
\hline & \multirow{6}{*}{ Interviewer } & Shazia Umer \\
\hline & & Ghulam Rubab \\
\hline & & Shahnaz Akhtar \\
\hline & & Nafees Manzoor \\
\hline & & Maryam Waqar \\
\hline & & Khalida Manzoor \\
\hline \multirow[t]{9}{*}{ Sindh } & Field Coordinator & Sayed Inayat Ali Shah \\
\hline & \multirow[t]{2}{*}{ Field Supervisor } & Zahida Ali \\
\hline & & Shaista Parveen \\
\hline & \multirow{6}{*}{ Interviewer } & Raheela Memon \\
\hline & & Lajwanti Kumari \\
\hline & & Fozia Gul Shaikh \\
\hline & & Khalida Pirzada \\
\hline & & Yasmin Ali \\
\hline & & Ghulam Fiza Shah \\
\hline \multirow[t]{9}{*}{ KP } & Field Coordinator & Wajid Ali \\
\hline & Field Supervisor & Shazia Tariq \\
\hline & \multirow{7}{*}{ Interviewer } & Sakina Luqmani \\
\hline & & Samina Jalil \\
\hline & & Tina Marry \\
\hline & & Saiqa Bibi \\
\hline & & Merry Mobin \\
\hline & & Nargis Bibi \\
\hline & & Lubna Gul \\
\hline \multirow[t]{7}{*}{ Balochistan } & \multirow[t]{2}{*}{ Field Supervisor } & Aisha Jalal \\
\hline & & Nazma Fida \\
\hline & \multirow{5}{*}{ Interviewer } & Khalida Yaqoob \\
\hline & & Nasreen Muskan \\
\hline & & Mahjabeen \\
\hline & & Zubaira Razaq \\
\hline & & Asiya Aman \\
\hline
\end{tabular}




\section{POPULATION COUNCIL \\ Ideas. Evidence. Impact.}

House 7, Street 62, F-6/3, Islamabad

Phone: 051-8445566 Fax: 051-2821401

Info.pakistan@popcouncil.org

www.popcouncil.org

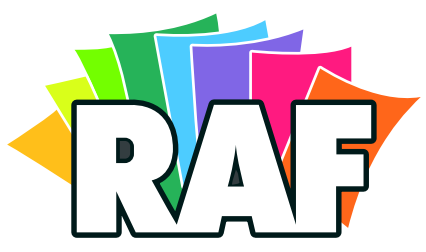

Working Towards Millennium Development Goals Research \& Advocacy Fund 